\title{
Behavioural Competition in
}

the Intertidal Shore Crab,

\section{Petrolisthes elongatus}

A thesis submitted in partial fulfilment for the requirements for the degree of Master of Science in Marine Biology

\section{Li Hao Yeoh}

2020

School of Biological Sciences

Victoria University of Wellington

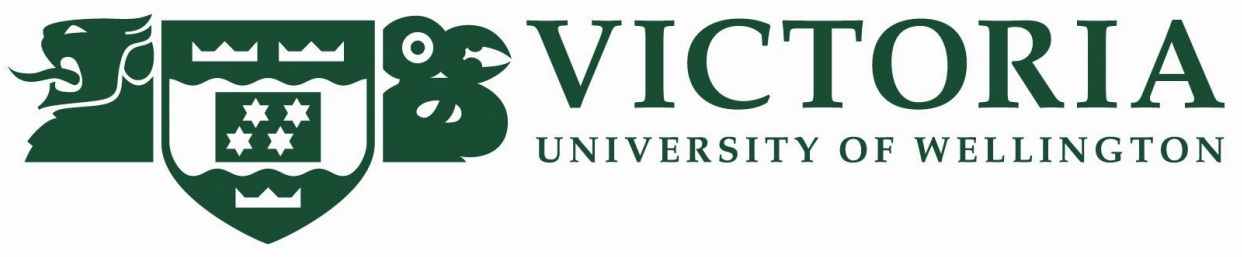




\section{Acknowledgements}

I would first like to thank my primary supervisor Nicole Phillips. Your un-ending support and guidance has been greatly appreciated during the course of my program. Thank you for the passion you bring to your work and I am truly grateful for your vast knowledge and incredible insight. I could not have done this without you.

I would also like to extend my appreciation towards the community at Victoria University Coastal Ecology Lab (VUCEL), for all the cheerful and insightful conversations I have had with the many students, but especially to the technicians, John Van der Sman and Daniel McNaughton, who have been readily available and incredibly willing to help with whatever I may have needed.

To my ever-supportive parents, thank you for giving me the opportunity to study what I love and for creating a positive environment to work in. To my eco pals; Dayanitha Damodaran, Brittany Florence-Bennett, Caitlyn Shannon, Baylee Wade, Jenna Mumford, Ronja Hauke and Rosella Nicolai, thank you for sharing this journey with me. It's been amazing to see all of us work so hard to achieve something so great.

Thank you to all my friends, especially my flat mates; Isaac Harper, Theo Moore, Sebastien Hamilton, and Josh van Bergen, who have helped and supported me in some way or other over the years. Thank you to those who have listened to my struggles, helped me enjoy life outside of work or tried to give me answers even when you had no idea what I was talking about.

Finally, I want to thank God for this amazing opportunity and blessing. "For from him and through him and to him are all things. To him be glory forever. Amen" - Romans 11:36 


\section{Table of Contents}



List of Figures and Tables ............................................................................................ 5

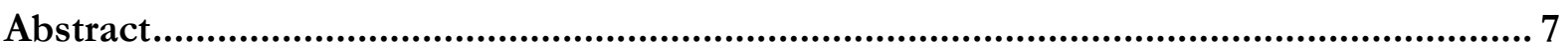

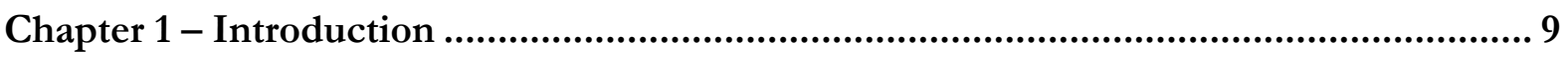

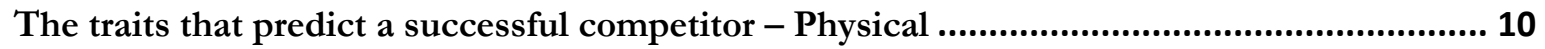

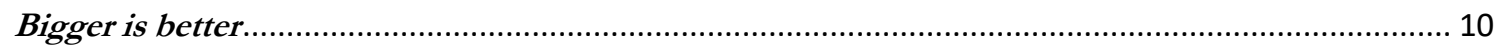

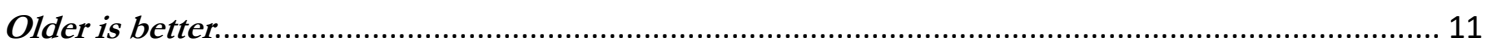

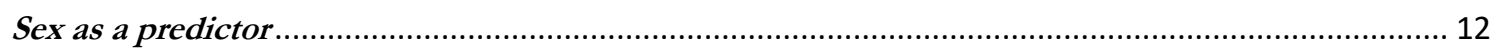

The traits that predict a successful competitor - Behavioural.................................................... 14

The influence of environmental conditions and predation pressures .................................... 15

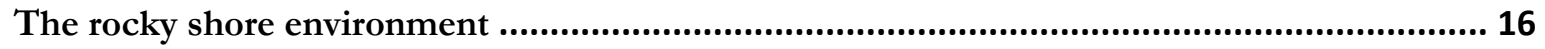

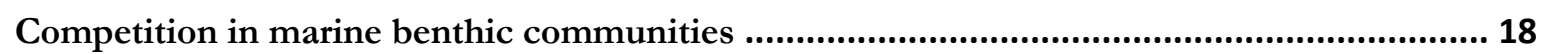



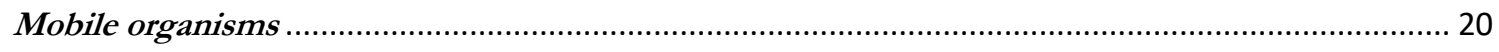



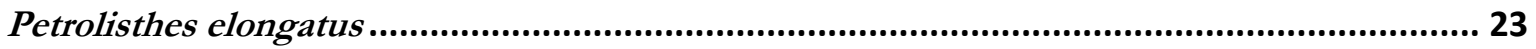

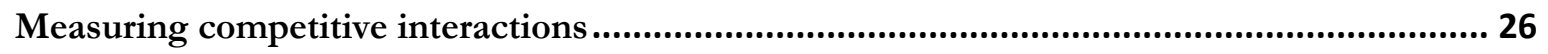

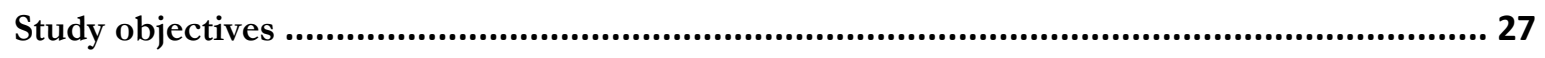

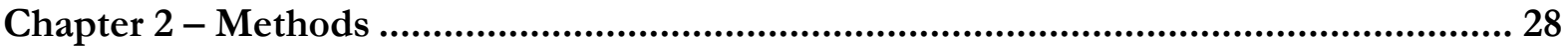

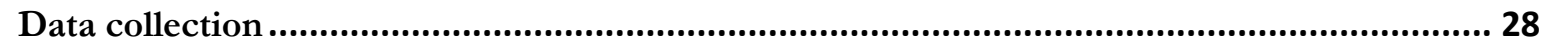

Assessing the competitive behaviour of $P$. elongatus........................................................... 31

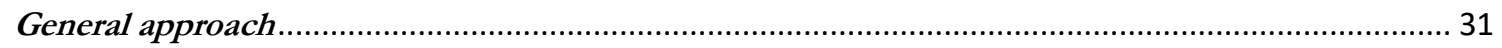

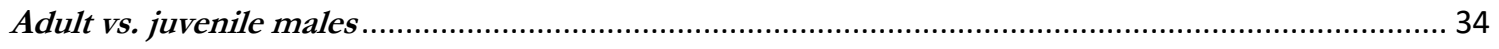

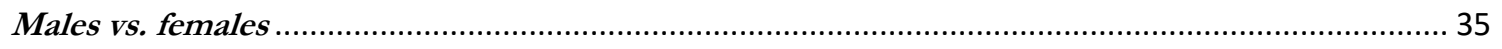

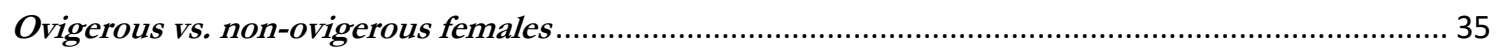

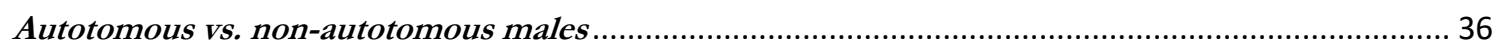

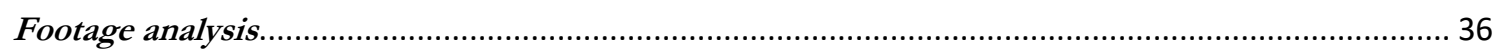

Assessing cheliped characteristics in the field ................................................................... 36

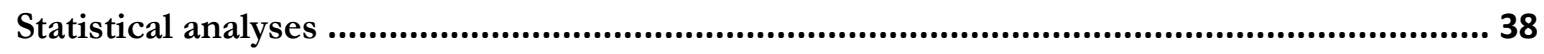

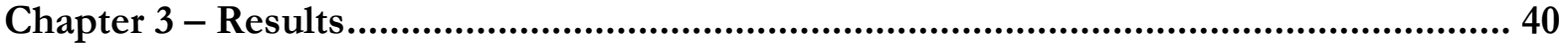

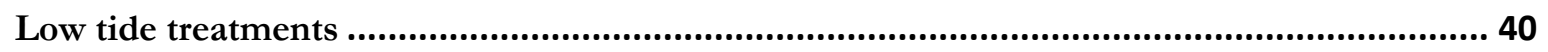

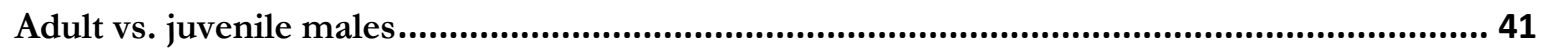

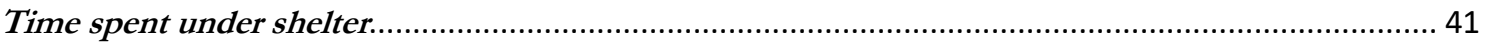

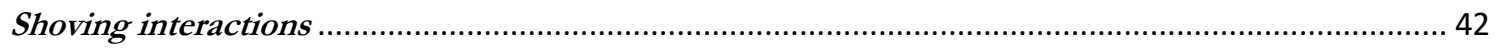

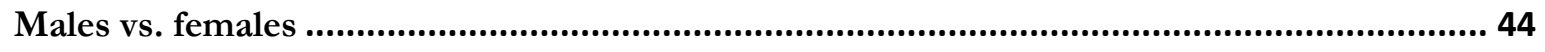

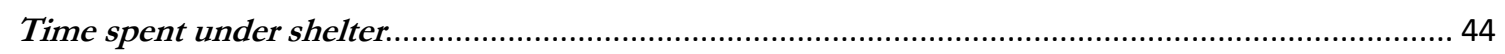


Ovigerous vs. non-ovigerous females................................................................ 47

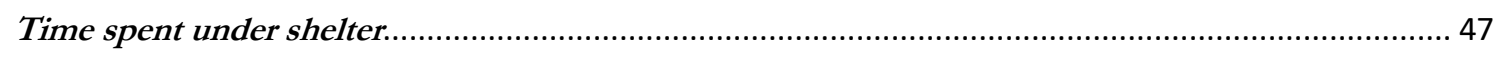

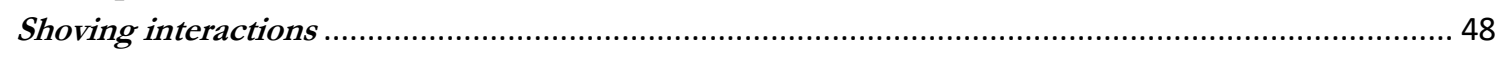

Autotomous vs. non-autotomous males .................................................................. 49

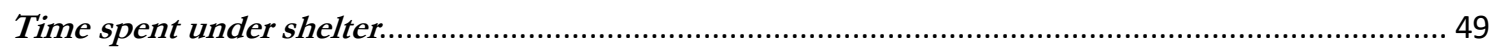

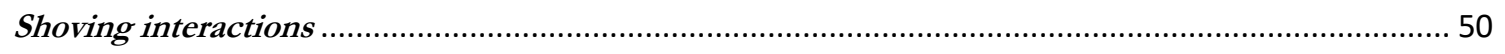

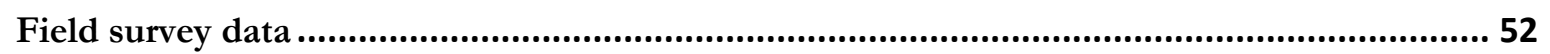

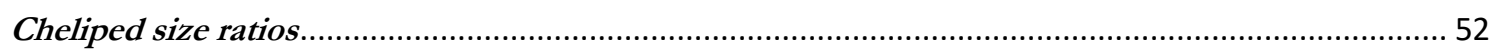

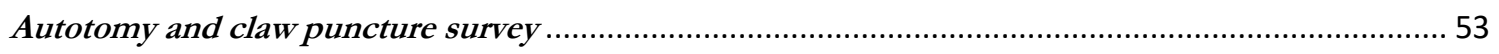

Chapter 4 - Discussion.................................................................................. 57

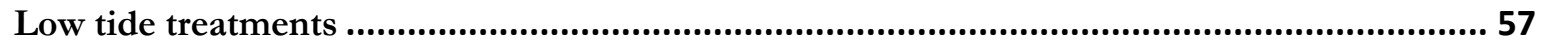

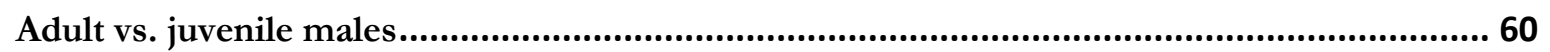

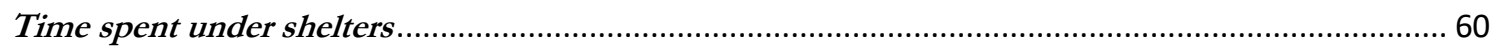

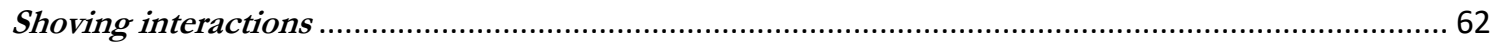

Males vs. females ............................................................................................... 64

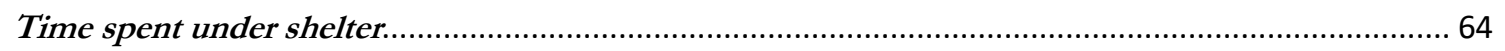

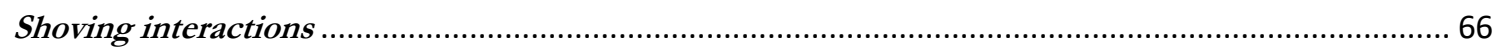

Ovigerous vs. non-ovigerous females.......................................................................68

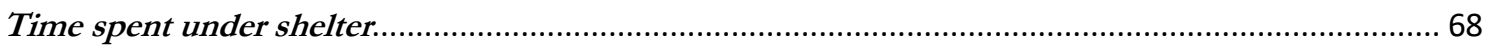

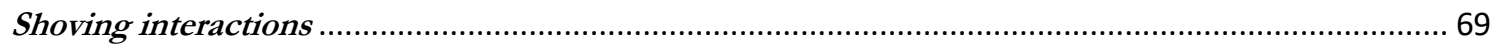

Autotomous vs. non-autotomous males ................................................................. 70

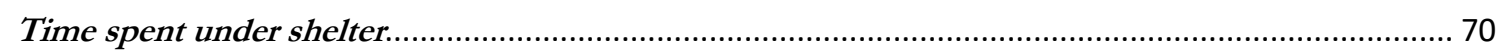

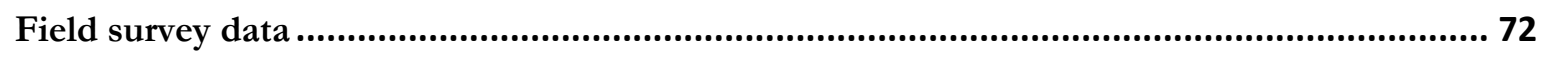

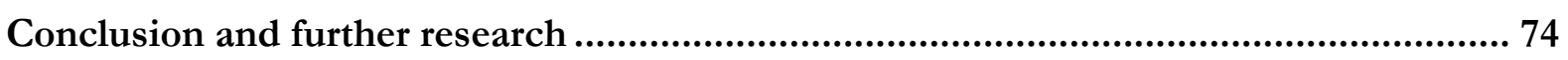

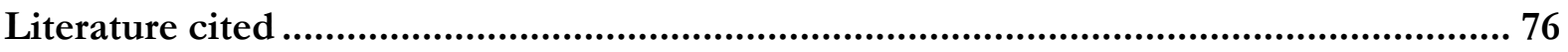

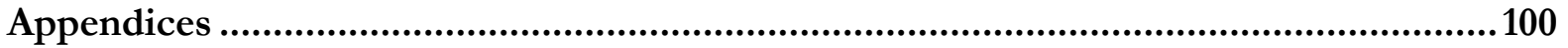




\section{List of Figures and Tables}

Figure 1: Photograph of an adult NZ half crab, Petrolisthes elongatus. Photographed by Graham

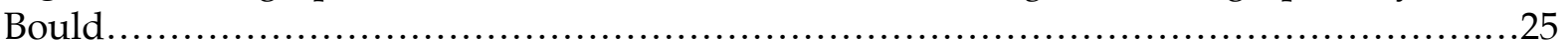

Figure 2: Satellite Map of samples sites around Wellington Harbour. Sourced from Google

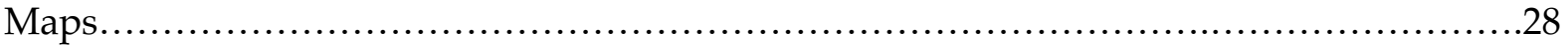

Figure 3: Study sites A) Kau Bay, B) Karaka Bay, C) Breaker Bay - Photos taken by Li Yeoh ..............................................................................29

Figure 4: Left) $P$. elongatus with liquid paper correction tagging on dorsal side of the carapace. Right) P. elongatus with liquid paper correction tagging on the ventral side of the chelipeds -

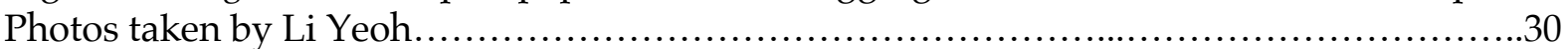
Figure 5: A) Ventral view of the male abdomen showing the arrangement of two fully developed pleopods on the second abdominal segment. B) Ventral view of the female abdomen showing the arrangement of three pairs of pleopods on segments 3-5 (Jones,

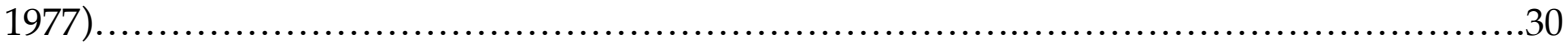

Figure 6: Experimental set up with 36L tank and tank stand, allowing housing for a GoPro to record the underside of the tank. - Photo taken by Li Yeoh................................32 Figure 7: A topside (left) and underside (right) view of standardized shelters constructed out of marine epoxy. Scale: $\sim 10 \mathrm{~cm}$ across - Photo taken by Li Yeoh...............................32

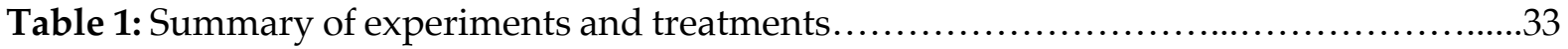
Figure 8: Experimental set up under the predator presence scenario depicting the area where

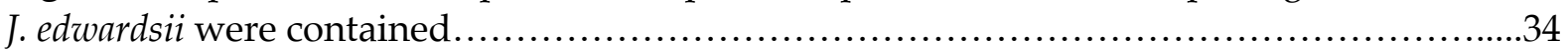
Figure 9: Ventral view of an ovigerous P. elongatus. Clutch can be seen under the abdominal flap, highlighted by the yellow circle - Photo taken by Li Yeoh..............................35

Figure 10: P. elongatus with missing left cheliped - Photo taken by Li Yeoh.....................36 Figure 11: Measurements taken from P. elongatus. Red line indicates Body Width (BW), Blue line indicates Chelped Length (CL). Orange line indicates Chelped Width (CW) - Adapted

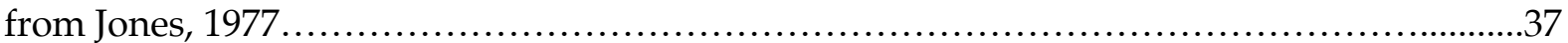

Figure 12: Ventral view of a P. elongatus with claw punctures on its chelipeds. (Identified by green circles) - Photo taken by Li Yeoh.................................................38 Figure 13: The average time spent under shelter in minutes by each size class of male Petrolisthes elongatus in the high tide and predator presence treatments. Error bars represent standard error. .41

Figure 14: The average number of times an individual (A) shoved another individual (A) and (B) was shoved by another individual across size classes for each treatment. Error bars



Figure 15: The mean number of times an individual shoved a conspecific that was smaller, same-sized, or larger than himself. Error bars represent standard error.......................43 Figure 16: The average time in minutes spent under shelter by male and female Petrolisthes elongatus of different size classes in the high tide and predator presence treatments. Error bars represent standard error...

Figure 17: The mean number of times males and females of different sizes shoved another individual (A) were shoved by another individual (B) across high tide and predator presence treatments. Error bars represent standard error................................................ 45

Figure 18: The mean number of times a male or females shoved another male or female, and whether that individual was smaller, the same size or larger. Error bars represent standard error 
Figure 19: Average total time spent under shelter by ovigerous and non-ovigerous females for the high tide and predator presence treatments. Error bars represent standard error........47 Figure 20: The mean number of shoves for each interaction between ovigerous and nonovigerous females for the high tide and predator presence treatments. Error bars represent standard error. .48

Figure 21: Average time spent under shelter for different sizes of autotomized vs. nonautotomized male Petrolisthes elongatus experiment across high tide and predator presence treatments. Error bars represent standard error.

Figure 22: The mean number of times autotomized and non-autotomized male Petrolisthes elongatus shoved another individual (A) were shoved by another individual (B) across high tide and predator presence treatments. Error bars represent standard error. .50 Figure 23: The mean number of times autotomized and non-autotomized shoved another individual, and whether that individual was smaller, the same size or larger. Error bars

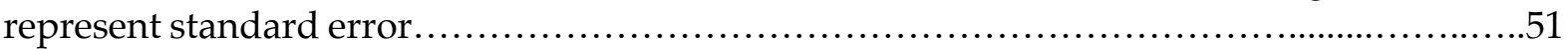
Figure 24: Cheliped Length (CL) to Body Width (BW) ratios for different sizes of male and females P. elongatus. Error bars represent standard error.....................................52 Figure 25: Percentage of males (M) and females (F) from shore collections that were autotomized (A) or had claw punctures (B).... .53 Figure 26: Percentage of different size classes of females (A) and males (B) from shore

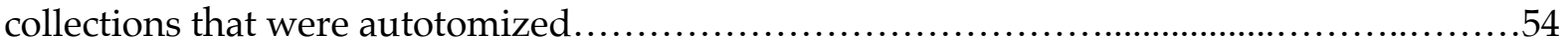
Figure 27: Percentage of different size classes of females (A) and males (B) from shore collections that had claw punctures. .55 Figure 28: Percentage of ovigerous and non-ovigerous females from shore collections that were autotomized $(\mathrm{A})$ and had claw punctures (B) .56 


\section{Abstract}

Competition is a well-documented ecological interaction that underpins community structures and much of population ecology. Physical characteristics such as size, age, sex and weaponry all have an important part to play in how an organism competes, and for many animals, competition is mediated by behavioural patterns. Outcomes of these competitive interactions are not only driven by these characteristics, but by the environmental conditions and external pressures that influence them.

The focal species of my study is Petrolisthes elongatus (H. Milne Edwards, 1837), a porcellanid crab that aggregates in high densities among cobblestone beaches along the intertidal shores of New Zealand and Tasmania. They utilize rocks and crevices as shelter spaces to protect themselves from environmental and predation pressures, displaying variation in physical characteristics, such as sexual dimorphism and autotomy, as well as high levels of behavioural complexity.

I used laboratory experiments with crabs collected from the field and placed them in shelter-limited tanks under the following comparisons; 1 ) adult and juvenile males, 2) males and females, 3) ovigerous and non-ovigerous females, and 4) autotomized and non-autotomized males. For each of these experiments I used three different environmental conditions; 1 ) a control high tide, 2) a low tide treatment (where water was drained from the experimental tank), and 3) with the presence of a predator, a juvenile spiny rock lobster (Jasus edwarsii). Each experiment was recorded for 8 hours, where time spent under shelter and shoving interactions among individuals were counted.

In the adult vs. juvenile and male vs. female experiments, smaller individuals spent a significantly more time under shelter than larger conspecifics, but increasing size resulted in more time spent under shelter in the autotomized vs. non-autotomized experiment. In all experiments, smaller individuals initiated the least amount of competitive interactions, and each size class was more likely to displace a smaller individual from a shelter, than a larger one. There was no significant difference in the time spent under shelter between males and females, but ovigerous females and autotomized males spent significantly more time under shelter than their respective 
competitors. Males also engaged in more shoving interactions than females, with smaller classes of males displacing larger classes of females from shelter spaces. Ovigerous females also outcompeted non-ovigerous conspecifics in the large majority of competitive interactions, and autotomized individuals engaged in significantly more contests than non-autotomized conspecifics. In all experiments, the presence of a predator had no effect on the number of shoving interactions and only resulted in an increase in time spent under shelter for individuals in the male vs. female and ovigerous vs. non-ovigerous experiments.

A field survey on body to cheliped size ratios, autotomy and claw punctures counts was also conducted in support of the shelter-competition experiments. Crabs were collected over a one-month period in November 2018, brought back to the lab to be sexed, measured (Carapace Width, BW; and Cheliped Length, CL) and then surveyed for autotomy and claw puncture wounds. Juveniles of both sex $(\mathrm{BW}=<6 \mathrm{~mm})$ did not differ in CL, while an increase in the CL/BW ratio was found in males with increasing size but not in females. Neither sex was more likely to be autotomized or have claw punctures, but these both increased with increasing size. Ovigerous females were also not more likely to have either injury than non-ovigerous females.

The results of this thesis support many other findings which predict the traits of a successful competitor, but also shows how behaviorally mediated competition for shelter can change in different environmental contexts. This is likely particularly important for mobile intertidal invertebrates like these porcelain crabs. 


\section{Chapter 1 - Introduction}

Stemming from one of the key foundational ideas developed by Gause (1934), the competitive exclusion principle predicts the survival of an individual or species based on their ability to compete for a limited resource. Competition can be described as an interaction between organisms which is harmful to one or both due to the sharing of a limited resource (e.g. food, space, mates) (Birch, 1957) and the outcome can be dependent on physical traits such as size, age, sex and weaponry (Yoshino et al., 2011; Leung et al., 2012; Heldt et al., 2013; Keevil et al., 2017) or behavioural traits e.g. boldness and aggression (Ibánez et al., 2013). This interaction can be further divided into interspecific, between species, and intraspecific, within species. Intraspecific competition is thought to be more intense than interspecific competition due to the similar characteristics of individuals from the same species (Connell, 1983). Because it is such an important selection force, competition is often considered a main evolutionary driver of behavioural and physiological traits, as well as a key factor in affecting community structure (Connell, 1961; Bonin et al., 2015; Kindinger, 2018).

While the benefits to successful individuals in competitive interactions can be bountiful; providing access to mates, vital feeding spots or prime shelter spaces, the negative repercussions to losers can be fatal. Competition, especially under high population densities, can result in stunted growth rates, the inability to reproduce, or higher risks to predation (Paszkowski et al., 1990; Holbrook \& Schmidt, 2002). Impacts are not only physical but can also be behavioural. Out-competed individuals have been shown to modify their diet to less preferred prey or increase their foraging range (Ratcliffe et al., 2018), while others avoid conspecifics to reduce the risk of aggressive interactions (Ibánẽ et al., 2013).

The mechanisms by which an individual competes varies not only from species to species but also between conspecifics. This can be shaped by physical differences or changes in environmental conditions that act as an external force of pressure for limited resources. Therefore, understanding the mechanisms by which a species competes, and the influences that act on this interaction, is crucial to understanding population dynamics within an ecosystem. 


\section{The traits that predict a successful competitor - Physical}

\section{Bigger is better}

For many organisms, size is often the best predictor of competitive interactions as this usually relates to heightened physical dominance such as increased strength, stamina and the ability to inflict injury (McEvoy et al., 2012). For example, Woerner \& Nelson (2009) looked at seven different scenarios to record different behaviours among pairs of juvenile tuatara, Sphenodon punctatus, and recorded conflicts that included chasing, biting, colliding and food stealing. Bigger individuals were more dominant and more successful at securing food through these interference behaviours which were mostly directed towards smaller individuals. In European brown frogs, Rana dalmatina, males were more successful in maintaining amplexus and in achieving takeovers when facing smaller conspecifics but were out competed by a larger rival species, Rana temporaria (Vági \& Hettyey, 2016).

Body size is important in species, such as fish, that don't use weaponry to mediate competitive interactions. In a study conducted by Paszkowski et al. (1990) on Crucian carp, Carassius carassius, larger individuals consumed more food quicker than smaller carp suggesting an exploitative advantage behaviour based on their size. In two species of river fish; Pseudorasbora parva and P. pumila, males of larger length and heavier body weight were more successful in acquiring spawning substrate (Konishi \& Takata, 2004) and in a species of goby, C. feroculus, that has a mutualistic interaction with a shrimp, smaller conspecifics were outcompeted by larger individuals for shrimp burrows (Thompson, 2005). Refuges provide crucial shelters for fish and smaller, out-competed individuals are often subjected to higher predation risks. Four species of coral fish were observed in the reefs around St. Croix, U.S. Virgin Islands and intraspecific competition for holes was recorded where, in almost all the interactions, larger conspecifics were more dominant (Shulman, 1985). Predation risks also increased for smaller damselfish that were out-competed due to intraspecific interference competition for microhabitats (Holbrook \& Schmidt, 2002).

Larger body sizes can also be advantageous as a visible deterrent from potential competitors, reducing the need for contests to escalate into potentially costly physical encounters. Prenter et al. (2008) looked at territory competition in male swordtail fish, 
Xiphophorus helleri, and found that winners were correlated with larger body sizes. Individuals with smaller swords seemed to more actively avoid conspecifics with larger swords as this could be indicative of an individual's condition or fighting ability. In snapping turtles, Cheldyra serpentina, both sex and body size were important in predicting their risk of wounding. This risk increased with body size in adult males, but not females while smaller males were less likely to be injured suggesting they avoid direct competition for mates (Keevil et al., 2017). These studies support the theory that male-male competition often hinges on the size of a competitor and that larger males are more likely to engage in direct competition to monopolize mates, and the retention of desirable space.

\section{Older is better}

Most organisms grow as they age, meaning that if size is positively correlated with success, then so too would age. Most studies indicate that many species will partition resources based on age and sex classes because of competitive exclusion. In black-andwhite snub-nosed monkeys, Rhinopithecus bieti, juveniles and adult females often foraged in the outer layer of fir tree crown while adult males foraged in the inner layer where food abundance was higher (Wan et al., 2013). Field studies revealed that cichlid morphs, Herichthys minckleyi, feed in different microhabitats and use different feeding behaviours within these microhabitats due to high densities of larger conspecifics (Swanson et al., 2003). Sub-optimal foraging sites not only provide a lower food quality but can also increase a subordinate's risk to predation. In yellow tits, Parus monanus and urban pigeons, Columba livia juveniles were outcompeted by adult conspecifics and forced to feed in lower quality, more exposed areas (Koivula et al., 1994; Sol et al., 2000).

Competitive interactions between adults and juveniles may be the most harmful form of competition to both age groups and can result in the destabilization of a population. Adult competitive effects on juveniles impact their survivability while juvenile competitive effects on adults reduce their fertility (Cushing \& Li, 1991). To mitigate this effect some species of juveniles and adults don't compete due to forced ontogenetic niche shifts, e.g. a change in diet (Osenberg et al., 1992), while in others,

smaller and younger individuals will avoid such interactions due to their inability to compete. In the tuatara competition study, Woerner \& Nelson (2009) found that one- 
year-old juveniles would not compete for space, while the study on snapping turtles found older males were more likely to engage in competition than younger and smaller conspecifics (Keevil et al., 2017).

\section{Sex as a predictor}

Sex is often closely related to size when used as a predictor for a winner of a fight, given that most species display a form of sexual dimorphism where males tend to be larger than females. Larger body sizes generally demand higher food requirements which can further drive competition between sexes. In great bustards, Otis tarda, male chicks feed twice as much as their female siblings by out-competing them for priority access to feedings from mothers, resulting in higher female mortality rates than their brothers in mixed-sex broods (Alonso et al., 2018). Like niche partitioning, sexual segregation can occur due to intense competition. In previous examples for tuatara and black-and-white snub-nosed monkeys females would acquire less food, or food of a lower quality, than males that were equal size or bigger but the same amount of food with smaller males (Woerner \& Nelson, 2009; Wan et al., 2013). This indicates that sex, and not just size, had a correlation with individual success.

Sexual segregation due to intraspecific competition has been well studied in terrestrial vertebrates (Kruckstuhl et al., 2006) but has been observed in a wide variety of taxa including fish, birds and mammals (Wearmouth \& Sims, 2008). In both downy woodpeckers, Picoides pubescens and black-capped chickadees, Parus atricapillus (Peters \& Grubb, 1983; Desrochers, 1989) females actively avoided male foraging areas. When the males were removed, females would adopt male foraging behaviour indicating a male dominant pressure for optimal foraging spots. Sex-specific dominance due to larger body-size has also been recorded in several marine taxa. In order to decrease intraspecific competition, female New Zealand sea lions, Phocarctos hookeri, were forced to forage in areas that overlapped with fisheries operations (Leung et al., 2012). Other examples include New Zealand fur seals, Arctocephalus forsteri, (Page et al., 2005), wandering albatross, Diomedea exulans (Xavier \& Croxall, 2006) and the American eel, Anguilla rostrata (Magurran \& Garcia, 2000) but fewer studies have recorded this phenomenon in benthic invertebrates. 


\section{Weaponry}

Competition not only influences community structures but can shape the evolutionary path for advantageous physical traits. Weaponry is an important mechanism that has evolved in competitors and can play a vital role in determining the success of an individual, especially in male-male competition. Many cervids such as deer, muntjacs and moose invest in the development of antlers and increasing shoulder height as a response to male-male competition for mates. Antlers are probably used as weapons in combats to assess each other's physical condition as well to avoid costly fights (Plard et al., 2011). For pinnipeds, such as seals, sea lions and walruses, investment in tusks gives individuals an advantage in holding harems and reduces the risk of post-copulatory competition (i.e. sperm competition) (Fitzpatrick et al., 2012).

Females may also develop weaponry due to intrasexual competition. However, this could trend towards resource, rather than mate, acquisition when breeding (Tobias et al., 2012). In ungulates like reindeer, Rangifer rangifer, and Soay sheep, Ovis aries, males utilise antlers and horns to gain access to mates, while females use their weapons to fight for access to prime foraging sites to raise their young (Espmark, 1964; Robinson \& Kruuk, 2007). In a species of dung beetle, Onthophagus sagittarius, body size was an important predictor when females were competing for breeding resources, with larger individuals outcompeting smaller conspecifics. However, when body sizes between females were equal, horn size became the key factor in determining the outcome of the contest, both as a direct physical interaction and as a signal for non-contact assessment of competitive ability (Watson \& Simmons, 2010).

The use of chelipeds as weaponry is showcased in many species of crustaceans and can be critical to an individual's competitive ability to defend or acquire resources. Fiddler crabs, uniquely possess a claw that is significantly larger than the other, and size of this fighting tool has been shown to increase an individual's success rate in intrasexual competition for mates (McLain et al., 2019). Cheliped size has even been shown to be a better predictor in contests than body size. When competing for females, larger claw sizes had a stronger effect on interactions than body sizes in male hermit crabs, Diogenes nitidimanus and mud crabs, Cryptograpsus angulatus (Yoshino et al., 2011; Daleo et al., 2009). High levels of sexual competition between males has led to 
sexual dimorphism in claw size in many species of crustaceans, with males needing greater weaponry for competitive advantages (Koga et al., 1999; Baeza \& Asorey, 2012). Therefore it is expected that in intersexual competitions, males would outcompete females for a shared resource. However, little research has been done on this interaction, as most focus on male-male competition for mates.

\section{The traits that predict a successful competitor - Behavioural}

Behavioural traits, such as aggression or boldness, can also be used as an indicator of a successful competitor and are often measured on a shy-bold continuum; where an individual is assessed upon their willingness to trade off potential increased predation risk or competition for possible gains in resources (Ward et al., 2004). More aggressive individuals can be better competitors for limited resources than less aggressive conspecifics, as aggression not only positively correlates with size, but with fighting ability. In Tegu lizards, Tupinambis merianae, larger, more aggressive lizards had a greater bite force which suggest a competitive advantage, potentially allowing them to gain or maintain resources over smaller conspecifics (Herrel et al., 2009). Similarly, aggressive behaviour in two species of salamander meant interspecific and intraspecific intruders were more likely to be deterred (Nishikawa, 1985). A study in two juvenile damselfish, Pomacentrus amboinensis $\mathcal{E}$ P. moluccensis, found that larger individuals would display more aggressive behaviour, pushing subordinates into higher risk habitats (McCormick \& Weaver, 2012), and bolder, more aggressive Carabid cave beetles, Neaphaenops tellkampfi, have been shown to outcompete conspecifics by stealing food rather than foraging for their own as it is far more energy-efficient (Griffith \& Poulson, 1993).

Intraspecific competition becomes more intense as characteristics between competitors become similar and sometimes size is not the only variable to be considered when predicting the outcome of a contest. As bodyweight differences decreased between pairs of male jumping spiders, Zygoballus rufipes, encounter duration increased, and more smaller males began to win than expected (Faber \& Baylis, 1993). Aggression has been shown to play a crucial role in competitive interactions when smaller contestants win, particularly if the difference in body size is small (Arnott \& Elwood, 2009). In male yellow-pine chipmunks, Tamias amoenus, 
smaller males performed more aggressive behaviours than larger males, dominating them in staged dyadic encounters (Schulte-Hostedde \& Millar, 2002). While qualities of boldness can result in a positive correlation in growth, for example in three-spine sticklebacks that out-competed shy conspecifics for food (Ward et al. 2004), increasing boldness in an individual can also mean higher risk behaviours when foraging, exploring or during resource competition (Webster et al., 2007). Ioannou et al. (2008) found that bolder pairs of three-spine sticklebacks, those that left a refuge quicker, ate a greater proportion of prey than shy conspecifics. Fish also left their refuge faster when a larger number of foods was presented, suggesting they accepted greater risk in return for a larger foraging reward.

As younger and smaller individuals may avoid older larger conspecifics, levels of intraspecific competition can be affected by the boldness or aggression in an individual. Spanish terrapins, Mauremys leprosa, avoid conspecifics based on chemical cues to reduce the risk of aggressive interactions between males. Males avoided water with an unfamiliar chemical while shy males avoided both familiar and unfamiliar (Ibánez et al. 2013). Aggression in an individual can be influenced by several things such as social context, environmental conditions and the assessment of physical traits in an opponent. For example, three-spine sticklebacks, Gasterosteus aculeatus, are more likely to forage in groups than when alone (Webster et al., 2007), while both predator presence and high sulfidic waters resulted in lower body conditions in mollies (Poecilia spp.) and had negative effects on their boldness (Riesch et al. 2009). In snapping shrimp, Alpheus heterochaelis, males were less aggressive when presented with larger conspecifics (Hughes, 1996). These ultimately determine one's predisposition to engage in a fight and their probability in winning.

\section{The influence of environmental conditions and predation pressures}

The high variability of our world requires organisms to be readily available to adapt, and shifts in behaviour are essential for survival. Individuals may alter their habitat use, foraging activity or other behaviours such as mate or resource seeking excursions if the risk outweighs the reward or if changing circumstances have resulted in an increased state of vulnerability. For example; sea otters, Enhydra lutris, will shift from optimal foraging bays to less exposed refuges to protect themselves from storms and 
rough weather (Kuker \& Barrett-Lennard, 2010; Stewart et al., 2015) while many ungulates will move out of grazing sites under trees to avoid the fierce heat from the sun during the hottest parts of the day (Proops et al., 2019; Haddy et al., 2020). Seasonal changes invoke differing depth distributions in Salmon sharks, Lamna ditropis, where they avoid colder surface temperatures during winter and spring (Carlisle et al., 2011), while activity patterns for geckos, Chondrodactylus tumeri, have been known to alter with moon phases due to luminosity levels (Eifler et al., 2017).

Predators can also have a significant impact on prey through indirect effects that alter their behaviours. Prey species will often utilise refuges to avoid predator detection. For example, populations of the Balearic lizard, Podarcis lilfordi, and the Caribbean Anolis lizards both displayed higher refuge use when in the presence of a predator in comparison to those without (Cooper et al., 2009; Losos et al., 2004). This reaction can also be seen in the foraging behaviours of many species, such as caterpillars (Lepidoptera spp.), wood mice (Apodemus sylvaticus), fiddler crabs (Uca vomeris), and dolphins (Tursiops aduncus) (Stamp \& Bowers, 1993; Díaz et al., 2005; Hemmi, 2005; Heithaus \& Dill, 2002), where animals would move to less optimal foraging areas if they perceived a predator threat. Prey that are especially vulnerable to predation, such as juveniles or females bearing offspring, may show more drastic changes in their behaviour such as increased aggression for refuge (Figler et al., 1995a; Mirera \& Moksnes, 2013).

\section{The rocky shore environment}

The rocky shore is a physically and biologically stressful environment that can present some of the harshest conditions for organisms to establish a living. Namely, the extreme differences in salinity levels, air exposure and habitat suitability (Menge \& Sutherland, 1987). Despite this, they provide a platform for a large range of biodiversity to thrive which can help drive the nutrient cycle around the coastal seas and surrounding ecosystems (Higgins et al., 2001; Aquilino et al., 2009). Rocky shores can also provide important nursery habitats for many coastal fish (De Raedemaecker et al., 2010) and stabilise inshore sediments (Gibson \& Atkinson, 2003). The high variability in habitat conditions; from the wave beaten sublittoral zone, to the exposed supralittoral zone, to the mid littoral zone that experiences large fluctuations of both; can result in distinct spatial patterns and dynamics, often leading to high rates of 
patchiness in the distribution of populations (Underwood et al., 1983; Thrush et al., 2011; Truemper, 2012). With its high structural complexity and accessibility, the rocky shore provides a good system for experimental studies of the causes of distribution patterns and community structure (Burrows \& Hawkins, 1998). These causes can be different for different scales but one such factor is the competitive interactions between the species that inhabit this environment (Dayton, 1971). Furthermore, the differing availability of resources such as food and shelter (Palmer, 2003), as well as pressures such as predation (Steele, 1998), disturbance (Tang et al., 2018) and recruitment (Sams et al., 2015) can drive the levels of competition even higher.

The influences of variation in biological and physical processes that shape intertidal communities have also been well documented (Worm et al., 2001; Mislan et al., 2011; Maggi et al., 2015). Extreme abiotic factors, common with the changing environment of the rocky shore, can also influence biological processes. For example, rain-induced changes in salinity are shown to have drastic impacts on predation along a rocky shore. In the fjords of south western New Zealand, marine predators like sea stars and sea urchins, are inhibited by low-salinity layers (LSL), providing a refuge for mussels. Lower rainfall during the month of September resulted in a reduction of the LSL and increased sea star and sea urchin foraging ranges (Witman \& Grange, 1998). Tidal flow is not only significant in supplying nutrients to suspension feeders and algae, and bringing larvae to settlement areas, but can also provide a refuge from competition and predation (Burrows, 2012). Sutherland \& Ortega (1985) found that barnacle mortality was reduced during low tides due to severe heat and desiccation stress on gastropod predators. However, most of these studies are conducted over a larger temporal scale, monthly instead of daily, and do not investigate the direct effects on competition levels. Greater risks to predation can result in an increased importance of refuges and can intensify competition (Lammers et al., 2010) but few studies have looked at how these interactions influence each other along the rocky shore.

New Zealand has approximately $14,000 \mathrm{~km}$ of coastline represented by either rocky shores/intertidal boulder fields, estuarine mudflats or loose sediment beaches. Rocky shores are ideal environments to study the facets of competition due to their accessibility and, despite their high demanding tolerance for extreme conditions, they have the greatest biodiversity of any other coastal habitat in NZ as they provide many ecological niches (Smith, 2013). 
Wellington Harbour (Port Nicholson, Te Whanganui-a-Tara) is located on the city's western side and is bounded by a narrow $1.8 \mathrm{~km}$ wide entrance at its southern point to the Cook Strait. Much of the coastline is protected from high wave exposure as the semi-diurnal tides have a relatively small range with low tide at $\sim 0.7 \mathrm{~m}$ and high tide reaching $\sim 1.5 \mathrm{~m}$ (Maxwell, 1955). They are characterised by large greywacke benches and outcrops, interspersed with cobblestone and sand beaches.

\section{Competition in marine benthic communities}

Marine organisms, compared to terrestrial organisms, often live in high densities and therefore are more likely to have competitive interactions (Connell, 1983; Ortega, 1985). Many marine benthic invertebrates settle gregariously as populations of conspecifics can often indicate ideal habitats to settle (von der Meden et al., 2015) or higher density populations can decrease an individual's risk to predation. Living in aggregations, while it has its benefits, can come at a cost due to intraspecific competition for limited resources, especially when density levels reach close to the carrying capacity of a habitat (Truemper, 2012). The mechanisms by which individuals compete will differ, often relating to the physical and biological constraints in their ecosystems. Gentoo penguins will increase foraging ranges and scopes, adding fish to their main diet of krill (Ratcliffe et al., 2018), while barnacles may change growth patterns, growing upwards into the water column (Sibomana et al., 2013).

Competitive interactions that influence sessile organisms are fundamentally different from those among mobile organisms. Due to their difference, or lack thereof, in mobility; competition for space among sessile invertebrates generally involves space pre-emption of overgrowth techniques while mobile invertebrates are more likely to out-compete each other through consumptive competition (Connell, 1983). The use of rock crevices during resting periods is a common strategy to avoid environmental stress (e.g. wave action, desiccation, heat stress) and / or to reduce the risk of predation and can be an important limiting factor for intertidal populations (Aguilera \& Naverrete, 2012). Intraspecific competition in marine benthic species can be predicted by factors such as size, age, sex, weaponry and even boldness (Ramsay et al., 1997; Steinberg \& Epifano, 2011; Yoshino et al., 2011). However, while the influences on competitive interactions may be the same, the key differences in physical traits means 
not only are the limiting resources different, but so too are the ways that individuals will compete.

\section{Sessile organisms}

For sessile benthic marine organisms, food resources are usually sourced from the water column and are much more abundant and still accessible if an individual is outcompeted. Inferior competitive grazers can still access some of the resources before dominant individuals consume them all. In contrast, competition for space is more absolute since space is finite and is often limited, so the displacement of other animals or the prevention of new recruits from occupying space usually results in the death of out-competed individuals (Boaventura et al., 2002). By obtaining space, individuals can often have better access to other resources such as food.

Pre-emption and overgrowth techniques are most common in sessile organism that compete for space. In the classic study by Connell (1961) barnacles, Balanus balanoides, would out-compete Cthamalus stellatus by smothering, undercutting or crushing subordinates. Mussels, Mytilus spp., often require a secondary space in the form of filamentous algae or barnacles for initial larvae settlement. By conceding initial competition for primary space, they can dominate other species by growing over pioneer species. Eventually underlying organisms will starve or be smothered (Dayton, 1971). Some species also compete via exploitative competition, where upstream individuals can limit the amount of food for downstream individuals. Lohse (2002) found that groups of crowded barnacles grow less than uncrowded barnacles, and the growth of downstream barnacles was affected by the number of upstream barnacles. Instead of growing outwards to undercut neighbours, barnacles would grow higher, as it increases their foraging ability in the water column. This was also observed in another species of barnacle, Tetraclita squamosa, (Sibomana et al., 2013). This technique was only seen in low density treatments suggesting that space competition is a stronger interaction than food competition in this species.

Sessile organisms have also been recorded to show behavioural variation in response to intraspecific competition. A sessile suspension-feeding worm-snail, Dendropoma maxima, is known to secrete a mucous web to capture planktonic prey. Under high densities, their webs can overlap and stick together creating direct intraspecific 
competition for food. Gagern et al. (2008) studied whether web overlap triggered a phenotypic response in feeding behaviour and found that individuals retracted feeding webs significantly earlier when close to a neighbour than when solitary. The authors also found a smaller body size in snails from high densities which is a consequence of web overlap, reducing foraging success and growth.

\section{Mobile organisms}

Studies that have looked at competition in mobile marine benthic species highlight that while they also compete for similar resources; the interactions can still vary between different taxonomic groups. For many gastropod species, food is obtained by grazing rock surfaces for algae, rather than through the water column which could be considered infinite in comparison. Therefore, most competitive interactions are exploitative, where indirect competition for food is often mediated by individuals who can graze faster and more effectively. When adult populations of the intertidal snail, Littorina obtusata, are low, food resources for recruits are large, and there is a high survival rate of juveniles (Kozminsky, 2013). Yet foraging efficiency can still be dependent on size as larger sizes require higher metabolic demands. Larger individuals will therefore compete for more resources to meet their required intakes. A study conducted by Putnam \& Peckol (2018) found that larger snails, L. littorea were able to outcompete smaller L. obtusata for algae, who suffered reduced growth rates and an altered distribution.

Unlike sessile organisms, the ability to move around means that the opportunities to find other suitable habitats increases. However, space can still be limited in the form of suitable shelter spaces such as rock crevices. The use of rock crevices is a common strategy to avoid environmental stress (e.g. wave action, desiccation, heat stress) and/or to reduce the risk of predation and has also been shown to be a limiting resource in gastropods such as L. rudis, L. neglecta and L. neritoides (Branch \& Branch, 1981). A larger species of limpet, Fissurella crassa outcompetes smaller Siphonaria lessoni for crevice space resulting in the reduction in growth rate of S. lesson. This is likely due to increased time spent outside crevices during daytime low tides resulting in the desiccation of individuals, higher energy expenditure and possibly reduced feeding rates (Aguilera, 2011). 
Higher orders often display more complex behaviours and can vary greatly in their competitive interactions. For hermit crabs, Pagurus bernhardus, that compete for food sources along the seafloor, the intensity of competition increased both with numbers of hermit crabs and decreasing food resources. Size was a big factor in determining the winner as larger crabs were more successful at feeding than smaller crabs under intense competition (Ramsay et al., 1997). In a sexually dimorphic species of hermit crabs, Calcinus verrili, males have a greater chela length to body size ratio than females. They often outcompeted females for preferred shells, and females only outcompeted males when they were larger in body and chela size. If body size was equal then chela size would predict the winner, emphasising the importance of weaponry, especially in decapods (Rodrigues et al., 2002).

Varying behavioural responses, which have been highlighted to impact competitive interactions, have also been documented in crustaceans and can be particularly impactful when species come into contact with biological invasions (naturally or human-induced). Success in establishing a population by an invasive species not only relies on a species' ability to survive the new environmental conditions, but their ability to outcompete species of similar niches for resources. The green crab, Carcinus maenus, successfully invaded Atlantic Canada in the 1950s and genetic studies have found the invading population originated from two separate introductions with different behaviours at the population-level. The more recent invaders from Newfoundland were more aggressive and able to dominate food sources over populations from Nova Scotia and New Brunswick (Rossong et al., 2012).

\section{Porcelain crabs (Petrolisthes spp.)}

Crustaceans are an important taxonomic group to many coastal habitats including mangroves, estuaries and rocky intertidal shores (Lee, 1998; O'Shaughnessy et al., 2014; Laidre \& Greggor, 2015). They are key scavengers in these systems, harvesting small particulates and decomposing plant and animal matter, and in turn are fed upon by higher trophic levels such as rockfish and crayfish. Unlike most benthic marine organisms, they exhibit a more sophisticated sensory and locomotor system, allowing for more complex behaviours, making them an interesting invertebrate group to study competitive interactions. 
Porcelain crabs, or false crabs, belong to the anomuran crustacean family Porcellanidae, and are easily distinguished from true crabs (Brachyura) by having a reduced fifth pereopod which is often hidden beneath the carapace. They can also be characterized by their abdomen which does not fit closely to the underside of the cephalothorax and antennae with an elongate flagellum (Beleem et al., 2016). They are a useful taxon to study competition as they tend to settle gregariously resulting in a patchy distribution of highly clumped populations providing a platform for potentially high levels of competition (Donahue, 2004). Petrolisthes cinctipes is a species of gregarious porcelain crabs known for living in high density, multi-size aggregations on the coast of California as this can be favourable for protection against predators and desiccation. For both in field and laboratory experiments, P. cinctipes growth rates declined with increasing conspecific density and was more severe for smaller individuals. Petrolisthes cinctipes also fed less frequently in high densities, an effect that was more pronounced for smaller individuals (Donahue, 2004).

The costs of aggregating in these high densities is more extreme for recruits than adults as recruits will suffer more from competition due to their small size. The benefits may outweigh this given that higher densities may indicate sites with higher food availability and higher quality settlement areas. A similar study conducted on the same species found similar results; observing puncture wounds on their claws which are used to shove conspecifics during competitive interactions. In field and laboratory experiments; sex did not appear to affect the likelihood of being punctured while size did. Smaller crabs tended to have more puncture wounds, likely due to their competitive inferiority (Rypien \& Palmer, 2007). Physical environment also played a role as the proportion of punctured individuals was significantly higher at high density, wave-exposed sites.

Petrolisthes spp. are mainly suspension feeders, using their third pair of maxillipeds covered in setae that form a fan-like structure (Achituv \& Pedrotti, 1999) and can sweep the water column for microalgae, detritus and other small particles (McGlaun \& Withers, 2012; Zimba et al., 2016). Though, they have also been observed to catch and shred worms using their chelipeds to then consume (Walsby, 1990). Filter feeders are often passive in their feeding habits however species of porcelain crabs have been shown to change behaviours based on current velocities (Achituv \& Pedrotti, 1999) or actively use their chelipeds to scrape oyster shells to loosen and resuspend algae to be 
collected by their maxillipeds (Caine, 1975). Therefore, space is not only important for shelter, but also to establish prime feeding spots where water flow is optimal. The study on P. cinctipes conducted by Rypien \& Palmer (2007) found that highly clumped distributions could result in reduced growth rates and fecundities, especially in smaller individuals. Like other suspension feeding intertidal marine invertebrates, the need to control areas with prime water flow conditions can be important and this has been shown to be dominated by specific individuals of a species, such as larger males (Zittin, 1979). Therefore, settlement patterns and feeding mechanisms, combined with their seemingly restrictive habitat type, may offer pressures that increased levels of competition. These competitive interactions have the potential to be further influenced by individual characteristics or other environmental factors.

Competition for different resources can result in investment into different physical aspects and different evolutionary pathways. In the urchin-dwelling crab, Petrolisthes mitra, male sexual competition is prominent and sexual dimorphism is considerable in terms of body size and weaponry (chelipeds). While in the anemone-dwelling crab, Petrolisthes spinifrons, where male sexual competition is trivial, sexual dimorphism was not detected and differences in cheliped relative to size were modest (Baeza \& Asorey, 2012). Intraspecific competition for habitat, anemones for the case of $P$. spinifrons, resulted in the investment of armament in both sexes as it increases resource-holding potential and the ability to monopolize hosts through aggression. By contrast, in P. mitra, there is a low intensity of intraspecific competition for hosts, but a higher intensity of competition for mates, indicating there is more importance in investing in body size and weaponry for males than in females.

\section{Petrolisthes elongatus}

There are five species of porcelain crabs in New Zealand (McLay, 1988); Pachycheles pisoides (Heller, 1865), the spiny half crab, Petrocheles spinosus (Miers, 1876), Petrolisthes lamarckii (Leach 1820), the red half crab, Petrolisthes novaezelandiae (Filhol, 1886), and the blue half crab, Petrolisthes elongatus (H. Milne Edwards, 1837). They are all widely distributed along coastal regions including Stewart and Auckland Islands (Wilkens \& Ahyong, 2015). The New Zealand half crab (Kokoriki), or blue half crab, P. elongatus (Figure 1), can be distinguished from other members of the Porcellanidae in New Zealand by their blueish / greenish colour and a smooth carapace (Yaldwyn \& Webber, 
2011). It is native to New Zealand, but is an invasive species in Australia, having been introduced to Tasmania and Victoria in the late $19^{\text {th }}$ century (Gregory et al., 2012). They are typically associated with cobblestone beaches, or boulder fields of the intertidal region, using crevices or cobbles as cover from desiccation and predators (Truemper, 2012), concealing themselves during low tide periods (Meyer-Rochow \& Meha, 1994). They are often predated upon by other larger crabs, crustaceans and fish that inhabit the same areas of the intertidal shore (Walsby, 1990; Truemper, 2012). Petrolisthes elongatus has a relatively short lifespan of 2-3 years and males can grow as large $16.5 \mathrm{~mm}$ carapace width (BW) while females typically don't exceed $14 \mathrm{~mm}$ BW (Jones, 1977). Both males and females reach sexual maturity at around $5 \mathrm{~mm} \mathrm{BW}( \pm 1 \mathrm{~mm})$ (Molenock, 1975) with breeding periods occurring over the summer (October-March) (Jones, 1977), although, ovigerous females have been found as early as August/September.

Females brood externally and can have several clutches during their lifespan (Jones, 1977), and most females carry at least two broods per reproductive season. Egg sizes of $P$. elongatus are often larger, while the number of eggs in each brood is relatively small, compared to other decapods (Truemper, 2012). Larger egg size results in lower fecundity but larger offspring - a trade-off seen in many species of porcellainid crabs (Dellatorre \& González-Pisani, 2011) that could suggest higher energy investments from mothers (Coleman \& Galvani, 1998). Brooding crustaceans have also been observed to actively increase oxygen flow to their broods via abdominal flapping and feeding rates can suffer during embryo development (Fernández \& Brante, 2003). Other crustaceans have been shown to exhibit increases in shelter seeking behaviour, such as the Signal crayfish, Pacifastacus trowbridgi, which retreated into shelter spaces directly after mating (Mason, 1970). Therefore, higher energy requirements and maternal care instincts may drive brooding P. elongatus to compete for ideal shelter spaces.

Autotomy, the ability to voluntarily detach limbs, has evolved in porcelain crabs as a defensive mechanism often to escape predation (Barría \& González, 2008). However, there are both short term costs (e.g. to foraging and defence) of losing a limb, and longterm costs (e.g. growth and reproduction) of replacing it (Wasson et al., 2002), resulting in negative repercussions on the competitive ability of an individual. Studies have also shown that in other species of porcelain crabs, characteristics such as smaller body 
size or sex, can predict the probability of autotomizing a limb (Wasson \& Lyon, 2005). While many studies have looked at the effect of predation on autotomy, few have looked at the influences of intraspecific competition, especially in invertebrates. Many studies document the direct effects of autotomy on porcelain crabs in relation to growth and development, but not directly at its competitive ability.

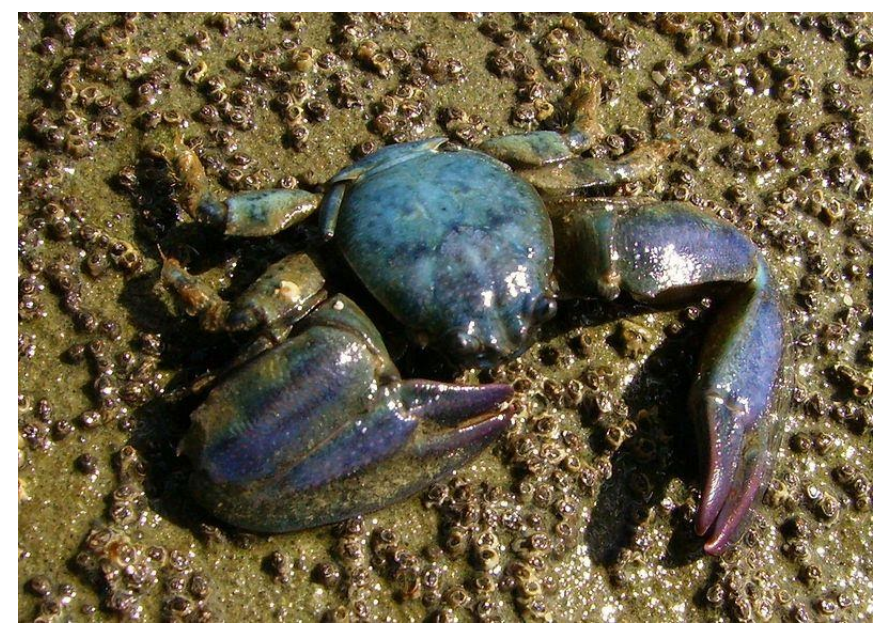

Figure 1: Photograph of an adult NZ half crab, Petrolisthes elongatus. Carapace length $\sim 15 \mathrm{~mm}$.

Photographed by Graham Bould 


\section{Measuring competitive interactions}

The study of competitive interactions is rooted in observations ever since its conception by Gause (1934). Many studies have observed and quantified the levels of competition by measuring the impacts on organisms through population dynamics (i.e. growth, fecundity or mortality rates) (Matveev, 1987; Creel, 2001; Smith et al., 2017). Accordingly, studies conducted on porcelain crabs, such as the study on claw punctures in a species of porcelain crabs (P. cinctipes), are a direct result of competition influenced by sex and size (Rypien \& Palmer, 2007). Other studies have looked at the effect of density on growth rates especially as high-density populations can affect feeding behaviours of suspension feeders (Archituv \& Pedrotti, 1999; Donahue, 2004).

The quantification of behaviour variables is another important aspect when studying competition. The methodology around observing the intricate behaviours of competitive interactions, especially in crustaceans, has been well established (Tran $e t$ al., 2014; Barki \& Karplus, 2016), and the use of recording equipment is becoming more prevalent - including the use of video analysis - as technology progresses. A study conducted by Steinberg \& Epifanio (2011) investigated space competition among three species of intertidal shore crabs (Hemigrapsus spp.) while Rossong et al. (2012) compared competitive behaviours of green crabs, both studies taking advantage of the use of modern recording equipment. A few studies have investigated behavioural competition in Petrolisthes spp. defining and quantifying a set of behaviours while competing for mates (Molenock, 1975) and shelters (Meyer-Rochow \& Meha, 1994), then recording their frequencies. However, these studies noted lack of video equipment to make recordings resulting in inaccurate calculations of relative percentages of crab behaviour. 


\section{Study objectives}

The overall aims of this research were to examine traits and conditions that mediate the outcome of intraspecific competitive interactions in Petrolisthes elongatus.

The specific objectives of this study were:

- to quantify the competitive interactions between; adult and juvenile males, males and females, ovigerous and non-ovigerous females, and autotomized and non-autotomized males in the laboratory

- to determine whether the competition levels for the above experiments were affected by changes in tides or the presence of a predator

- to examine the levels of sexual dimorphism by examining the cheliped and body size ratios

- to quantify the effects of competition in the field by examining individuals for claw punctures and loss of limbs.

The specific hypotheses of this study were:

1) Adults, males, ovigerous females and non-autotomized individuals will all spend more time under shelter than their competitors and be more successful in their competitive interactions.

2) Both lower tide levels and the presence of a predator will result in an increased level of shoving interactions.

3) Petrolisthes elongatus will display sexual dimorphism where males will have larger body and claw sizes than females

4) The number of claw punctures and lost limbs in situ will correlate to the outcompeted individuals of the laboratory experiments. 


\section{Chapter 2-Methods}

\section{Data collection}

Samples of $P$. elongatus were collected monthly over an eight-month period (March August 2019) from cobble beaches around Wellington where they have been found in particularly high densities previously: Kau Bay, Breaker Bay and Karaka Bay (Truemper, 2012) (Figure 2, Figure 3) under the Ministry for Primary Industries Special Permit (No. 711). Due to the ease of access and the availability of individuals, the largest number of specimens were collected at Kau Bay and site effect was not looked at in this study. Collection took place over about two hours during low tide periods and involved scooping or grabbing individuals by hand when rocks were overturned. Some individuals would cling to rocks as they were uplifted, so they could be collected by shaking the rocks over a bucket. Collected specimens were then placed in large buckets to be transported back to the lab to be measured and classified by sex and size. To avoid collection bias of "bolder" members, all individuals that had been exposed when overturning rocks were collected.



Figure 2: Satellite map of samples sites around Wellington Harbour. $\overbrace{}^{\wedge}$ Indicates the Kau Bay site where most of the samples were taken from. shows the Breaker Bay site. Sourced from Google Maps. 

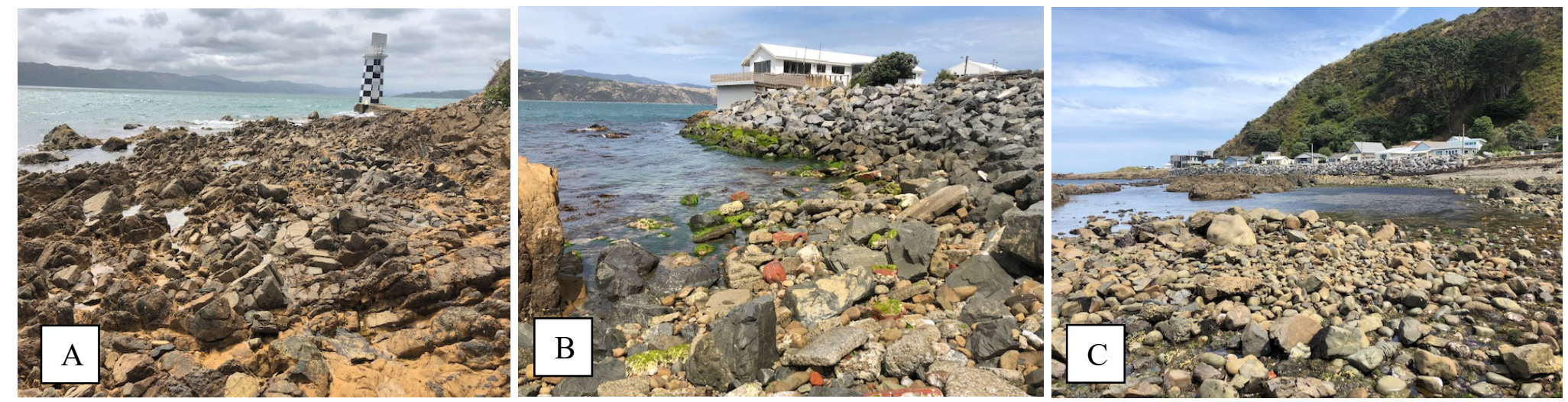

Figure 3: Study sites A) Kau Bay, B) Karaka Bay, C) Breaker Bay - Photos taken by Li Yeoh

After collection from the field, crabs were maintained in aquaria with running seawater at the Victoria University of Wellington Coastal Ecology Lab (VUCEL). Due to the need to identify and keep track of individuals, a variety of tagging mechanisms were trialled including paint pens, sharpie markers, nail polish and bee tags (Donahue, 2004). A combination of permanent markers (Sharpie) and liquid paper correction (Impact) were ultimately used as they were more likely to remain on the crabs during the experimenting periods as well as being more easily seen on the video recordings - preliminary testing showed that marking crabs did not inhibit their ability to compete or affect their behaviour. Crabs were tagged on the dorsal side of the carapace as well as the ventral side of the chelipeds (Figure 4). 

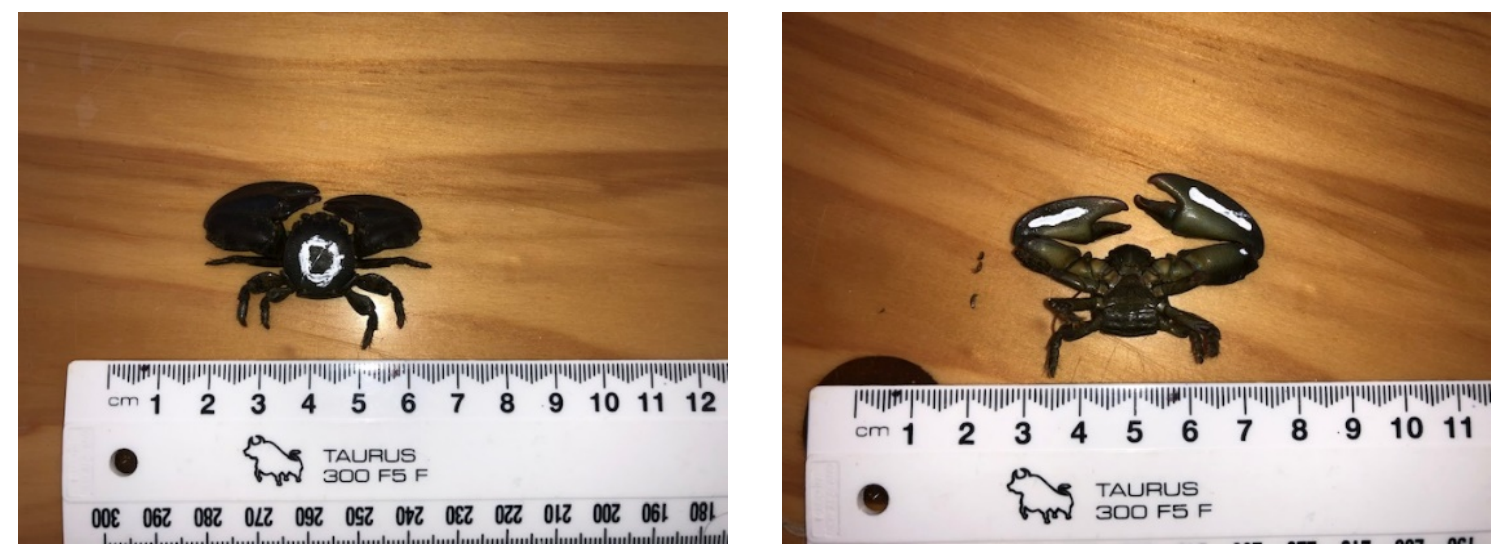

Figure 4: Left) $P$. elongatus with liquid paper correction tagging on dorsal side of the carapace. Right) P. elongatus with liquid paper correction tagging on the ventral side of the chelipeds - Photos taken by Li Yeoh

Individuals were sexed by checking their abdomens. Mature males have a pair of fully developed pleopods on the underside of their second abdominal segment (Figure 5A) while females have three pairs on segments 3-5 (Figure 5B) (Jones, 1977). Carapace width was measured using a set of digital callipers (Mako) and taken from the widest point along their carapace.
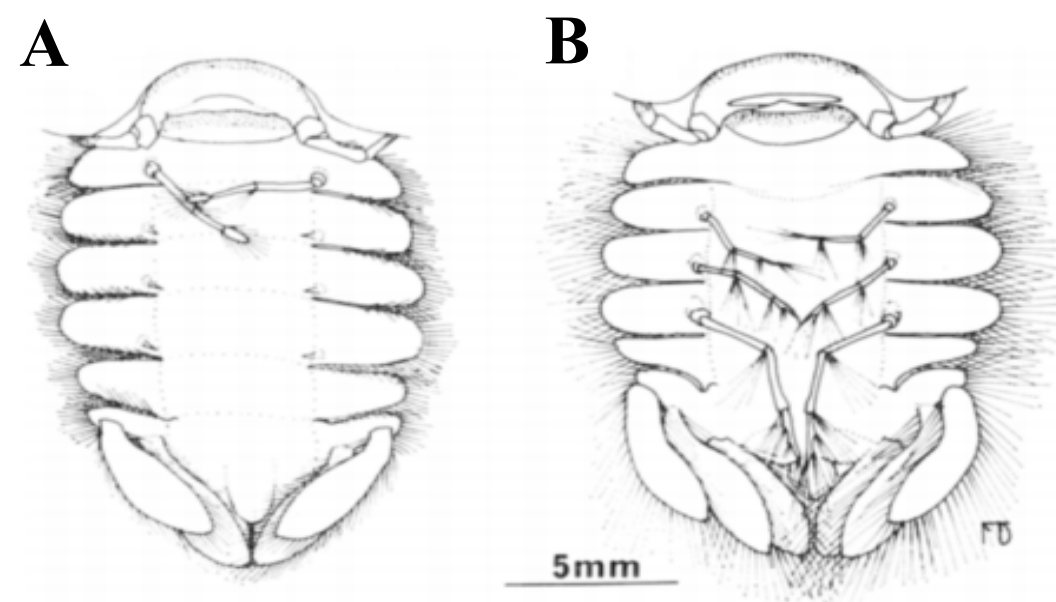

Figure 5: A) Ventral view of the male abdomen showing the arrangement of two fully developed pleopods on the second abdominal segment. B) Ventral view of the female abdomen showing the arrangement of three pairs of pleopods on segments 3-5 (Jones, 1977) 


\section{Assessing the competitive behaviour of $\boldsymbol{P}$. elongatus.}

\section{General approach}

I used a series of laboratory experiments to test the competitive behaviour of $P$. elongatus for shelter spaces under artificial "rocks" made to mimic shelters available under cobbles in the natural habitat, while keeping the shelter spaces standardized (details below). All the experiments were conducted in $36 \mathrm{~L}$ aquaria $(300 \mathrm{~mm} \times 300 \mathrm{~mm}$ $x 600 \mathrm{~mm}$ ) supplied with running seawater that were elevated using frames $(310 \mathrm{~mm} x$ $500 \mathrm{~mm} \times 610 \mathrm{~mm}$ ). These frames were built in order to provide space for recording cameras underneath the aquarium, so that the interior of the shelter spaces could be viewed. Ambient lighting was provided by the laboratory lights in order for the cameras to record, while a cover was placed over the top of the aquaria to reduce glare and excessive lighting from direct sunlight. Three replicate aquaria in frames were assembled (Figure 6).

Cameras used during the experiments were two GoPro Hero 7 Whites and a GoPro HERO 2018. Both of the GoPro Hero 7 whites had external battery packs in order to film for the full 8-hour experiment, while the GoPro HERO 2018 had to have its battery replaced every 2 hours using rechargeable batteries. All cameras were fitted with SD cards that allowed them to record for 4 or 8 hours at a time. All recordings began at around $12 \mathrm{pm}$ and finished in the evening $(\sim 8 \mathrm{pm})$ after the standardised length of the experiments. 

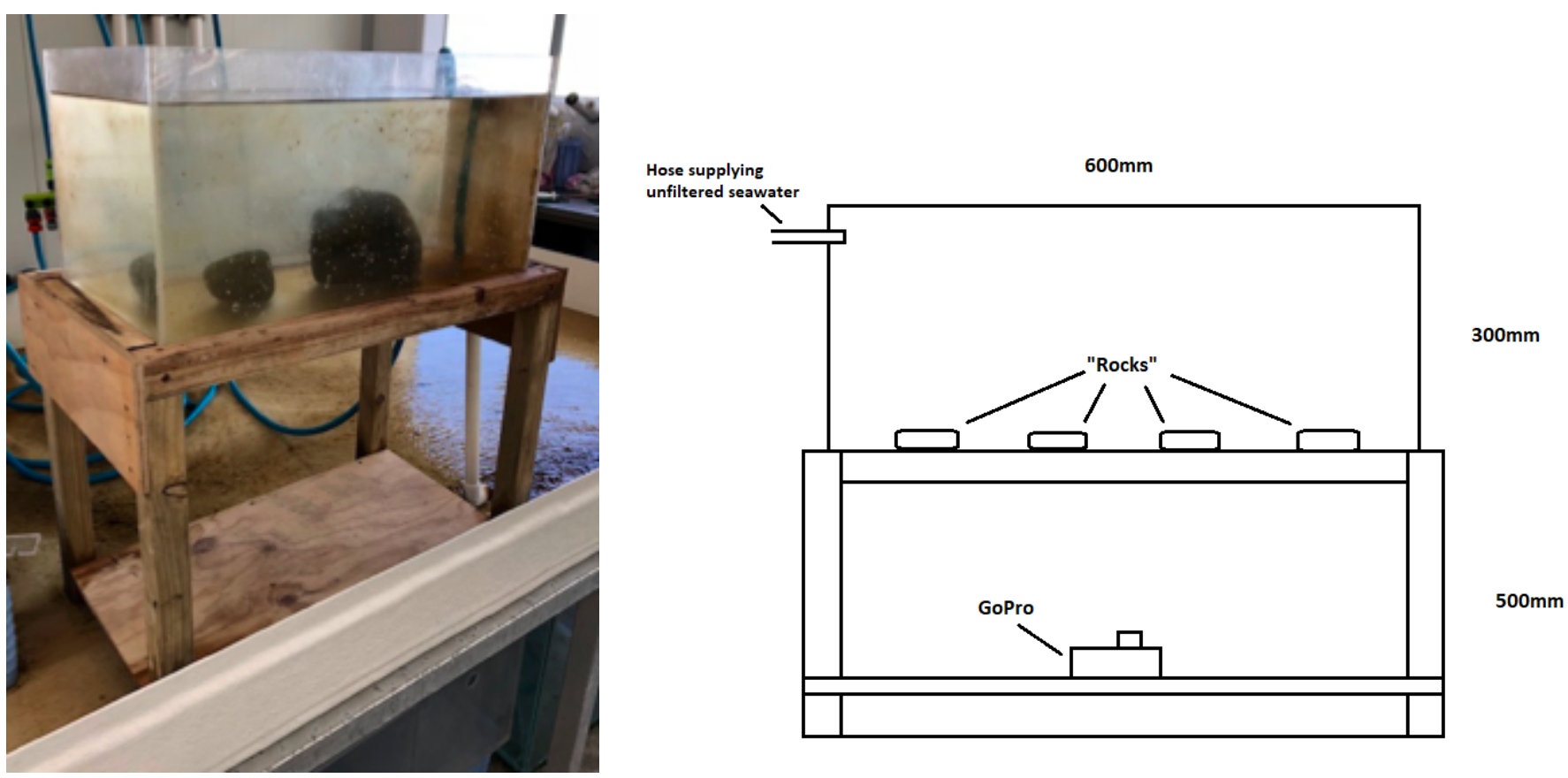

Figure 6: Experimental set up with 36L tank and tank stand, allowing housing for a GoPro to record the underside of the tank. - Photo taken by Li Yeoh

Artificial shelter spaces were created and standardised in order to assess competitive interactions (Steinberg \& Epifanio, 2011) (Figure 7). “Rocks" (120mm x 120mm) were constructed out of marine epoxy, by mixing one-part Carboline Carboguard A-788 Splash Zone Part A with one-part Carboline Carboguard A-788 Splash Zone Part B, then moulded by hand to create four distinct half-dome shaped shelter spaces under each rock. Each shelter space was shaped to roughly fit one adult crab $(30 \mathrm{~mm} \times 30 \mathrm{~mm} \times$ $15 \mathrm{~mm}$ ) and each rock had to be heavy enough $(\sim 300 \mathrm{~g})$ so that the crabs couldn't

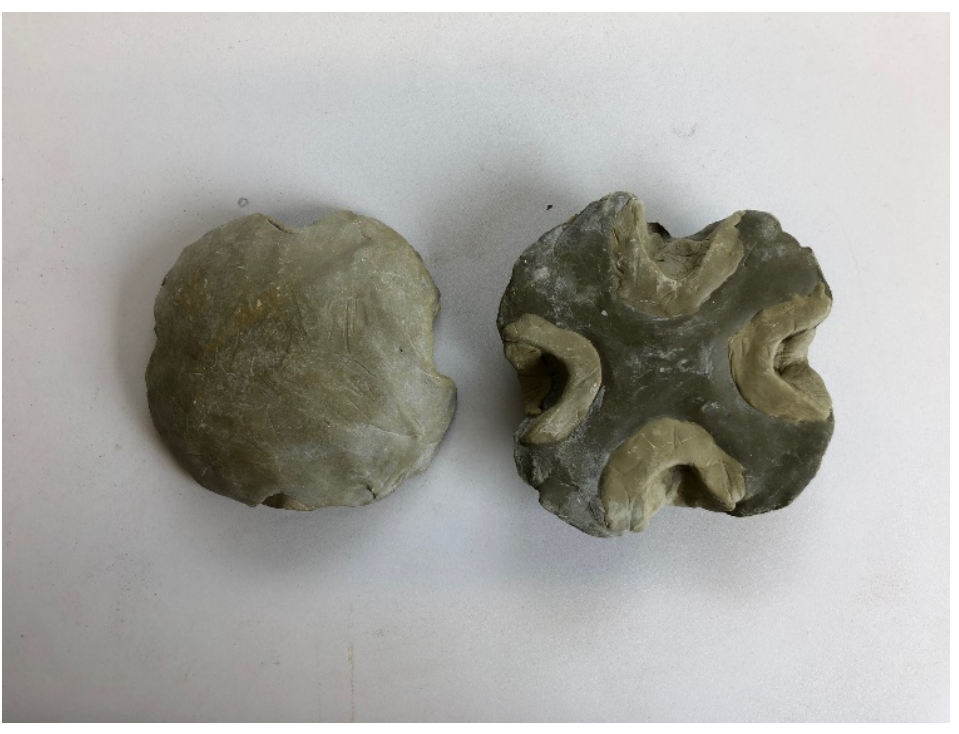

Figure 7: A topside (left) and underside (right) view of standardized shelters constructed out of marine epoxy. Scale: $\sim 10 \mathrm{~cm}$ across - Photo taken by Li Yeoh move them.

All experiments were run under three different conditions, one in each aquarium: constantly submerged (mimicking high tide), drained of seawater (mimicking low 
tide), and submerged with a predator present (Table 1). For the high tide treatment, a constant supply of running unfiltered seawater was supplied to the aquarium such that it was nearly full. For the low tide scenario water was siphoned from the aquarium using a hose, while the remaining puddles of water were sponged out, after the crabs were acclimated for an hour. For the predator presence treatment, part of the aquarium was cordoned off with a mesh partition which still allowed the flow of water between the two sections but stopped any individuals from passing through (Figure 8). After at least an hour in which the crabs were left to acclimatize, a single juvenile rock lobster (Jasus edwardsii, $140 \mathrm{~mm}$ Carapace Length) was placed in the cordoned off area before being recorded. Preliminary testing showed that J. edwarsii prey on P. elongatus, consuming almost all sizes under laboratory conditions. Juvenile rock lobsters were supplied by VUCEL where some were maintained in captivity and starved for at least 48 hours prior before use in the experiment.

In all cases, crabs were introduced to the experimental aquaria and then left for at least an hour in running seawater to acclimatize to the new tank conditions before being recorded. For the high tide and predator presence conditions, experiments were recorded for eight hours, and the experiment was repeated three times with a new set of individuals each time. For each experiment, the low tide treatment was only run once, for four hours, due to very limited activity in each case (see Results).

Table 1: Summary of the above experiments and their treatments where replicates indicate the number of times an experiment was run.

\begin{tabular}{|l|l|l|l|l|}
\hline & $\begin{array}{l}\text { Adults vs. } \\
\text { Juveniles }\end{array}$ & $\begin{array}{l}\text { Males vs. } \\
\text { Females }\end{array}$ & $\begin{array}{l}\text { Ovigerous vs. } \\
\text { Non-Ovigerous }\end{array}$ & $\begin{array}{l}\text { Autotomized vs. } \\
\text { Non-Autotomized }\end{array}$ \\
\hline High tide & 3 Replicates & 3 Replicates & 3 Replicates & 3 Replicates \\
\hline Low tide & 1 Replicate & 1 Replicate & 1 Replicate & 1 Replicate \\
\hline $\begin{array}{l}\text { Predator } \\
\text { Presence }\end{array}$ & 3 Replicates & 3 Replicates & 3 Replicates & 3 Replicates \\
\hline
\end{tabular}




\section{Adult vs. juvenile males}

In the first set of experiments, I examined whether crab size mediated the effect of competition for shelter in the three different conditions. Crabs were sorted into five different size classes based on their carapace width (A: 4-6mm, B: 6-8mm, C: 8-10mm, D: 10-12mm, E: 12-14mm). Ten individuals from each size class A, B and C were used while only five individuals from size class $\mathrm{D}$ and $\mathrm{E}$ were used, totalling to 40 crabs per aquarium, as this is similar to natural densities observed around Wellington (Truemper, 2012). Only males were used due to being able to find them in a wider range of sizes more frequently and throughout the whole year, compared to females (Jones, 1977), and to ensure that sex was not a confounding variable. Individuals that were smaller than $4 \mathrm{~mm}$ were not used as they had not reached sexual maturity and could not be sexed (Jones, 1977). While this would classify them as "juveniles" my aim for this experiment was to test size-related interactions in males, with smaller adult males being an indicator of younger $P$. elongatus.

Individuals were placed in the experimental aquaria with four "rocks" providing a total of 16 units of shelter in each.

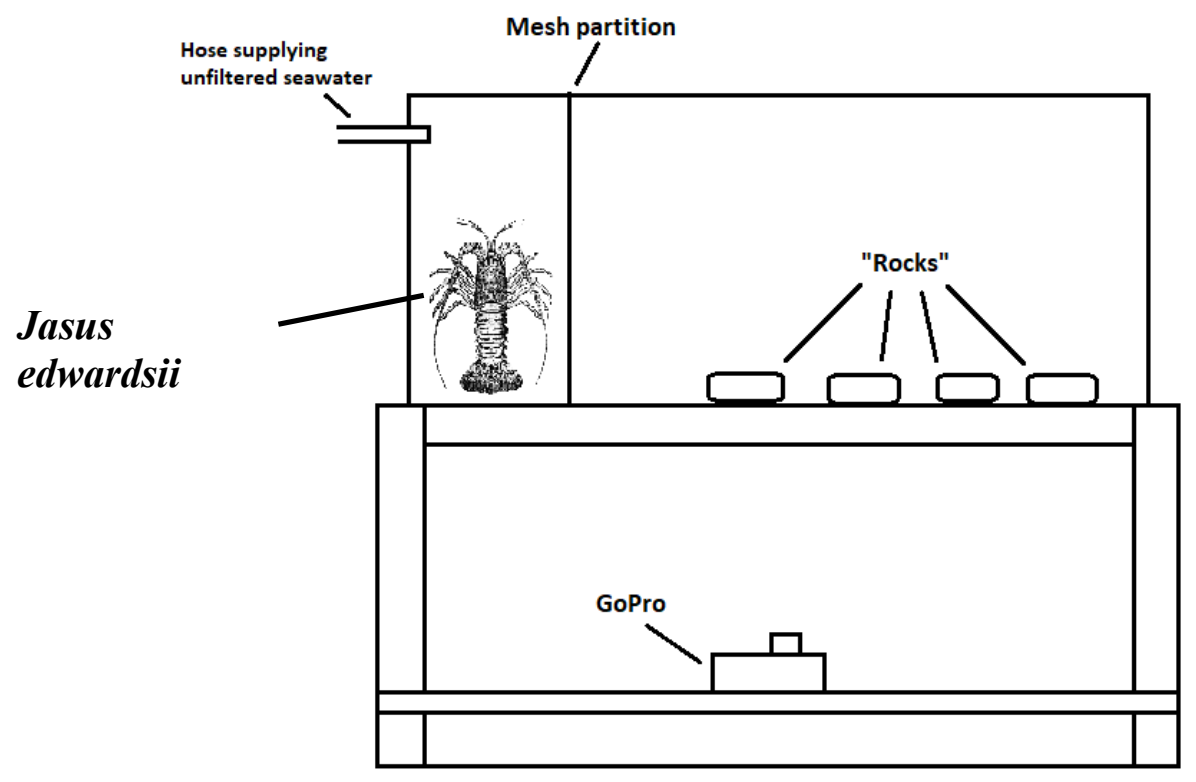

Figure 8: Experimental set up under the predator presence treatment depicting the area where $J$. edwardsii were contained 


\section{Males vs. females}

In the second set of experiments, I tested the competitive interactions between males and females. In each trial, I used five males and five females from three size classes (C: 8-10mm, D: 10-12mm, E: $12-14 \mathrm{~mm}$ ), totalling to 30 crabs per aquarium, with four rocks and 16 shelter spaces available in each. Larger size classes were used in this experiment as preliminary testing and previous research (Prenter et al., 2008) indicate that smaller individuals were less likely to compete for space.

\section{Ovigerous vs. non-ovigerous females}

In the third set of experiments, I examined competitive interactions between ovigerous (egg-bearing) and non-ovigerous females. While individuals were being sexed, they were also checked for eggs under their abdominal flap (Figure 9). Most of the time the eggs could be seen between the sternum and abdominal flap, but sometimes the abdominal flap had to be lifted in order to double check whether the female was brooding. Due to the limited number of non-ovigerous females during the breeding season (August - March; Jones, 1977), only individuals within the smaller size classes could be tested. Larger females were already brooding, and the majority of non-ovigerous females were in the $6-10 \mathrm{~mm}$ range. Therefore, only individuals measuring from $7-9 \mathrm{~mm}$ were used in the ovigerous vs. non-ovigerous experiments.

Ten ovigerous and ten non-ovigerous crabs were used, 20 in total. Three "rocks" were used due to the lower density of crabs, providing a total of 12 units of shelter.

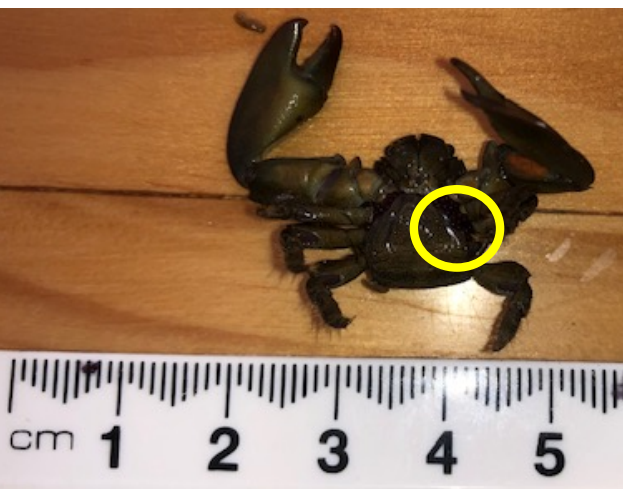

Figure 9: Ventral view of an ovigerous P. elongatus. Clutch can be seen under the abdominal flap indicated by the circle - Photo taken by Li Yeoh 
The final set of experiments were between autotomized (individuals who had lost limbs) and non-autotomized individuals. Only males were used as during the time of testing (September - November 2019), a large portion of the larger females were ovigerous and autotomized females were harder to find. Further, preliminary results suggested males had a greater tendency to compete for space. Autotomized individuals were limited to those who had lost either their left or right cheliped (Figure 10). Due to the limited availability of autotomized individuals,



Figure 10: $P$. elongatus with missing left cheliped - Photo taken by Li Yeoh smaller size classes were used (A: 7-8mm, B: 8-9mm, C: 9-10mm). Five individuals from each size class were used, totalling to $30 \mathrm{crabs}$ for each replicate. Therefore, four "rocks" were used providing a total of 16 units of shelter per aquarium.

\section{Video analysis}

Once experiments had been completed, all video footage was played back and watched. For each trial, I noted which class of individual (size, sex, ovigery or autotomized) had occupied a shelter and for how long. An individual was counted as being under a shelter if any part of its carapace was under cover.

I also counted the number of shoving interactions between individuals. A shoving interaction was defined as occurring when an individual used its chelipeds to push another. I noted who initiated the shoving and whether the interaction took place under a shelter or outside. The shoving interaction was further defined as a "critical" shove if it resulted in an individual displacing another out of a shelter space, or an individual in a shelter space shoving another to prevent the individual from entering.

\section{Assessing cheliped characteristics in the field}

Weaponry has been well established as a factor that can determine the outcome of competitive interactions (Judge \& Bonanno, 2008), and for crabs cheliped size can be more of an effective determinant when competing with each other for a resource 
(Yoshino et al., 2011) especially as chelipeds in porcelain crabs are often bigger than their bodies. Therefore, to determine whether the outcome of a competitive interaction is influenced by cheliped size in P. elongatus, cheliped:body size ratios were compared between size and sex classes. Three samples were taken during the month of November 2019 from Kau Bay where as many individuals as possible were collected during the low tide period. Specimens were then transported back to the lab to be measured. 30 individuals from each size class were then randomly selected and their carapace width (BW), right cheliped length (RCL) and width (RCW) and left cheliped (LCL, LCW) were measured using a set of digital callipers (Mako) (Figure 11). Crabs were also sexed and sorted into size classes ( $<4 \mathrm{~mm}$, A: 4-6mm, B: 6-8mm, C: 8-10mm, D: $10-12 \mathrm{~mm}, \mathrm{E}: 12-14 \mathrm{~mm}, \mathrm{~F}:>14 \mathrm{~mm}$ ). The maximum cheliped length and width to carapace width ratios were then calculated. Due to limited numbers, only 10 females in the E size class could be found, while no females were found in the F size class, and only 13 males were found in the F size class.

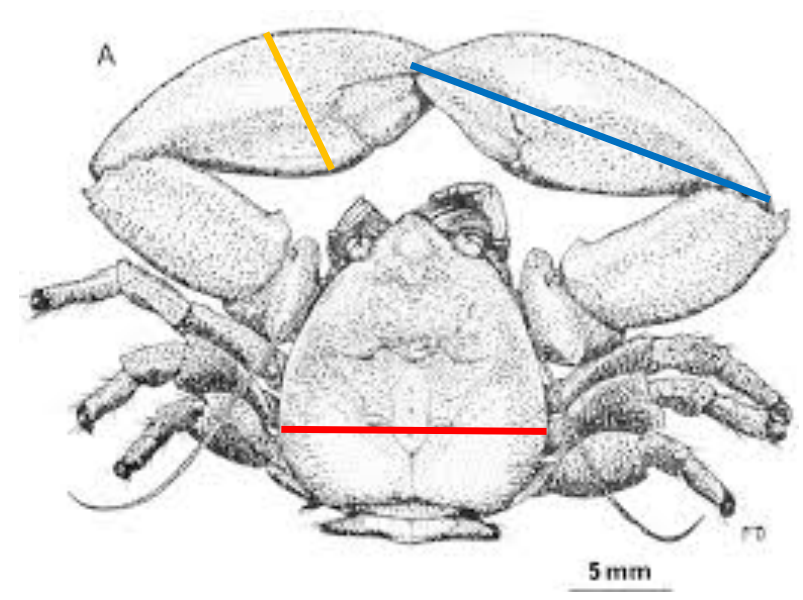

Figure 11: Measurements taken for P. elongatus. Red line indicates Body Width (BW), Blue line indicates Chelped Length (CL). Orange line indicates Chelped Width (CW) - Adapted from Jones, 1977

Claw punctures can be an important indicator of competition as chelipeds can serve several functions in mediating competitive interactions including physically pushing conspecifics (Rypien \& Palmer, 2007). Crabs from the field were therefore assessed for claw punctures as indicators of aggressive interactions from congeners in their chelipeds and also autotomy. After crabs had been sexed and measured, they were checked for punctures in their claws both on their ventral and dorsal sides (Figure 12). 
The number of punctures was then recorded. I also recorded autotomy, noting which limb or limbs had been lost.

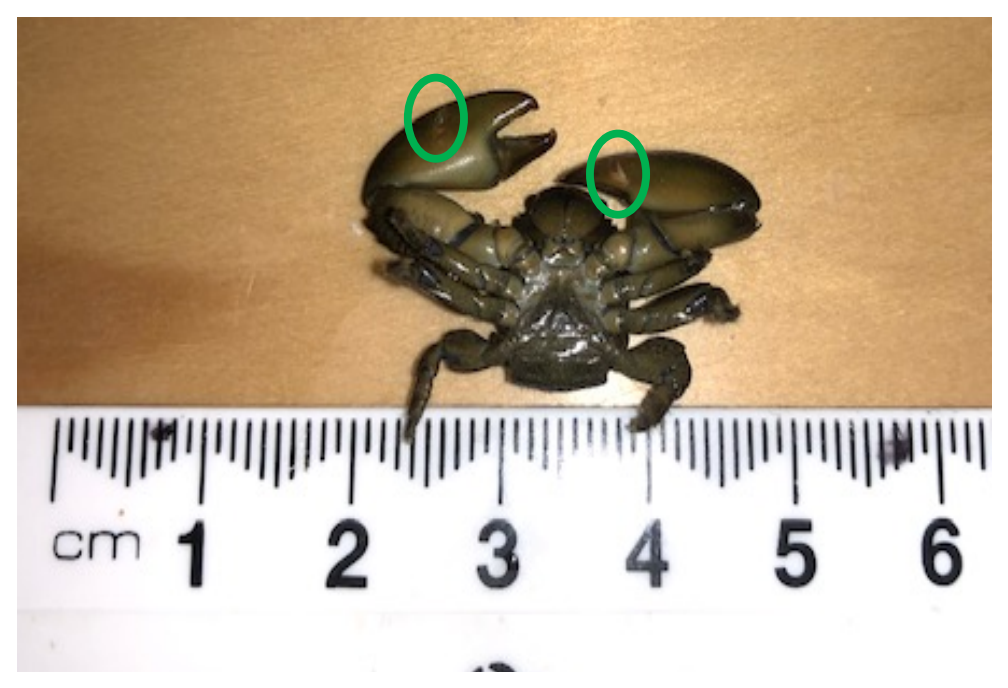

Figure 12: Ventral view of a $P$. elongatus with claw punctures on its chelipeds. (Identified by green circles) Photo taken by Li Yeoh

\section{Statistical analyses}

All analyses were conducted in R (version 3.0.1+) using R Studio (version 1.2.5033). All low tide treatments were excluded from formal analyses due to inactivity of crabs during the experiment, however notes were still made and a descriptive analysis can be found in the Results section.

When analysing the time spent under shelter, the total time in minutes was calculated for all individuals in each class of crabs. This was done by multiplying the number of crabs that were under a shelter by the total time that number of crabs remained under shelter for the duration of the whole experiment. This was repeated for each number of crabs (1-5 or 1-10) and then totalled. In the adult vs. juvenile experiments, there were more crabs of size class A $(4-6 \mathrm{~mm}), B(6-8 \mathrm{~mm})$ and C $(8-10 \mathrm{~mm})$ than the larger size class $D(10-12 \mathrm{~mm})$ and $\mathrm{E}(12-14 \mathrm{~mm})$, so the average time that a crab of a certain size class would spend under shelter was calculated. This was done by calculating the total time as before, but then dividing this by the total number of crabs for that specific size class. The same was done when analysing shoving interactions in the adult vs. 
juvenile experiment, and so the average number of shoves per individual per size class was calculated instead of the total.

For the adults vs. juvenile and ovigerous vs. non-ovigerous experiments, analysis of the time under shelter and shoving interactions were done through two-way ANOVAs where the factors were crab type (2 levels) and environment (2 levels). Assumptions for parametric tests were checked through visual analysis of the Q-Q plots. Any departures from the assumptions involved removal of the outliers, followed by a rerun of the ANOVA test. For the males vs. females and autotomous vs. non-autotomous experiments, analysis was conducted through a three-way ANOVA where the additional factor was either sex or autotomy, respectively. In all cases, significant main effects were further explored with Tukey Post hoc tests.

Data collected from the field survey on cheliped size ratios, autotomy and claw punctures were first checked for homogeneity of variance and normality by the Levene's and Shapiro-Wilk tests respectively. The mean cheliped to body ratio as examined with a two-way ANOVA on the factors and size class. If an interaction effect was found, it was explored with a post-hoc test on the combination of factors. Autotomy and claw punctures were calculated as a percentage of the total population and then compared across classes using Chi-squared tests. 


\section{Chapter 3 - Results}

\section{Low tide treatments}

In general, very little activity occurred during the low tide treatment. I observed similar behaviours in all experiments over the period of time that it took water levels to decrease, during the four hour period of simulated low tide, and over the period of time that it took to refill the tanks with water. As water was drained from the tank to simulate the tide going out, individuals that had managed to climb up the sides of the tank, and those who were on top of the "rock" shelters, would retreat as the water level fell. Once the water level had fallen below a level where crabs could not retreat any further, i.e. the bottom of the tank, crabs would aggregate in clusters either in the corners of the tank or under shelters. Aggregations in corners of the tank would consist of all classes and sizes, and could contain anywhere between 5 to 20 individuals. Crabs that had gathered in shelters were usually ones that were already in a shelter or nearby, and contained clusters from 3 to 5 individuals, depending on the sizes of the crabs. As crabs were moving into these aggregations, whether it be in the corner of the tank or in a shelter, very little shoving occurred across all of the experiments. Any shoving that did occur, only happened as the tide was going out, as crabs were settling into their chosen "shelters". An individual's tendency to aggregate in corners or under shelter often depended on what other conspecifics were doing or whether it was near a shelter already. In some experiments, almost every individual was under shelter, while others had some under shelter and some aggregated in the corners of the tank. Shelter-seeking behaviour often involved backing up until a suitable shelter was found, whether that be the edge of the tank, or a constructed shelter.

Once water had been drained from the tank, very little movement occurred during the four-hour experiment. The odd crab would move about the tank, from shelter to shelter, or between aggregations, but no shoving or other interactions occurred. As the tank was refilled, movement would resume almost instantly from all crabs. Aggregations would split up, and individuals in shelter would spread out slightly. Not only did movement occur, but almost all crabs would instantly start feeding, once feeling the increased water flow. Due to the similarity in behaviour, and reduced 
shoving activity and interactions between crabs during the low tide treatments, this treatment was omitted from the following analyses.

\section{Adult vs. juvenile males}

\section{Time spent under shelter}

When comparing the time spent under shelter for different size classes of adult and juvenile $P$. elongatus males, there was no significant interaction between size class and treatments (two-way ANOVA: $\mathrm{F}_{4,20}=0.267, \mathrm{P}=0.89$ ). While there was also no significant difference in time spent under shelter between the hightide and predator presence treatments (two-way ANOVA: $\mathrm{F}_{1,20}=3.321, \mathrm{P}=0.083$ ), time spent under shelter varied between size classes (two-way ANOVA: $F_{4,20}=6.910, P=0.001$ ) and appeared to decrease as size class increased (Figure 13). Post hoc tests showed that the smallest size class, (A: 4-6mm) spent significantly more time under shelter than the larger size classes (C: 8-10mm, D:10-12mm, and E: $12-14 \mathrm{~mm}$ ) (Tukey tests, $\mathrm{P}=0.0494$, $0.0024,0.003)$ and size class B (6-8mm) also spent significantly more time under shelter than size class $\mathrm{E}$ (Tukey test, $\mathrm{P}=0.0408$ ). The larger size classes did not differ in time spent under shelter.

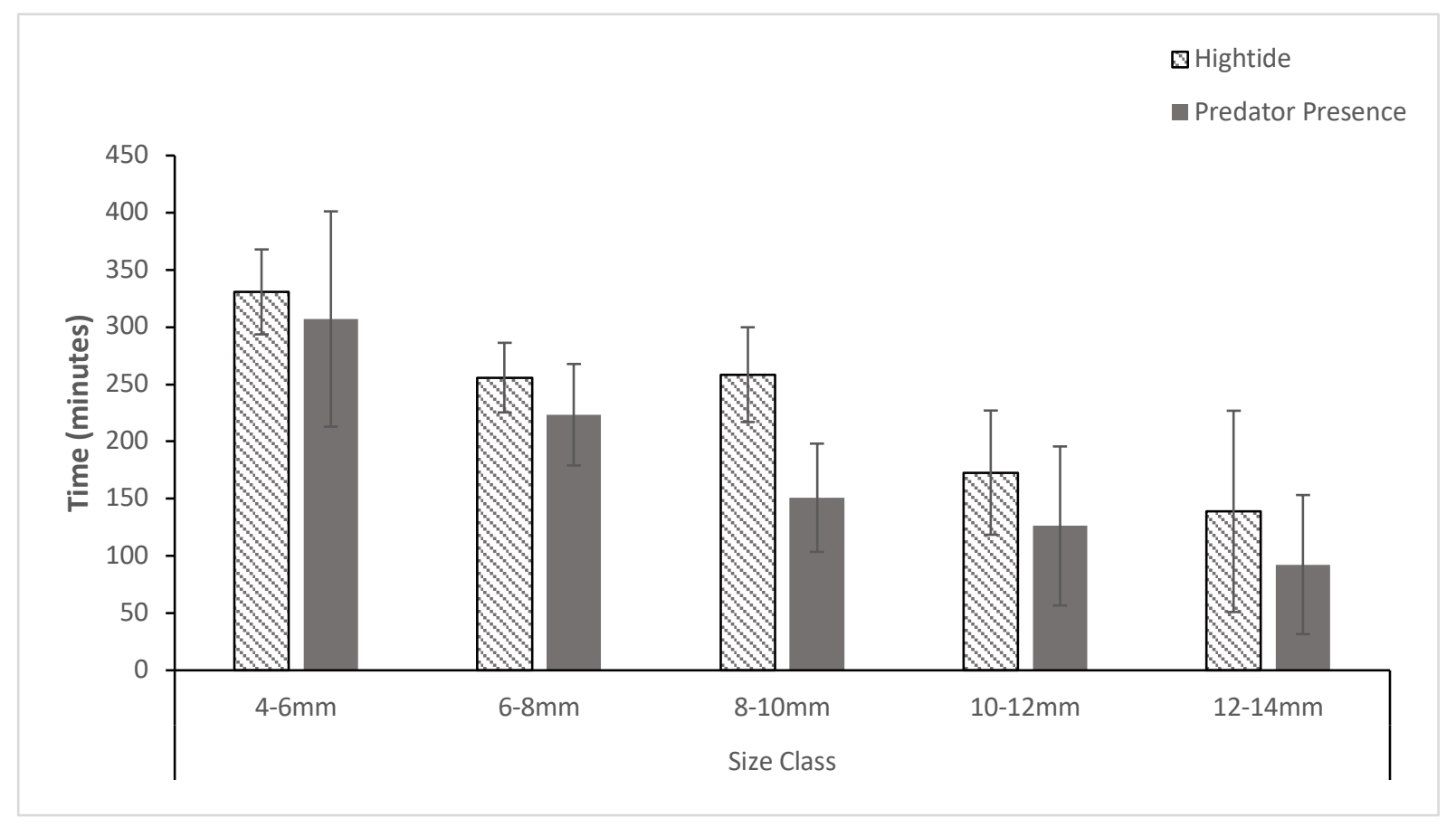

Figure 13: The average time spent under shelter in minutes by each size class of male $P$. elongatus in the high tide and predator presence treatments. Error bars represent standard error. 
There was no interaction effect between treatment and size class when comparing the mean total number of shoves given by adults or juveniles (two-way ANOVA: $F_{4,20}=$ 1.083, $\mathrm{P}=0.391$ ). There was also no difference between the hightide and predator presence treatments (two-way ANOVA: $\mathrm{F}_{1,20}=1.114, \mathrm{P}=0.304$ ), however there was a significant effect of size class (two-way ANOVA: $\mathrm{F}_{4,20}=13.218, \mathrm{P}=<0.0001$ ). The mean number of shoves given increased with body size, with the largest males (E: $12-14 \mathrm{~mm}$ ) shoving all other size classes others significantly more (Tukey tests, P: E-D $=0.023$, E$\mathrm{B}=0.0002$, $\mathrm{E}-\mathrm{A}=<0.0001)$ except for medium-sized males, class $\mathrm{C}$ (Figure 14A). Size class D males $(10-12 \mathrm{~mm})$ also shoved significantly more than size class B $(8-10 \mathrm{~mm})$ males (Tukey test, $\mathrm{P}=0.0002)$ while size class $C(8-10 \mathrm{~mm})$ males also shoved significantly more than the smallest males (Tukey test, $\mathrm{P}=0.0059$ ).

For the mean number of shoves received, there was once again no interaction between treatment and size class (two-way ANOVA: $\mathrm{F}_{4,20}=2.014, \mathrm{P}=0.131$ ) and there was no difference in the amount of shoves received between size classes (two-way ANOVA: $\left.\mathrm{F}_{4,20}=1.549, \mathrm{P}=0.227\right)$. However, after the removal of an outlier, the predator presence treatment resulted in a decreased number of shoves compared to the high tide treatment (two-way ANOVA: $\mathrm{F}_{1,19}=8.692, \mathrm{P}=0.0083$; Figure 14B).
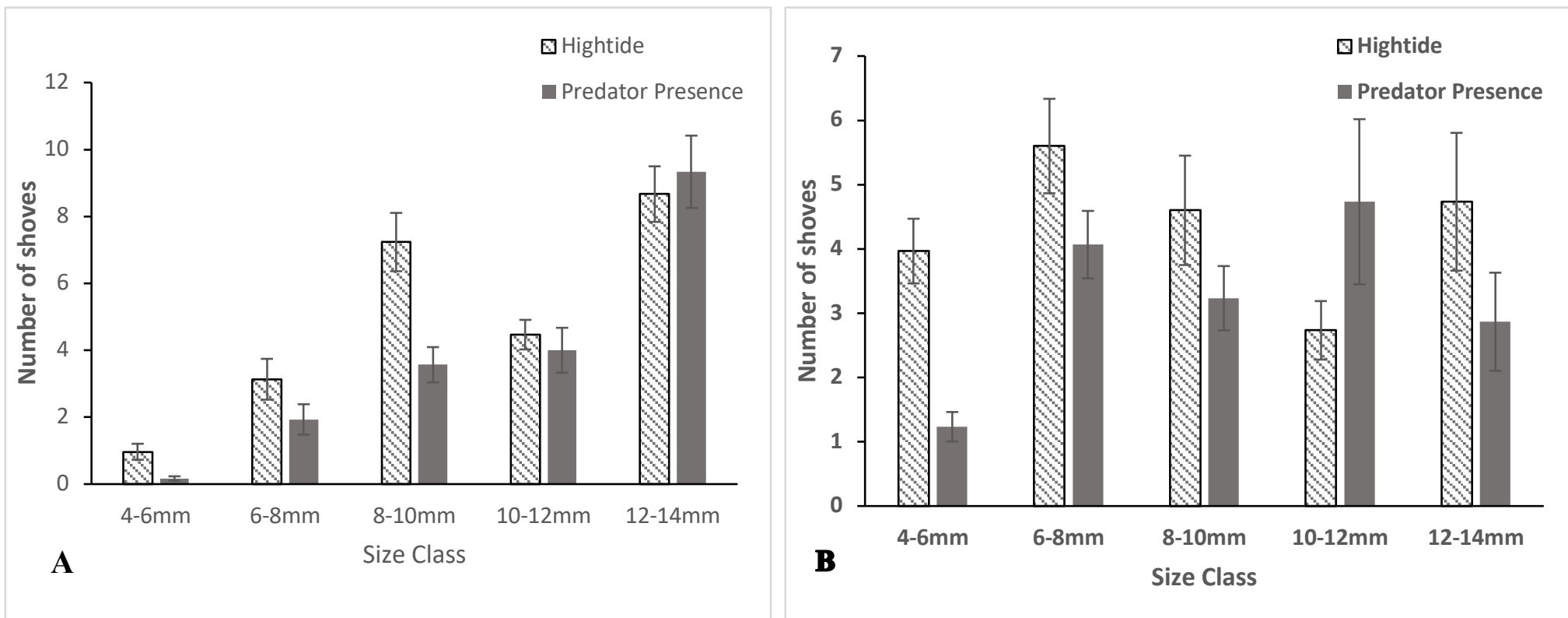

Figure 14: The average number of times an individual (A) shoved another individual (A) and (B) was shoved by another individual across size classes for each treatment. Error bars represent standard error. 
For both treatments, I also examined whether size class relative to an individual had an effect on the number of shoves initiated. There was a significant effect of relative size (two-way ANOVA: $\mathrm{F}_{2,12}=21.98, \mathrm{P}=<0.0001$ ). Individuals shoved smaller conspecifics more than same-sized (Tukey test, $\mathrm{P}=0.0109$ ) or larger (Tukey test, $\mathrm{P}=$ $<0.0001)$ conspecifics. They also initiated more shoves on same-sized conspecifics than larger conspecifics (Tukey test, $\mathrm{P}=0.023$; Figure 15).

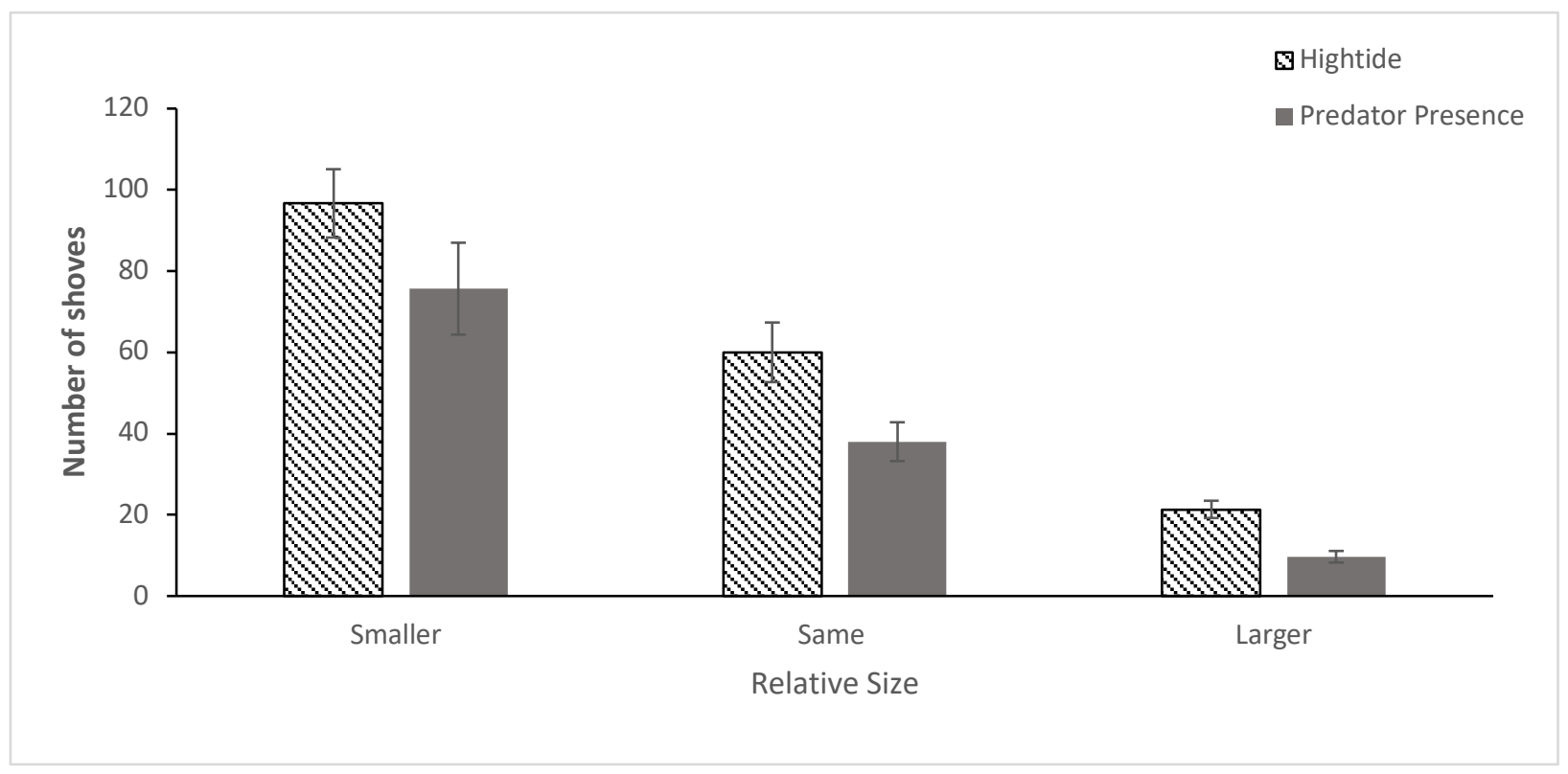

Figure 15: The mean number of times an individual shoved a conspecific that was smaller, same-sized, or larger than himself. Error bars represent standard error. 


\section{Males vs. females}

\section{Time spent under shelter}

There were no significant interactions between any of the factors of sex, size class or treatment on the time P. elongatus spent under shelter (three-way ANOVA: P for all interactions > 0.05; Appendix Table A1). The main effect of sex also had no effect, thus males and females spent similar amounts of total time under shelter (three-way ANOVA: $F_{2,24}=3.1211, P=0.09$ ). However, there was an effect of treatment, where crabs spent more time under shelter when in the presence of a predator (three-way ANOVA: $\mathrm{F}_{1,24}=4.666, \mathrm{P}=0.041$; Figure 16 ), and there was also a significant difference among size classes (three-way ANOVA: $\mathrm{F}_{2,24}=4.638, \mathrm{P}=0.0198$ ). A post hoc test showed that, similar to the first experiment, the largest class of individuals spent significantly less time under shelter than the smallest class of individuals (Tukey test, $\mathrm{P}=0.0244)$ and medium-sized individuals spent an intermediate amount of time under shelter, but not different to either of the other size classes (Figure 16).

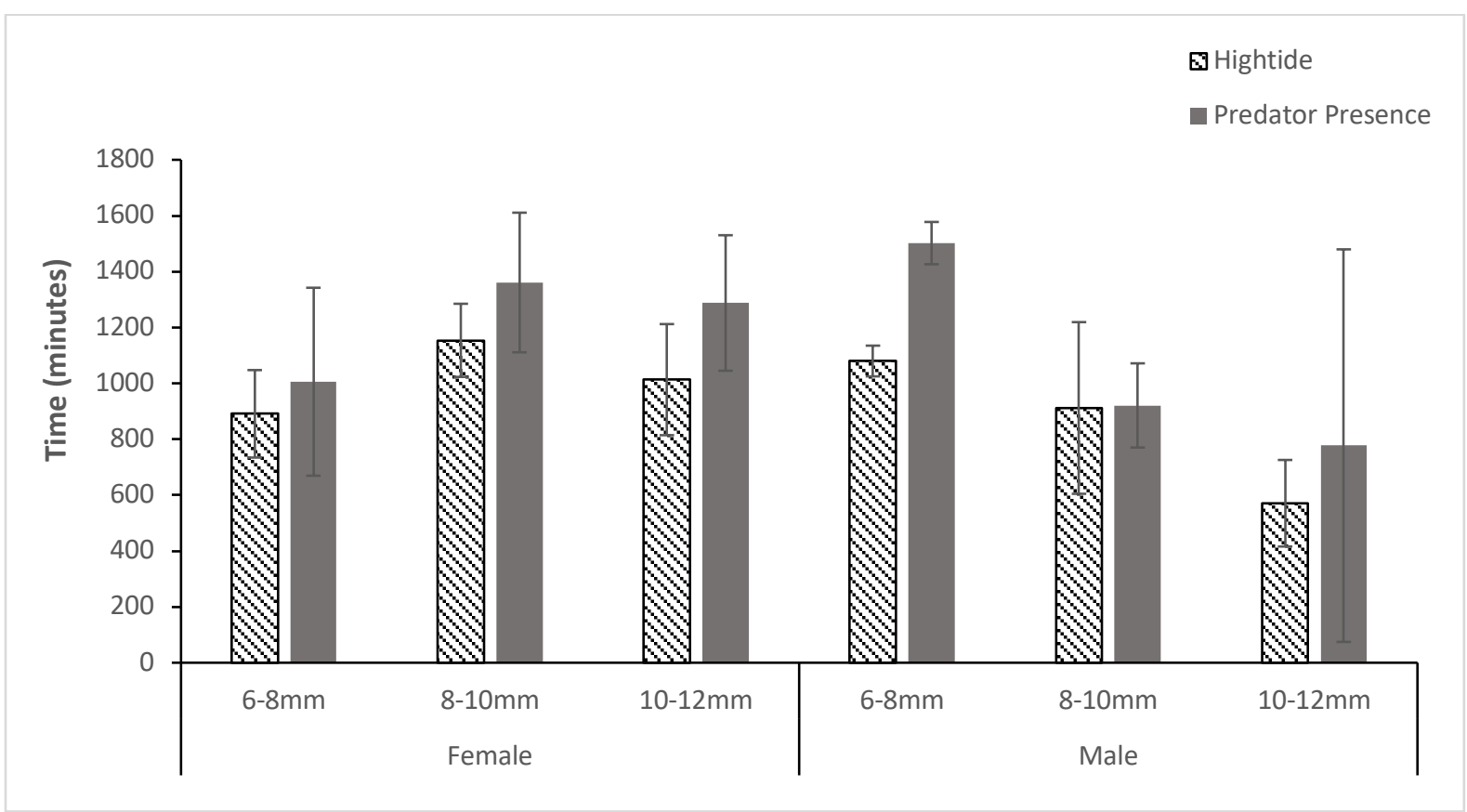

Figure 16: The average time in minutes spent under shelter by male and female $P$. elongatus of different size classes in the high tide and predator presence treatments. Error bars represent standard error. 
When examining the number of shoves given or received, there were no significant interactions between sex, size class and treatment (three-way ANOVA: $\mathrm{P}$ for all interactions >0.05; Appendix Table A2 and A3).

For shoves given, the presence of a predator did not have an effect (three-way ANOVA: $F_{1,24}=0.424, P=0.521$ ), however, males dealt significantly more shoves than females (three-way ANOVA: $\mathrm{F}_{1,24}=36.607, \mathrm{P}=<0.0001$ ) and there was also a significant difference between size classes (three-way ANOVA: $F_{2,24}=15.745, \mathrm{P}=<0.0001$; Figure 17A). Overall, individuals of the largest size class $(10-12 \mathrm{~mm})$ and medium-sized class $(8-10 \mathrm{~mm})$ shoved more than the smallest size class $(6-8 \mathrm{~mm})$ (Tukey tests, $\mathrm{P}=<0.0001$, $\mathrm{P}=0.008$ ) while there was no significant difference between the two larger size classes (Tukey test, $P=0.079$ ). The number of shoves received was not affected by any of the main effects, so did not vary with predator presence (three-way ANOVA: $\mathrm{F}_{1,24}=0.474$, $\mathrm{P}=0.498$ ), sex (three-way ANOVA: $\mathrm{F}_{1,24}=1.561, \mathrm{P}=0.224$ ), or size class (three-way ANOVA: $\left.\mathrm{F}_{2,24}=3.055, \mathrm{P}=0.066\right)$, and thus was statistically similar across all of these factors (Figure 17B).
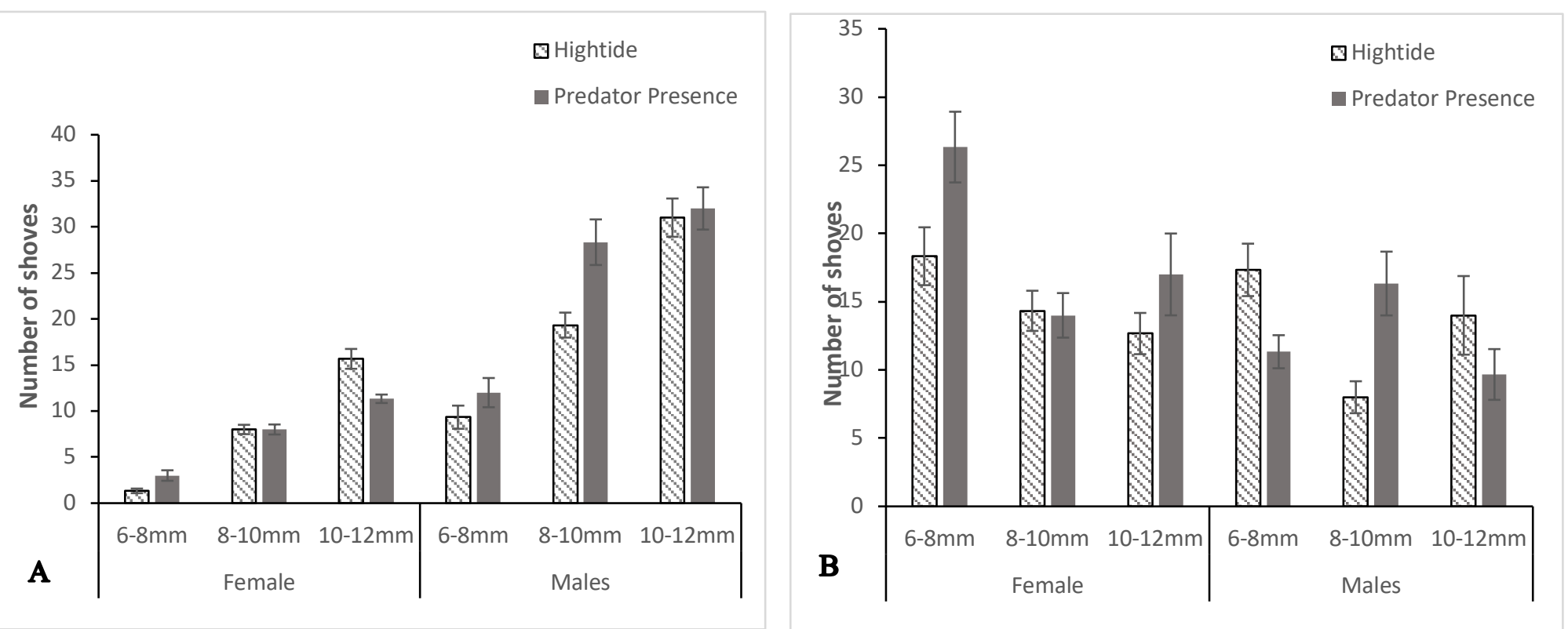

Figure 17: The mean number of times males and females of different sizes shoved another individual (A) were shoved by another individual (B) across high tide and predator presence treatments. Error bars represent standard error. 
There were no significant interactions between any of the factors of sex, size class or treatment when analysing the relative size of a shoved individual (three-way ANOVA: $P$ for all interactions $>0.05$; Appendix Table A4).

However, there was a significant effect of relative size (three-way ANOVA: $F_{2,48}=$ 27.586, $\mathrm{P}=<0.0001)$. Individuals shoved smaller or same-sized individuals significantly more than larger conspecifics (Tukey tests, $\mathrm{P}=<0.0001, \mathrm{P}=<0.0001$ ) while shoving same-sized or smaller conspecifics equally (Tukey test, $\mathrm{P}=0.4548$ ). Males also shoved larger females significantly more than females shoved larger females (Tukey test, $\mathrm{P}=0.041$ ) or males (Tukey test, $\mathrm{P}=0.041$; Figure 19). Neither males or females showed a preference for which sex they would shove (Tukey tests, $\mathrm{P}$ $=0.433, \mathrm{P}=0.934)$, however, males shoved females more than females would shove males (Tukey test, $\mathrm{P}=<0.0001$ ).

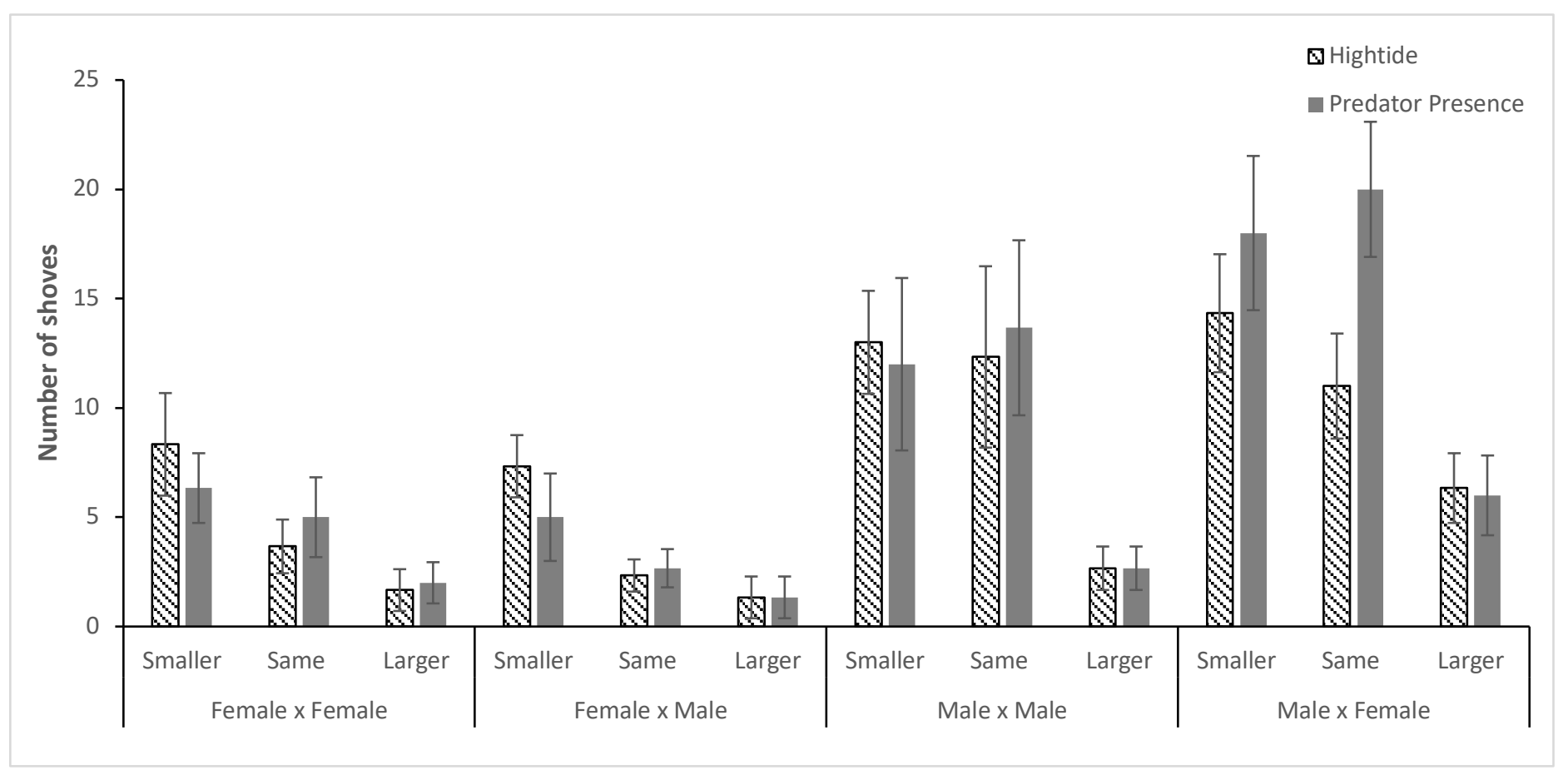

Figure 18: The mean number of times a male or females shoved another male or female, and whether that individual was smaller, the same size or larger. Error bars represent standard error 


\section{Ovigerous vs. non-ovigerous females}

\section{Time spent under shelter}

There was no significant interaction between ovigery state and treatment on time spent under shelter by female P. elongatus (two-way ANOVA: $\mathrm{F}_{1,8}=2.198, \mathrm{P}=0.176$ ). Individuals spent significantly more time under shelter when in the presence of a predator than without (two-way ANOVA: $\mathrm{F}_{1,8}=8.006, \mathrm{P}=0.022$ ). Ovigerous females also spent significantly more time under shelter than non-ovigerous females (two-way ANOVA: $\mathrm{F}_{1,8}=21.061, \mathrm{P}=0.002$; Figure 19).



Figure 19: Average total time spent under shelter by ovigerous and non-ovigerous females for the high tide and predator presence treatments. Error bars represent standard error. 
There was no interaction between treatment and ovigery state when comparing the different shoving combinations (two-way ANOVA: $\mathrm{F}_{3,16}=0.202, \mathrm{P}=0.893$ ).

There was no difference in the number of shoving interactions between high tide and predator treatments (two-way ANOVA: $\mathrm{F}_{1,16}=0.103, \mathrm{P}=0.753$ ) but there was a difference in the number of shoves between the type of shoving interaction (two-way ANOVA: $\left.\mathrm{F}_{3,16}=7.912, \mathrm{P}=0.002\right)$. Ovigerous females and non-ovigerous females shoved non-ovigerous females more than the other way around (Tukey test, $\mathrm{P}=$ 0.0005). After an outlier was removed, ovigerous females also shoved non-ovigerous females more than they shoved other ovigerous females (Tukey test, $\mathrm{P}=0.001$; Figure 20).

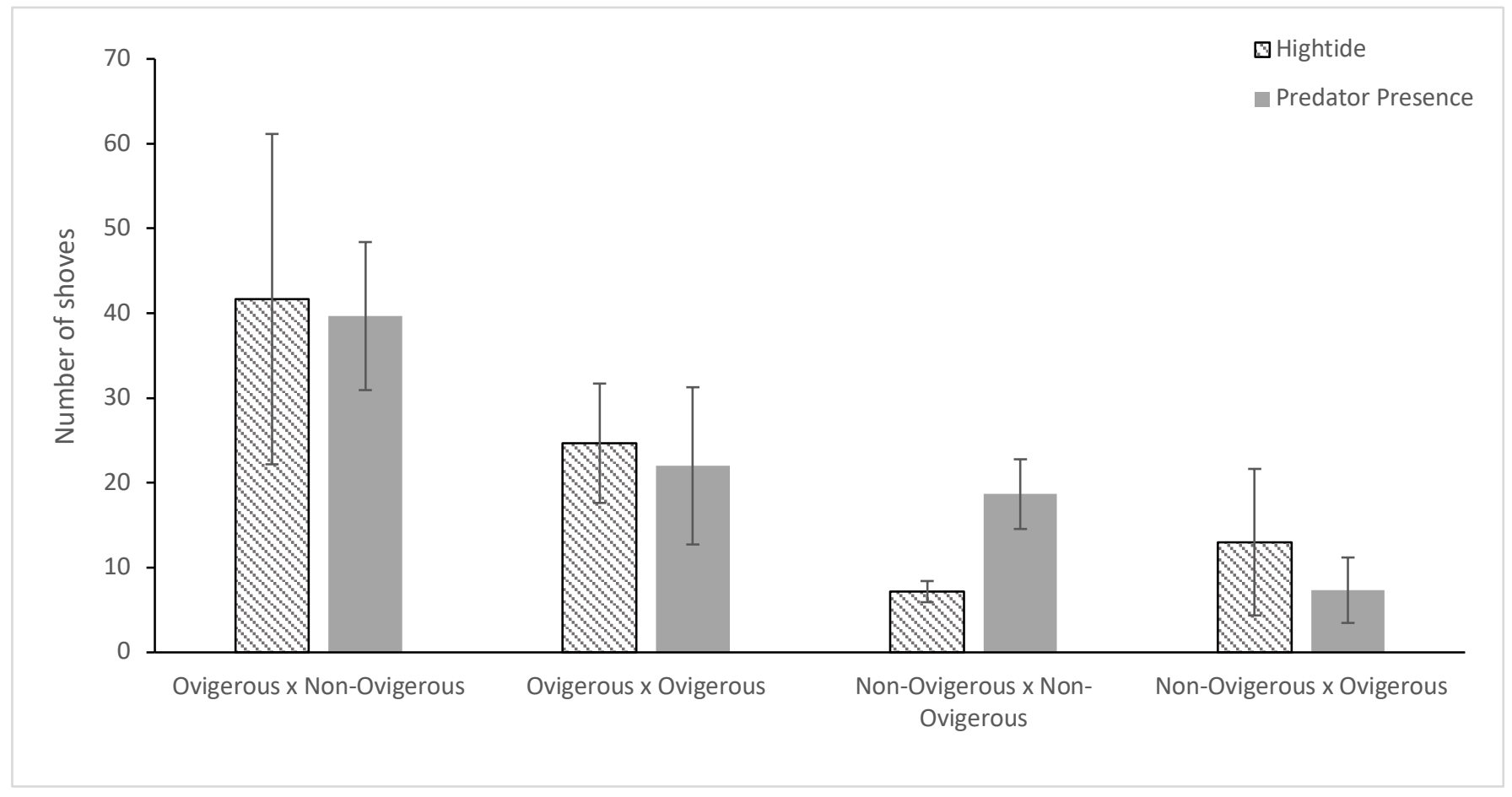

Figure 20: The mean number of shoves for each interaction between ovigerous and non-ovigerous females for the high tide and predator presence treatments. " $\mathrm{x}$ " indicates which ovigery state is shoving the other. Error bars represent standard error. 


\section{Autotomous vs. non-autotomous males}

\section{Time spent under shelter}

There were no significant interactions between autotomy state, size class and treatment on the time spent under shelter for male P. elongatus (three-way ANOVA: $P$ for all interactions $>0.05$; Appendix Table A5).

There was no significant difference between the hightide and predator presence treatment (three-way ANOVA: $\mathrm{F}_{1,24}=0.101, \mathrm{P}=0.752$ ). However, autotomized individuals spent significantly more time under shelter than non-autotomized classes (three-way ANOVA: $\mathrm{F}_{1,24}=13.513, \mathrm{P}=0.001$ ) and there was also a significant difference between size classes (three-way ANOVA: $\mathrm{F}_{2,24}=3.569, \mathrm{P}=0.044$ ). Smallest individuals spent the least amount of time under shelter (Tukey test, $\mathrm{P}=0.0438$ ), while mediumsized and the largest class spent the most time, but did not differ between them (Figure 21).

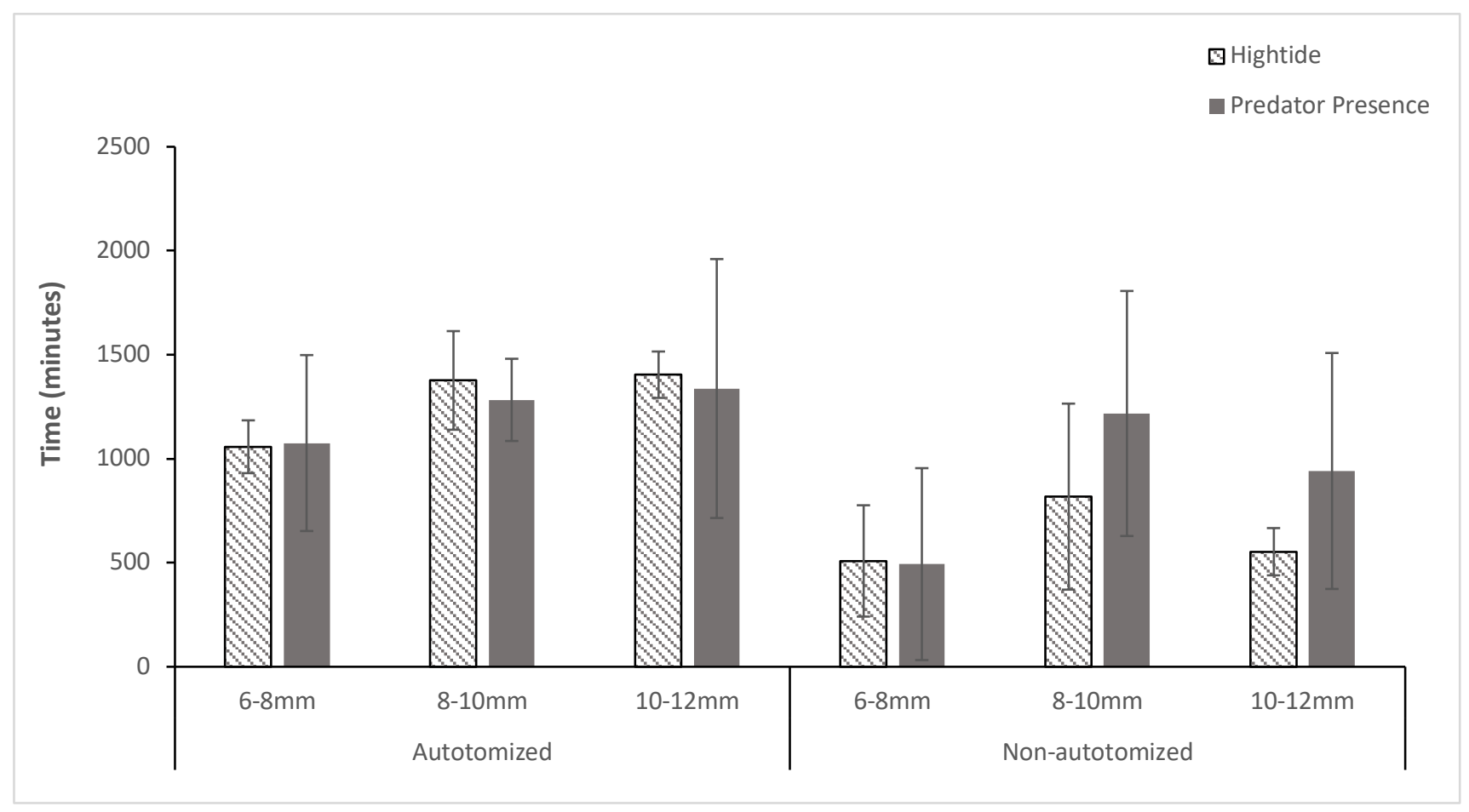

Figure 21: Average time spent under shelter for different sizes of autotomized vs. nonautotomized male $P$. elongatus experiment across high tide and predator presence treatments. Error bars represent standard error. 
When examining the number of shoves given or received, there were no significant interactions between autotomy state, size class and treatment (three-way ANOVA: P for all interactions $>0.05$; Appendix Table A6 and A7).

The number of shoves given did not vary with predator presence (three-way ANOVA: $\mathrm{F}_{1,24}=0.978, \mathrm{P}=0.333$ ) or autotomy state (three-way ANOVA: $\mathrm{F}_{1,24}=1.587, \mathrm{P}=0.22$ ), however, there was a significant difference between size classes (three-way ANOVA: $\left.\mathrm{F}_{2,24}=3.732, \mathrm{P}=0.039\right)$. The largest size class shoved significantly more than the smallest size class (Tukey test, $\mathrm{P}=0.03$ ) while medium-sized individuals did not differ from either size class (Figure 22A). The number of shoves received also did not vary with predator presence (three-way ANOVA: $\mathrm{F}_{1,24}=1.459, \mathrm{P}=0.239$ ), however, autotomized individuals received significantly more shoves than non-autotomized individuals (three-way ANOVA: $\mathrm{F}_{1,24}=6.475 \mathrm{P}=0.018$ ) and there was a significant difference between size classes (three-way ANOVA: $F_{1,24}=3.738, P=0.039$ ). Again, the largest size class received significantly less shoves than the smallest size class (Tukey test, $\mathrm{P}=0.034$ ) while medium-sized individuals did not differ from either size class (Figure 22B).
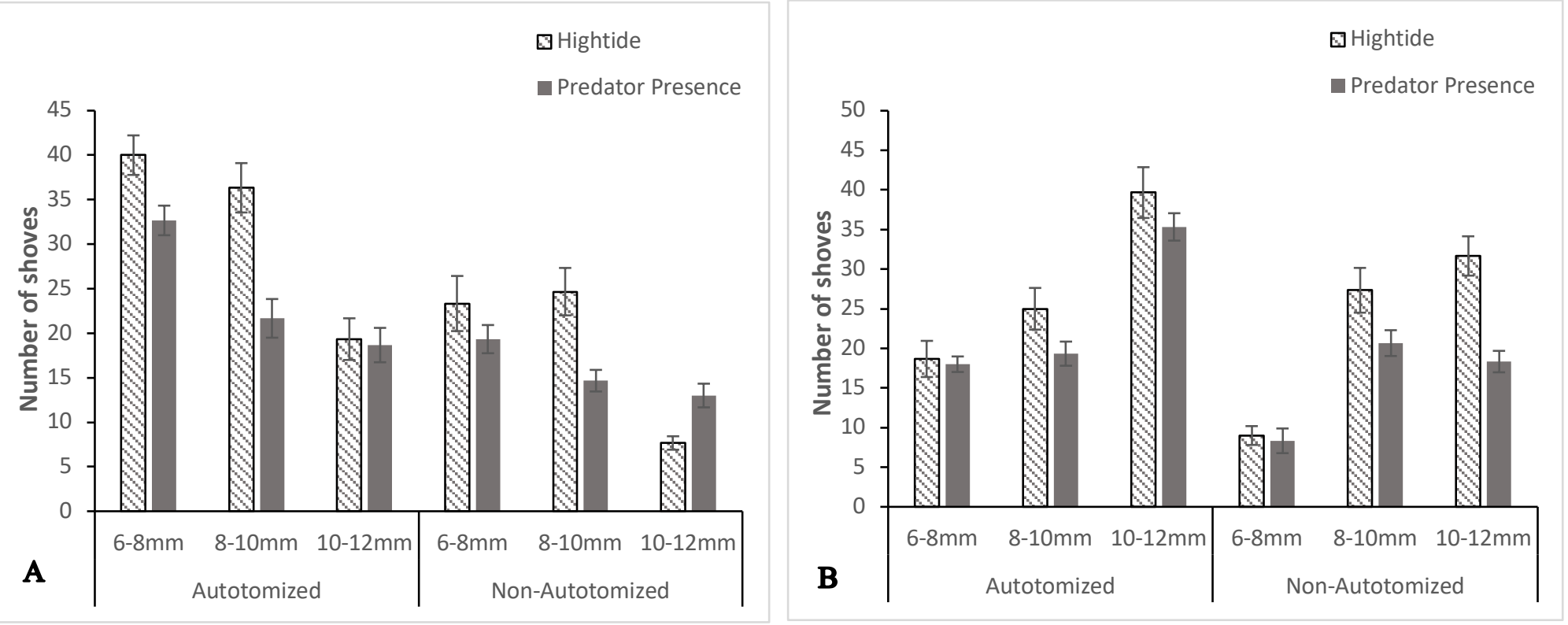

Figure 22: The mean number of times autotomized and non-autotomized male $P$. elongatus shoved another individual (A) were shoved by another individual (B) across high tide and predator presence treatments. Error bars represent standard error. 
There were no significant interactions between any of the factors of autotomy state, size class or treatment when analysing the relative size of a shoved individual (threeway ANOVA: P for all interactions >0.05; Appendix Table A8).

However, there was a significant effect of relative size (three-way ANOVA: $\mathrm{F}_{3,48}=4.651$, $\mathrm{P}=<0.0001)$. Males shoved smaller conspecifics significantly more than same-sized (Tukey test, $\mathrm{P}=0.007$ ) or larger ones (Tukey test, $\mathrm{P}=<0.0001$ ), while there was no difference between larger and same-sized classes. Unlike the comparison between males and females, there was no signficant difference between classes when looking at shoving larger conspecifics (two-way ANOVA: $\mathrm{F}_{3,16}=1.415, \mathrm{P}=0.275$ ). Neither autotomized individuals or non-autotomized individuals showed a preference for which class they would shove, and neither class shoved each other more than the other (Figure 23).

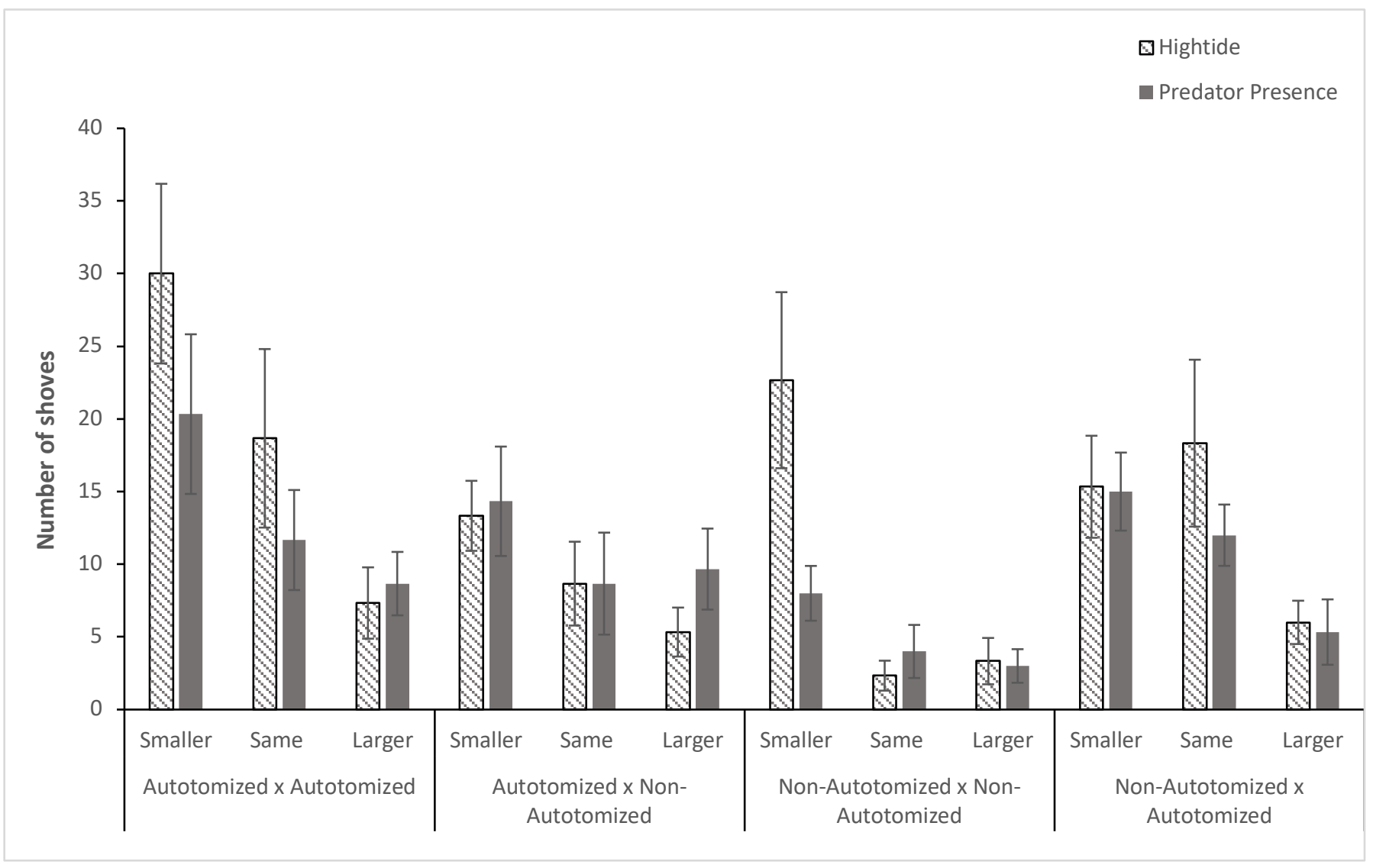

Figure 23: The mean number of times autotomized and non-autotomized males shoved another individual, and whether that individual was smaller, the same size or larger. Error bars represent standard error. 


\section{Field survey data}

Individuals smaller than $4 \mathrm{~mm}$ could not be sexed and no females were found with a carapace width greater than $14 \mathrm{~mm}$, and therefore these size classes were not included in these analyses. A summary of their findings is included in the results below.

\section{Cheliped size ratios}

When comparing cheliped length to carapace width ratio between male and female $P$. elongatus of different size classes, there was a significant interaction between sex and size class (two-way ANOVA: $\mathrm{F}_{4,269}=7.725, \mathrm{P}=<0.0001$ ). The interaction effect was explored further with a post hoc Tukey Test comparing all combinations of sex and size class with each other. From this analysis, female cheliped length to body width ratios did not differ between any of the size classes (Figure 24). Significant differences were found between females and males in all size classes except the smallest (Tukey test, $\mathrm{P}=0.055)$. For males, every other increasing size was significantly different (Tukey tests, $\mathrm{P}<0.05$ in all cases). Overall, the difference in claw-to-body size ratios between males and females increased as body size increased (Figure 24). The same patterns were seen when looking at cheliped-width-to-carapace-width ratios and so is not reported here.

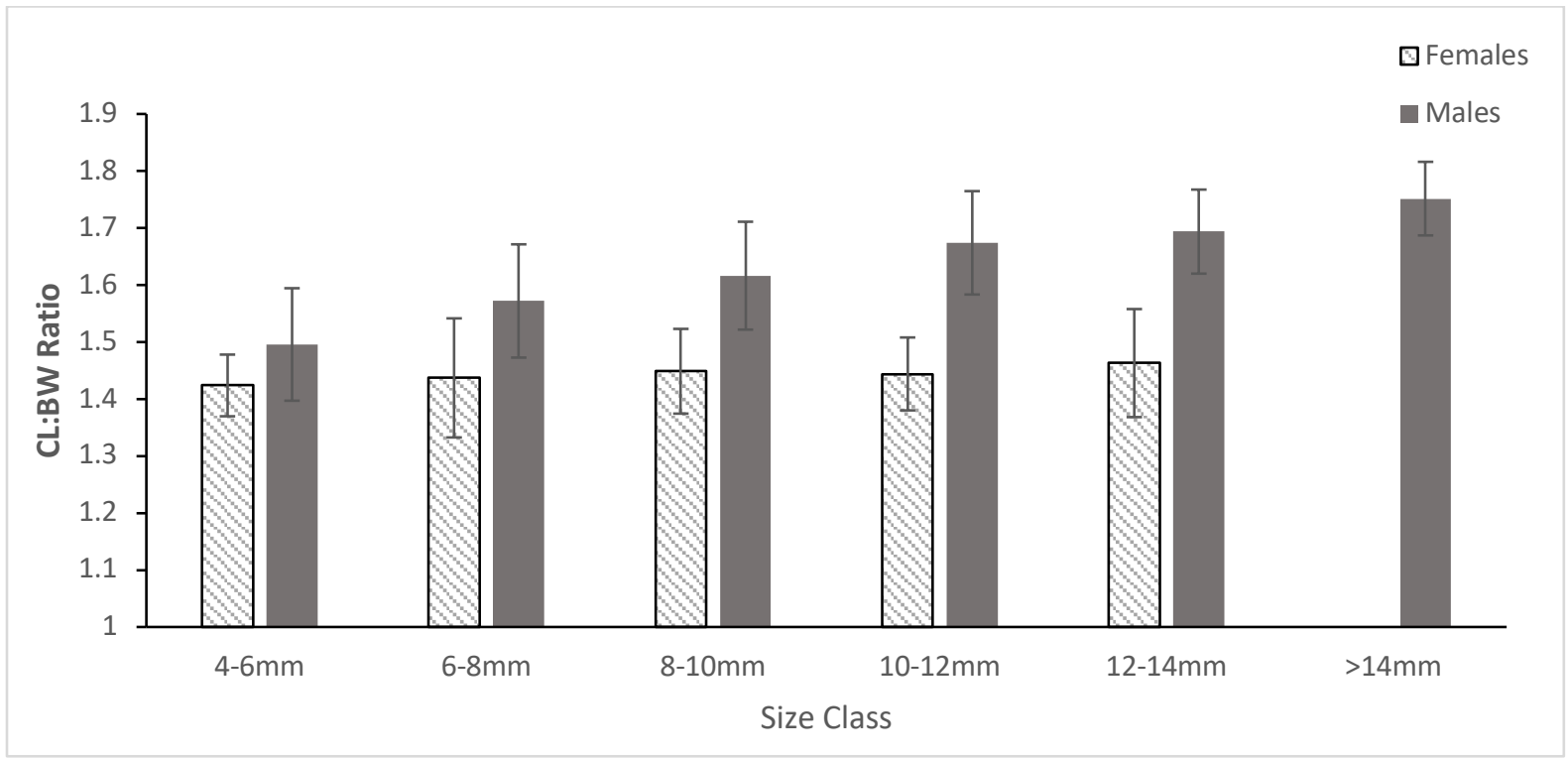

Figure 24: Cheliped Length (CL) to Carapace Width (BW) ratios for different sizes of male and females $P$. elongatus. Error bars represent standard error. 
In general, males were not only bigger, but they had bigger cheliped sizes relative to their carapace widths. While no females had carapace widths greater than $14 \mathrm{~mm}$, males in this size class appeared to have the largest cheliped size to carapace width ratio. The largest female CL to BW ratio was 1.6 while for males it was 1.9 and the largest female $\mathrm{CW}$ to $\mathrm{BW}$ ratio was 0.7 while for males it was 0.8 . Overall, the largest male recorded had a carapace width of $16.5 \mathrm{~mm}$, with cheliped length and width of $30.2 \mathrm{~mm}$ and $13.5 \mathrm{~mm}$ respectively, while the largest female had a carapace width of $13.9 \mathrm{~mm}$, with a cheliped length and width of $21.1 \mathrm{~mm}$ and $9.0 \mathrm{~mm}$ respectively.

\section{Autotomy and claw puncture survey}

From the autotomy and claw puncture survey, neither females $(n=134)$ or males $(n=$ 301) were more likely to be automized than the other sex (Chi-squared test, $\chi^{2}=1.473$, $\mathrm{df}=1, \mathrm{P}=0.225$ ), and neither were more likely to have claw punctures (Chi-squared test, $\left.\chi^{2}=2.734, \mathrm{df}=1, \mathrm{P}=0.098\right)$. However, a trend was apparent where a larger percentage of females were missing limbs and/or had claw punctures (Figure 25).



A

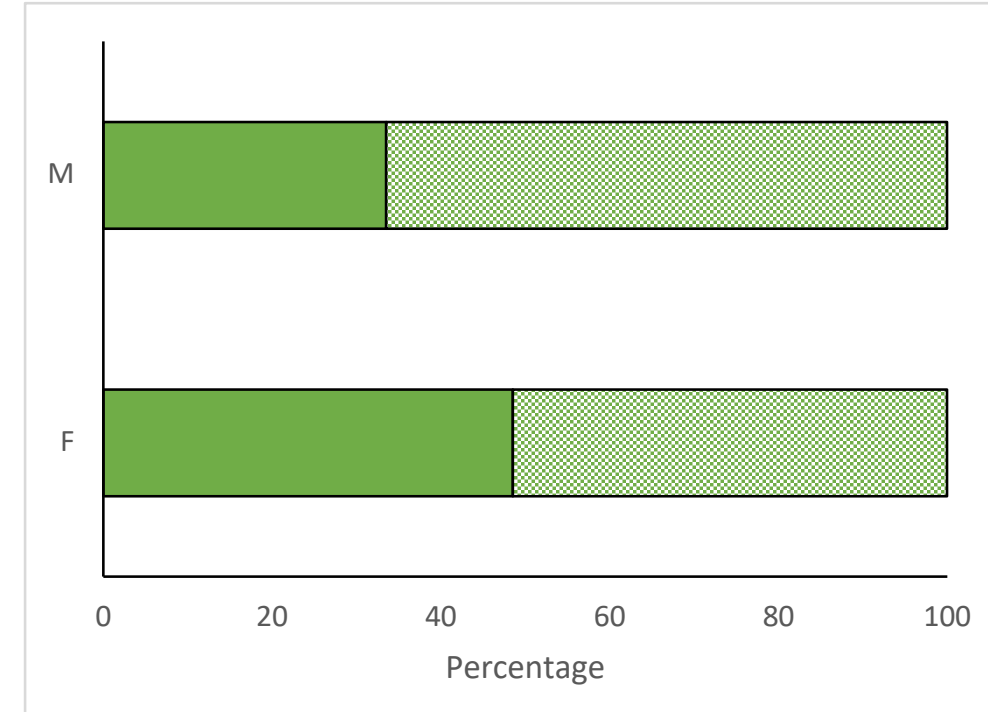

B

Figure 25: Percentage of females (F) and males (M) from shore collections that were autotomized (A) or had claw punctures (B) 
For the following analyses, crabs were grouped into the following size classes to accommodate for low numbers collected during the survey; 4-8mm (Female; $\mathrm{n}=40$, Male; $\mathrm{n}=58$ ), $8-10 \mathrm{~mm}$ (Female; $\mathrm{n}=61$, Male; $\mathrm{n}=122$ ), and 10-14mm (Female; $\mathrm{n}=16$, Male $\mathrm{n}=87$ ).

For females, the likelihood of an individual being autotomized increased with size (Chi-squared test, $\left.\chi^{2}=9.567, \mathrm{df}=2 \mathrm{P}=0.008\right)$, but this trend was not apparent for males (Chi-squared test, $\chi^{2}=0.111, \mathrm{df}=2, \mathrm{P}=0.946$; Figure 26).
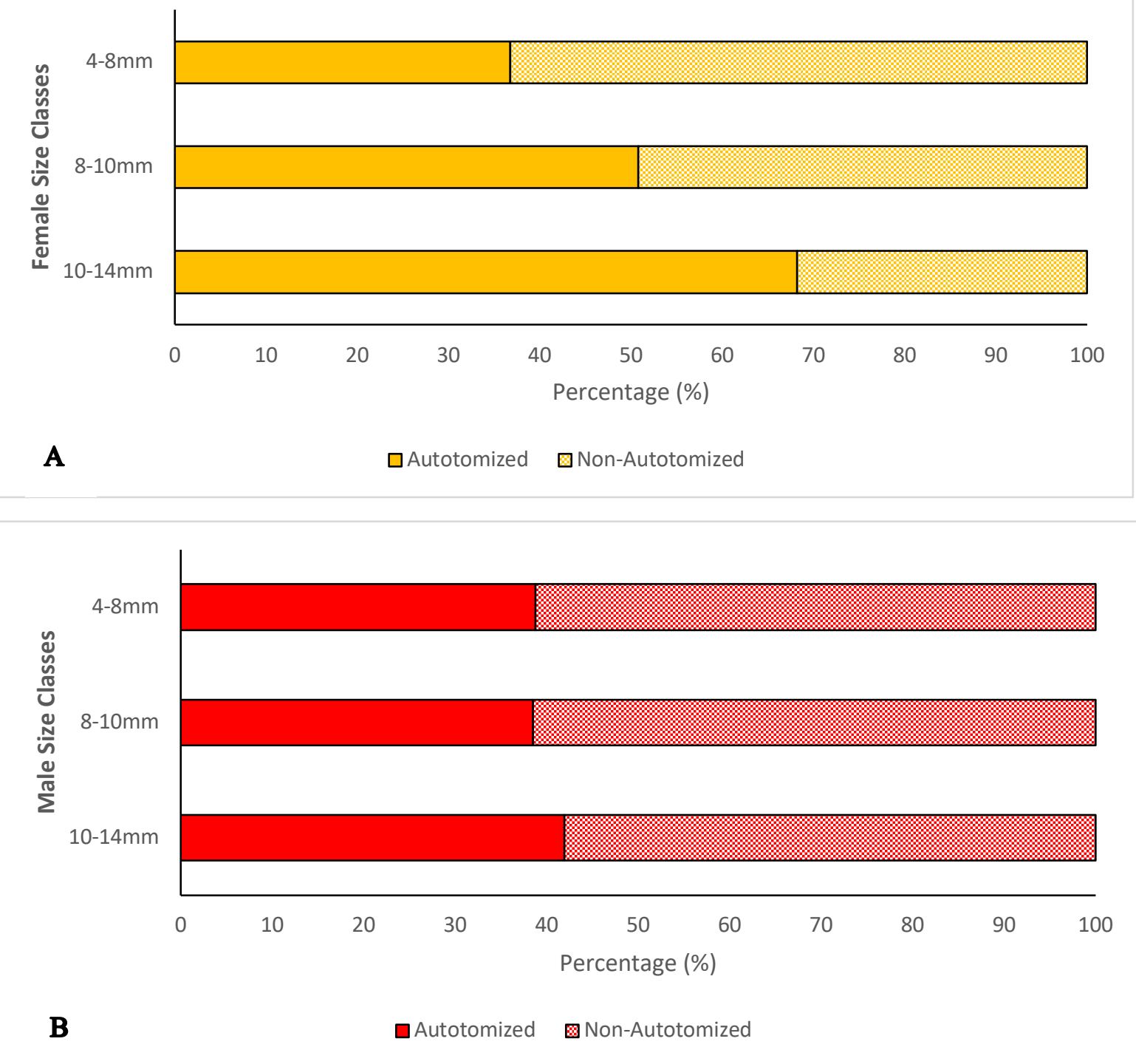

Figure 26: Percentage of different size classes of females (A) and males (B) from shore collections that were autotomized 
A similar trend was found when assessing puncture wounds in chelipeds (Figure 27). The likelihood of an individual having puncture wounds increased with body size for females (Chi-squared test, $\chi^{2}=7.273, \mathrm{df}=2, \mathrm{P}=0.026$ ) but not for males (Chi-squared test, $\left.\chi^{2}=3.889, \mathrm{df}=2, \mathrm{P}=0.143\right)$.

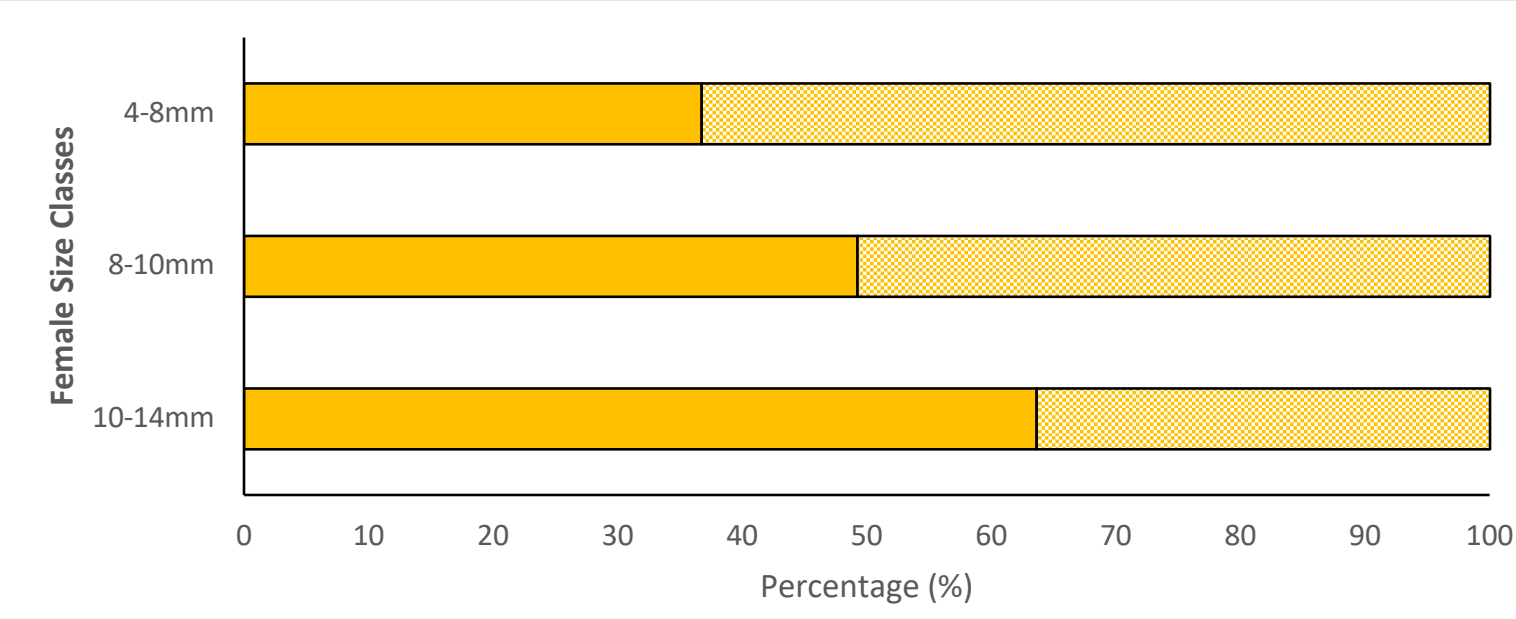

A

$\square$ Punctured $\square$ Not Punctured

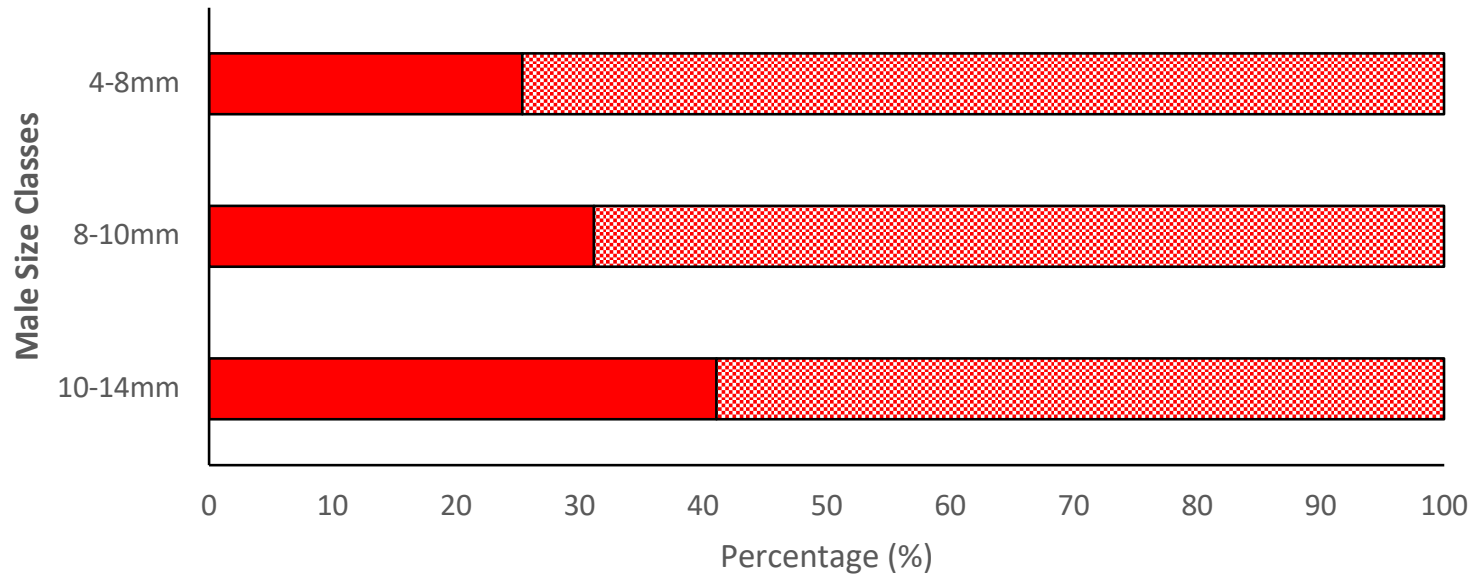

B

Punctured Not Punctured

Figure 27: Percentage of different size classes of females (A) and males (B) from shore collections that had claw punctures 
When comparing ovigerous and non-ovigerous females, neither class of females were more likely to be autotomized (Chi-squared test, $\chi^{2}=1.102$, $\mathrm{df}=1, \mathrm{P}=0.294$ ) or have claw punctures (Chi-squared test, $\chi^{2}=0.0002, \mathrm{df}=1, \mathrm{P}=0.988$ ) than the other (Figure 28).

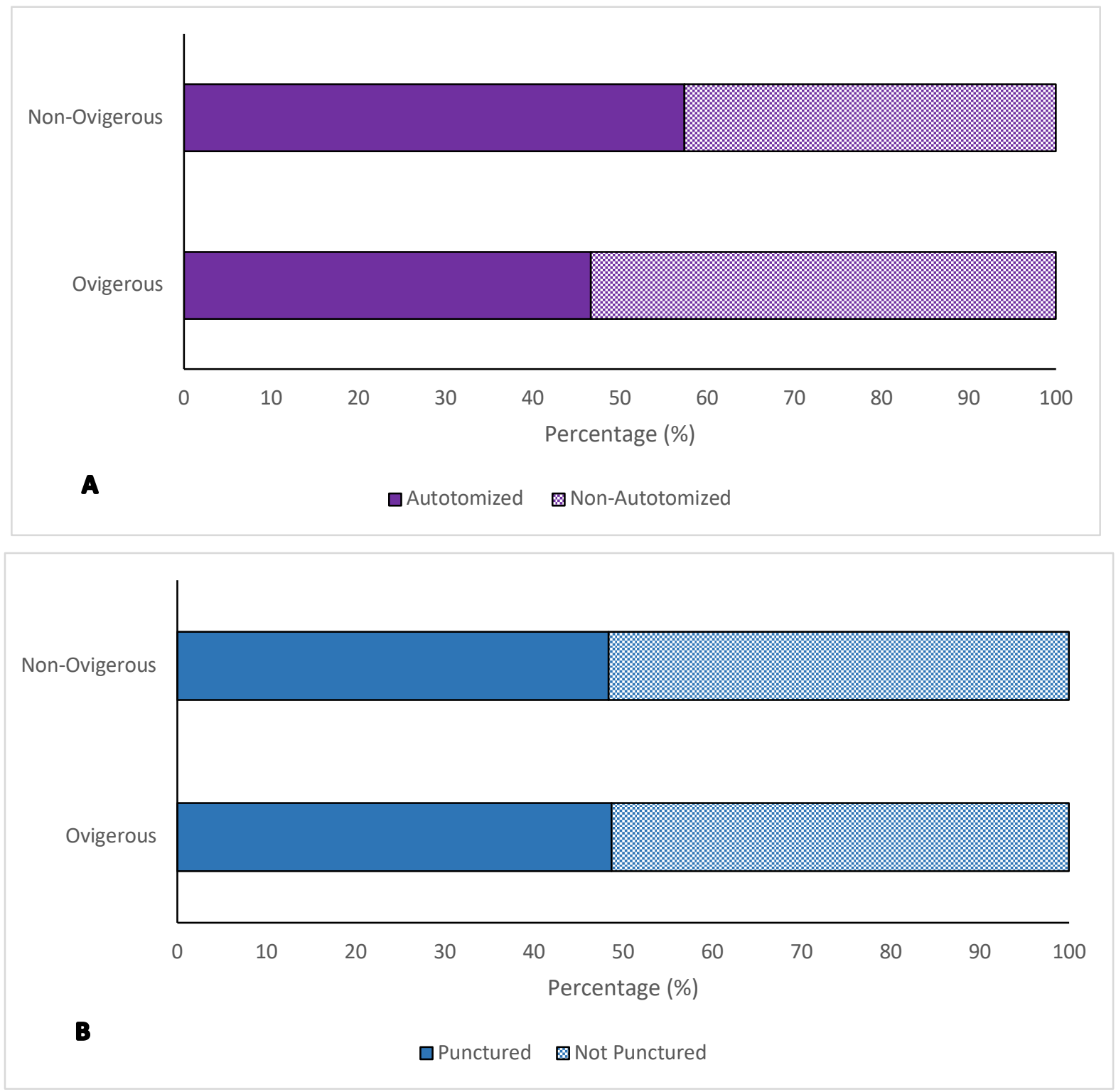

Figure 28: Percentage of ovigerous and non-ovigerous females from shore collections that were autotomized (A) and had claw punctures (B) 


\section{Chapter 4-Discussion}

This is the first study of the competitive interactions of Petrolisthes elongatus, as well as one of the first to look at how external environmental factors can impact them. Other studies have investigated competitive interactions in other species of porcelain crabs as well as how competitive behaviour can be mediated by environmental conditions in other taxa. These findings complement these studies on how competitive behaviour can be predicted, and how the outcomes can drive P. elongatus population structures.

\section{Low tide treatments}

In general movement and interactions were considerably reduced when $P$. elongatus was tested under a low tide treatment. For all experiments, individuals would seek shelter as the tide went down and would settle either in shelters as clusters, or aggregations in the corners of the tank. Shelter seeking behaviour has been defined as actively seeking to avoid adverse environmental conditions, including to avoid predation (Hassall \& Tuck, 2007). In sheep and red deer, herds congregate under trees and man-made shelters to avoid low temperatures, rain and strong winds (Pollard \& Littlejohn, 1999; Conradt et al., 2000). Ungulates such as horses, cattle, donkeys and mules have all been seen to seek shelter/shade to avoid direct sunlight and high temperatures (Proops et al., 2019; Nogueira et al., 2016; Haddy et al., 2020). Terrestrial invertebrates such as grasshoppers move to avoid overheating in the sun (Lensink, 1963) and species of woodlice susceptible to water loss sheltered in areas that provided shade and protection from desiccation, while also sheltering less in rainy conditions (Hassall \& Tuck, 2007). Cane Toads, Bufo marinus, seek suitable diurnal shelters in order to prevent dehydration and temperature stress during the dry season (Seebacher \& Alford, 2002), while sheltering can reduce water loss by as much as $81 \%$ in the Hoopoe Lark, Alaemon alaudipes (Williams et al., 1999).

Many marine intertidal organisms have to tolerate periods of air exposure and shelterseeking is a critical strategy to help protect themselves from desiccation and heat when exposed. Rocky shore chitons and intertidal snails are often found in crevices, tide pools, and other areas where moisture will collect, in order to avoid such physical 
stresses (Coffin et al., 2008; Mendonça et al., 2015). Behavioural selection of cool, shaded overhangs or crevices, can also vastly improve tolerance for warm temperatures in high intertidal snails such as Echinolittorina malaccana (Marshall et al., 2013). Many species of crabs, like $P$. elongatus, are able to survive these dry periods by moving to suitable moist cracks, crevices or burrows that significantly reduce the risk of water loss (Nybakken, 1993).

While aggregation in animals can occur for a number of reasons i.e. breeding, hibernation, aestivation, sleeping (Allee, 1927), some species use aggregation with other conspecifics as a form of "shelter" to avoid extreme environmental stress when other forms are unavailable. Many species of penguins, huddle together as a way of reducing heat loss during extreme cold (Wilson, 2009). Overwintering aggregation in animals is well known, especially in bees and many other invertebrates (Hill et al., 1976; Benton \& Crump, 1979) and is often due to a lack of available shelter spaces. Studies show that for bees, aggregations allows them to control the temperature within their cluster, preventing them from succumbing to the cold (Allee, 1927).

The change from submersion to exposure as the tide recedes can be physically demanding and very drastic for intertidal organisms. They are subjected to evaporative water loss, the effects of wind, conduction, and heating from solar and thermal radiation from the atmosphere and its surroundings (Spotila et al., 1989). Therefore, another possible benefit of aggregation is moisture control and the reduction of water loss, especially in dry environments. Isopods, earthworms and ground beetles have been shown to lose water more slowly under dry conditions when aggregated, decreasing their mortality rate (Allee, 1927). Water loss rates were also recorded to have reduced in aggregations within a particular instar than rates of individual caterpillar. In addition, survival of water loss tends to be higher in individuals from aggregations than in single individuals (Klok \& Chown, 2002).

For organisms subjected to the drying conditions along the intertidal shore, seeking shelter and aggregation can be the difference in their survival. Nodilittorina unifasciata Gray, is a species of periwinkle that aggregates in clusters when emersed during low tide on most shores in New South Wales, Australia (Chapman, 1988). Aggregation is associated with inactivity during emersion but is lessened during high tide. These behaviours can be attributed to responses from different cues. For example, snails may 
respond to aspects of habitat, or local patterns of water-movement during the falling tide (Chapman, 1998). This sort of behaviour was seen in P. elongatus, where crabs situated on rocks or high above the side of the tank, would retreat as the tide fell, forming aggregations at the bottom of the tank and in the corners. Many other organisms display behaviours that are closely related to tidal rhythms such as hermit crabs that cluster and seek shelter during low tides where they remain inactive until the tide returns (Turra \& Leite, 2000). Aggregating during low tide can also provide protection against dilution of seawater, especially during periods of rainfall. For example, green flatworms, Convoluta sp., can better resist dilution of sea water in large numbers than when there are few present (Drzewina \& Bohn, 1927). Aggregation may help organisms to tolerate more exposed conditions, with less reliance on natural shelter sites, and may also account for differing sheltering behaviours in porcelain crabs. Work on porcelain crabs by Stillman and Somero (1996) showed that during emersion these animals are found in the shade under rocks where their body temperatures and physiological adaptations relate to relatively cool air temperatures. Their observations also included aggregative behaviours and lack of movement between rocks during low tide.

Not only was there a lack of shoving interactions during the simulated low tide in my experiments, but movement in general was greatly reduced (with the exception of an occasional exploratory individual that would move around the tank). Movement and feeding was noticeable when the tank was refilled and crabs immediately began to spread out. This suggests that $P$. elongatus would rather aggregate than compete for shelter resources as a form of mitigating desiccation pressures, and that these pressures are great enough to inhibit unwarranted energy expenditure. Individuals would also aggregate outside of shelter even when there were available spaces. Shelter spaces were designed so that only one individual could comfortably fit, however there were occasions where multiple smaller individuals could squeeze into a singular shelter. At the most, there were only a maximum of three crabs that could fit into a shelter at any one time. Aggregation in larger groups of up to 20 crabs in the corner of the tank, while shelter spaces are still available, suggest that aggregation provides more protection than the shelter spaces. This behaviour could therefore be favourable even when desirable space is unoccupied, suggesting aggregation can be a more beneficial form of shelter, than other physical shelters. Further study could be conducted to investigate whether there are certain drivers to influence aggregative 
behaviours and the cues that allow them to form these clusters; i.e. sight, aggregating pheromones, or random chance.

\section{Adult vs. juvenile males}

\section{Time spent under shelters}

In general, the average time that a crab would spend under shelter was associated with size. The smaller classes (4-6mm and 6-8mm) spent significantly more time under shelter than the larger size classes $(8-10 \mathrm{~mm}, 10-12 \mathrm{~mm}$ and $12-14 \mathrm{~mm})$, while the larger classes did not differ between themselves. In the wild, individuals must seek shelter to protect themselves from exposed conditions and predation. For younger individuals, this risk is increased often due to their smaller size, inexperience, and overall inability to protect themselves. Juvenile bridled nailtail wallabies, Onychogalea fraenata, spend their whole days sheltering in dense vegetation avoiding open areas more than adults, while at night they would not venture as far as adults out of cover (Fisher \& Goldizen, 2001). Juvenile spotted wolffish, Anarhichas minor, when given the opportunity to use shelter, would do so significantly more than spending time in the exposed water column (Andrée-Anne et al., 2010).

Adults on the other hand, with possible adaptations to fend off predators and deal with harsh environmental conditions, may not be as inclined to hide in shelter. Ontogenetic shifts in shelter use is common among many other species. Juvenile deer and antelope will adopt concealment behaviours by lying still in shelters such as dense bush and tall grass. Generally, as they become older, their behaviour changes to running from cover at greater distances from predators (Fitzgibbon, 1990). A negative relationship with body size and shelter use was also found in lemon sharks, with juveniles using mangrove shelters significantly more than adult conspecifics (Stump et al., 2017). A study looking at cover-seeking behaviour of juvenile and adult crayfish, Procambarus clarkii, provided individuals with choices between an open area, a dark shelter and a clear shelter. Overall, adults were found in the open area and dark shelter significantly more than under the clear shelter, but there was no difference between the dark and open area. Juveniles opted for the dark shelter the most, significantly more than the clear shelter and open area. Any juveniles that were found outside shelter tried to manipulate gravel to form their own shelter (Antonelli et al., 1999). 
Larger crayfish may also prefer shelter types that are less confining, allowing easier maneuverability of their chelae, which are the chief weapons of offense and defence for the crayfish. This apparent ontogenetic transition in shelter selection may be due to the reduced risk of predation as the animals increase in size and could explain the differences in shelter use between larger and smaller $P$. elongatus. Larger individuals may have not been able to comfortably fit their whole bodies, including their chelipeds under some of shelter spaces. Feeding and maneuverability would have been greatly reduced in these circumstances, and therefore may not have been preferable.

There was no significant difference in time spent under shelter between hightide and predator presence treatments. Sheltering has been shown to be critical to the survival of juveniles of many species. Shelter use in juvenile largemouth bass, Micropterus salmoides, resulted in higher survival rates than those without (Stahr \& Shoup, 2015), while habitat complexity reduced vulnerability of juvenile red sea bream, Pagrus major, to predation by piscivorous fish by serving as physical and/or visual barriers and limiting the predator's ability to pursue and capture prey (Shoji et al., 2007). However, due to a juvenile's increased vulnerability, they may have a tendency to seek shelter no matter what conditions are present. Juvenile Atlantic salmon, Salmo salar, like other species of freshwater fish, are known to use crevices under stones on the substrate as shelters to avoid direct predation, but also other harsh environmental conditions. Individuals out of shelter had higher metabolic rates even when there was no predator presence suggesting that a lack of shelter results in higher energy costs for the preparation for a potential threat (Millidine et al., 2006).

Juvenile $P$. elongatus may seek shelter to pre-emptively avoid unexpected harsh environmental conditions, such as increased water flow, or a sudden predator encounter. The smallest individuals were also able to fit in very small cracks and would sometimes lodge themselves deep under a rock shelter. Some of the other smaller size classes were also able to squeeze more than one individual under the same shelter and may have become tolerant if they were small enough such that space was no longer limiting. These factors could contribute to the little change seen between the two conditions of a predator being present or not.

Another reason that the time spent under shelter may not be significantly different is that many species, especially in their juvenile stages, aggregate when threatened so as 
to protect themselves. Emperor penguin chicks huddle to avoid predation when extreme cold isn't a driving factor (Wilson, 2009) while juvenile blacktip reef sharks are more vulnerable to predation than their older conspecifics, and therefore during the day, aggregating behaviours are increased (Heupel \& Simpfendorfer, 2005). Aggregation is common behaviour in many decapods as many types of crabs form piles to protect themselves from predation. In Europe, the spider crab, Maja squinado, aggregate into "heaps" to protect molting animals or to provide protection from predatory octopi (Carlisle, 1957), while king crabs form large "pods" containing up to 1000 crabs which makes distinguishing individuals difficult and could deter predators (Stevens, 2014). My experimental set up meant that shelters only provided comfortable space for one individual and so aggregation occurred in the corners of the tank, often on the other side to where the predator was located.

Aggregating behaviour also seems to be associated with age and size, with younger and smaller members often displaying this behaviour more than larger ones. Small periwinkles, Nodilittorina unifasciata Gray, (Chapman, 1998) and hermit crabs (Turra \& Leite, 2000) were more likely to be found in aggregations than larger ones. These were often attributed to their increased vulnerability to desiccation, and clusters helped retain water content during low tide. The youngest blacktip reef sharks aggregated more often and for larger periods and is consistent with behaviours of juveniles for many species. I observed smaller individual crabs leaving individual shelters and aggregating where larger individuals were located, sometimes trying to "hide" underneath larger conspecifics. This behaviour has also been reported in juvenile snake starfish which have been observed to huddle underneath each other in aggregates in a display of negative phototropism (Allee, 1927).

\section{Shoving interactions}

The largest males, on average, shoved significantly more than other size classes, except for medium-sized classes, while the smallest size classes shoved the least. Porcelain crabs are known for their relatively large chelipeds, which are used as weaponry in shoving contests (Rypien \& Palmer, 2007). Larger body sizes are indicative of larger chelipeds and therefore gave larger animals an advantage in shoving interactions. Each size class also shoved larger conspecifics far less than samesized or smaller-sized classes, and it was rare that shoves that were directed towards 
larger conspecifics resulted in the displacement of the larger individual from shelter space. One of the most reliable predictors of the outcome of aggressive encounters in decapods is relative size: larger individuals win aggressive encounters against smaller adversaries (Pavey \& Fielder, 1996), however this outcome can be less predictable if the size difference is very small (Peeke et al., 1995). Competitive advantages become less apparent and contests fairer, the closer competitors become in physical characteristics (Arnott \& Elwood, 2009). In my study on P. elongatus, most size classes did not differ in the number of shoving interactions between size classes that were only one smaller or greater, except for the largest one, which may have resulted from the fact that ratios between cheliped size and body size increase with size class in males. There was also a great variation in cheliped size even within the same size class which could be a result of differing growth rates or previous autotomy. Cheliped size has been shown to be a better predictor of competitive interactions than body size in contests between some crustaceans (Yoshino et al., 2011), therefore individuals with larger body sizes may not always have the competitive advantage.

Shoving interactions may not have always been a result of direct competition for shelter. Shoving interactions were also recorded out in the open area away from shelter spaces while others were directed towards individuals who were "passing by". Shoves also did not always end up in the displacement of an individual from a shelter space. These "critical shoves" were only observed on a small number of occasions from smaller individuals to larger ones, and would often only occur between size classes which were similar in size. Dominance of smaller individuals in these cases are often only explained by prior experience as dominants or subordinates (Pavey \& Fielder, 1996) or by the "prior residence effect" which dictates a contest advantage to the individual who secures an area first. While this effect was not explored in this study, observations were made such that when individuals shoved larger conspecifics, it was often to retain shelter, rather than shoving them out.

While the number of shoves dealt increased with body size, there was no difference between size classes in the number of shoves received, indicating that competitive interactions were seen from all size classes and that while smaller size classes shoved others the least, it did not necessarily mean they were shoved the most. Predator presence did not have an effect on the number of shoving interactions, a similar trend to the time spent under shelter. The removal of an outlier did result in a decrease in 
shoving activity in the presence of a predator and could be due to the tendency for juveniles to aggregate in the presence of a predator for protection (Wilson, 2009). Increasing behaviours of aggregation are also often associated with periods of longer inactivity (Chapman, 1998) which could be another reason for the differences in shoving activity between the two treatments.

\section{Males vs. females}

\section{Time spent under shelter}

There was no difference in the time spent under shelter between males and females. However, both sexes followed trends of the adult vs. juvenile experiment where increasing size resulted in a decrease in time spent under shelter. Unlike the sizerelated experiment with males, the presence of a predator resulted in an increase in the time that individuals spent under shelter for all size classes. Differential habitat use as an anti-predator behavioural response is common in a wide range of taxa. Mule deer, Odocoileus hemionus, and white-tailed deer, O.virginianus, shifted to different habitats; rugged and gentle terrain respectively, that suited their flight response capabilities in the presence of gray wolves, Canis lupus (Dellinger et al., 2019). Antipredatory behavioural responses are major contributors in influencing habitat use in many marine vertebrates. For example, Indian Ocean dolphins, Tursiops aduncus, green turtles, Chelonia mydas, pied cormorants, Phalacrocorax variax, and dugongs, Dugong dugong, all shift from shallow, productive seagrass foraging areas to deeper and safer, but less productive, habitats when their predator the tiger shark, Galeocerdo cuvier, is present (Heithaus \& Dill 2002, Heithaus et al., 2008). Specifically, shelter and refuge use can be a critical component of anti-predator survival as seen in populations of the Balearic lizard, Podarcis lilfordi, where populations under predation pressure used refuges significantly more than populations without a predator nearby (Cooper et al., 2009).

Structured habitat use may also differ in the way that a threat is perceived. Olfactory and vision cues affected the way juvenile roach, Rutilus rutilus, avoided predators. When presented with the olfactory cue of a predatory fish, roaches would select to remain in the open water habitat, while when presented with a visual cue they opted for the sheltered habitat. When presented with both cues, shelter was often sought, 
suggesting a visual cue may be a stronger response to seek shelter (Martin et al., 2010). The threat perceived with olfactory senses can be different from a visual threat, as the visual threat may seem more apparent. However this threat may also change from predator to predator. Pikes usually hunt out in the open areas, while perches appear to move in and out of sheltered areas and their perceived threat from olfactory senses could be more apparent (Martin et al., 2010). Other studies have indicated that prey species may not always perceive structured shelter as the optimal refuge. Ungulates, such as deer, often use tall grass to hide in, however, predator such as lions, may utilise the same tall grass for ambush tactics (Martin et al., 2010). Petrolisthes elongatus are also predated upon by olive rockfish, Acanthoclinus focus, which lives sympatrically among them (Truemper, 2012). These predators have the ability to survive exposure to air, and are often found in low tide in high aggregations of $P$. elongatus, utilising the same rock crevices for protection against desiccation and possibly to prey upon them. There have been no studies on the predator-prey interactions of Jasus edwardsii on P. elongatus but I observed that crayfish had the ability to pry $P$. elongatus out of shelters while olive rockfish were observed hiding among rocks leaping out to consume individuals who were exposed in the open. These differences in predation behaviour could have an effect on their tendency to seek shelter.

Studies have shown that olfactory senses are incredibly important for aquatic crustaceans to mediate vital behaviours such as foraging or predator avoidance (Hazlett \& Mclay, 2005; Rosen et al., 2009; Tran, 2013). Vision may also play an important role in semi-terrestrial crabs such as fiddler crabs which retreat into burrows if they perceive a predator threat (Hemmi, 2005). Little research has looked into anti-predatory behaviours of porcelain crabs and the cues that initiate them, but studies have shown that they rely on waterborne cues for settlement and aggregation (Truemper, 2012). Petrolisthes elongatus has also been shown to be negatively phototactic (Meyer-Rochow \& Meha, 1994), and so sheltering behaviour can be influenced by the amount of light that was perceived during the experiment. While the experimental set up was meant to reduce as much light as possible, shelters were not completely devoid of light, which would have entered through the bottom of the tank (which remained uncovered in order to record behaviours). My personal observations also found that crabs would react to movement passing by the tank, as well as movement from crayfish during predator presence treatments and therefore, 
vision must play an important role for cues when individuals are emersed, as waterborne cues are unavailable here. Red swamp crayfish, Procambarus clarkia, reacted not only to phototactic stimuli, but to thigmotactic stimuli when seeking shelter (Antonelli et al., 1999), something which was not explored in my experiment. Crabs across all experiments spent virtually no time in the middle of the tanks and were always either on the edge of the tanks, rocks or inside shelters. Movement from crabs was almost always backwards or sideways, and individuals roaming the tank would often move until they had bumped into shelters, other conspecifics or the sides and corners of the tank. This factor could explain the large variability of sheltering behaviours seen across all experiments.

Despite the obvious benefits of hiding, such anti-predator behaviour can also be costly, since time spent inside the refuge is traded for time spent in other essential activities, such as feeding, reproduction or defending resources. The New Zealand mud crab, Austrohelice crassa, burrows in the sand to hide from predators, but much of their activity occurs on the surface such as feeding and mating behaviours (Guerra-Bobo \& Brough, 2011). In general, water flow can be reduced in shelter spaces (Webb, 2006) and feeding can become less efficient. My personal observations saw less feeding in shelter spaces by P. elongatus and sheltering could come as a trade-off for a chance to mate.

\section{Shoving interactions}

Males dealt significantly more shoves than females, while both sexes followed similar trends of the adult vs. juvenile experiment where the number of shoves dealt was significantly higher in larger size classes than smaller ones. The number of shoves received did not differ between sexes or size classes indicating that, again, competitive interactions were not directed towards a certain sex or size class. It is a common occurrence in aggressive interactions that males will dominate female conspecifics. Sex differences play an important role in aggressive crayfish interactions over shelter resources and generally males will outcompete females for these resources (Karnofsky \& Price, 1989; Peeke et al., 1998; Figler et al., 1999), with a few exceptional cases where females will dominate (Peeke et al., 1995). With size often playing such a critical role in mediating competitive interactions, contests in species that display sexual dimorphism will generally favour the sex with competitive advantages. However, 
even in studies where size was not a factor, sex can still be an important predictor. Male and female hermit crabs, Pagurus bernhardus, that compete for shells will often have to be the same size, in order to fit in the same desired shell. Briffa \& Dallaway (2007) found that in these intersexual competitive interactions, males were more successful at defending shells from females.

Weaponry is another important predictor in mediating competition and is closely related to factors surrounding sexual dimorphism as many males develop these in order to compete in male-male interactions for mates (Plard et al., 2011). Chelipeds are key weapons used by many different crustaceans in order to defend and obtain resources (Imafuku, 1989; Wasson \& Lyon, 2005; Yoshino et al., 2011) and larger chelae can be directly related to one's competitive ability through aspects of crushing power (Spooner et al., 2007) or shoving capabilities (Rypien \& Palmer, 2007). Male P. elongatus have significantly larger chelipeds than females, giving them a competitive advantage when intersexual competition is at play. All sex and size classes preferentially shoved similar-sized or smaller conspecifics than larger ones. However, males also shoved larger females significantly more than any other combination where a larger individual is shoved. Males also, on multiple occasions, displaced larger females from shelter spaces, while the opposite was not seen at all. When comparing cheliped ratios between females and males, even the largest size class of females (12-14mm) only differed significantly with males smaller than $8 \mathrm{~mm}(\mathrm{BW})$. Similar results were found in a study conducted on shelter retention in the lobster, Homarus americanus, where small males were able to successfully defend their shelters from larger females (Karnofsky et al., 1989). Few studies investigate intersexual competitive interactions and most focus on either intrasexual competition or niche segregation as a result of these interactions. Therefore, this may be the first study to document male dominance in physical interactions over female conspecifics in porcelain crabs.

Overall, predator presence did not have an effect on the number of shoving interactions. This was unexpected because many studies show that the presence of a predator can increase an individual's desire to compete for shelter (Heithaus \& Dill, 2002),. However, the presence of a predator can also reduce a prey species' activity (Reviewed by Wooster \& Sih, 1990). The review showed that in a series of studies on stream invertebrate prey species, the presence of a predatory species resulted in a reduction of activity and emergence from their refuges less. Grazing activity was also 
reduced in two estuarine copepods Acartia tonsa and A. hudsonica, when subjected to chemical and visual cues of a natural predator (Cieri \& Stearns, 1999). Indirect consequences of changes in prey species behaviour due to the presence of a predator is a well recorded phenomenon and could attribute to the variation in levels of shoving activity seen in $P$. elongatus across all experiments.

\section{Ovigerous vs. non-ovigerous females}

\section{Time spent under shelter}

Ovigerous females spent significantly more time under shelter than non-ovigerous females of the same size class. Both classes again spent more time under shelter in the predator presence treatments than in the high tide treatments, which is indicative of similar sheltering responses from predation threats as seen in the male vs. female experiment. Females of large herbivorous mammals often alter their patterns of habitat use according to their reproductive status. Ungulates such as deer and antelope with suckling young reduce their home ranges, concentrate activity around shelter and/or migrate to more isolated terrain (Berger, 1991; Clutton-Brock, 2009). Female bridled nailtail wallabies with dependent young changed their behaviour in ways likely to reduce predation on their young by reducing home ranges, staying closer to cover and were more wary than other females (Fisher \& Goldizen, 2001). Shelter is incredibly important for ovigerous crabs, especially as egg clutches are unable to display anti-predatory behaviours of their own and are incredibly vulnerable to predation (Archer, 1988). Ovigerous mothers are therefore often displaying anti-predatory behaviours that defend not only their own life, but that of their offspring. Ovigerous Dungeness crabs show strong selective behaviours in specific habitats, including high fidelity to brooding sites (Stone \& Clair, 2002).

Energy requirements of ovigerous females are higher than non-ovigerous females, and the need to protect their young is evident in their sheltering behaviours. Time spent out of shelter can result in higher ventilation rates, and energy spent on being aware of potential threats which could be detrimental to a female's offspring. Mental activity is metabolically demanding and so heightened vigilance may increase energy costs with various knock-on consequences. Persons et al. (2002) reported that antipredator behaviour of the wolf spider, Pardosa milvina, increased energy costs and 
decreased foraging efficiency, which resulted in both fewer and lighter egg sacs being produced compared with spiders with reduced predator vigilance. Both mortality and fecundity were not tested in this experiment, but studies suggest that outcompeted females will suffer higher mortality rates, and lower fecundity rates (Maginnis, 2006).

\section{Shoving interactions}

Overall, ovigerous females shoved significantly more than non-ovigerous females, while in general, non-ovigerous females did very little shoving. In fact, ovigerous females shoved non-ovigerous females significantly more than they shoved other ovigerous females. Ovigerous females appear to be more likely to engage in competitive behaviour and are also more likely to win these competitive interactions due to the higher number of shoves as well as the higher amount of time spent in the shelter. Maternal aggression is common in a variety of taxa, and it has been shown that female reproductive status can influence shelter-related aggression in red swamp crayfish, Procambarus clarkii. Shelter-holding ovigerous females or those tending hatched offspring show a significant shelter-related contest advantage, and won a significant number of encounters against non-maternal female intruders. Of the few instances where maternal residents lost their shelter to an intruder, all of them made an attempt to re-secure the shelter, while a significant number of non-maternal losers did not (Figler et al., 1995a; Figler et al., 1997). Similar studies of ovigerous mantis shrimp found that they were far more successful at defending their shelters than nonovigerous females (Montgomery \& Caldwell, 1984).

Contradictory to several theories, shoving interactions in my ovigerous vs. nonovigerous experiment were not affected by the presence of a predator. Maternal aggression has been linked to anti-predatory behavioural responses (Archer, 1988), however there was no evidence for this in the present experiment. This may be due to the fact that, like all other experiments in this study, shoving interactions did not facilitate competition as theory would suggest. Subordinates (such as) juveniles and females have been known to avoid areas where larger, more aggressive males are dominant (Wan et al., 2013) and non-maternal females may display similar behaviours against maternal females if losing is inevitable. While this experiment did not look at the competitive interactions of ovigerous females against males, other studies have shown that there is a "reproductive status advantage" in this contest, with maternal 
females outcompeting significantly more males than non-ovigerous females (Figler et al., 1995a). This maternal aggression may be the first recorded among porcelain crabs but is consistent with other studies on other crustaceans.

\section{Autotomous vs. non-autotomous males}

\section{Time spent under shelter}

Overall, autotomized individuals spent more time under shelter than nonautotomized individuals but there was no difference between high tide and predator treatments. Chelipeds are highly functional tools that are used by crustaceans for feeding, mate selection, mediating competitive interactions, and fending off predators (Caine, 1975; Lee \& Seed, 1992; Baeza \& Asorey, 2012; Wasson \& Lyon, 2005). The loss of a cheliped can be incredibly detrimental to an individual and they must endure the costs of this trade-off until the limb can be replaced. Therefore, refuges and shelters will be of higher importance to give an injured individual a greater chance of survival. It has been reported on many occasions that animals will change their behaviours after having suffered an injury. Wounded wild toque macques, Macaca sinica, decreased activity and sheltered in the safety of trees more than healthy conspecifics (Dittus \& Ratyaneke, 1989) while two species of skinks, Lampropholis delicata \& L. guichenoti, both showed preferential use in shelter sites over open areas once their tails had been autotomized (Cromie \& Chapple, 2012). A study found that brittle stars will experience a brief increase of speed shortly after autotomy, which the authors hypothesised was a "scramble" in order to find shelter as quickly as possible due to their increased vulnerability (Shaeffer, 2016). Similar to juveniles, shelter seeking behaviour in autotomized $P$. elongatus was not affected by the presence of a predator and could be a result of increased vulnerability as well as the need to avoid expending unnecessary energy when exposed.

Injured individuals have also been known to release chemical cues (Tran, 2013) which predators can use to locate them, and is a well-studied theory in aquatic systems (Ferrari et al., 2010). Chemical cues from injured animals can affect behaviours of both predator and other conspecifics. Chemical cues from injured aquatic snails, Physa gyrina, resulted in increasing activity of their crayfish predator, Orconectes juvenilis, while conspecifics significantly increased their refuge use (McCarthy \& Dickey, 2002). 
However, autotomy is the voluntary shredding of an appendage, and the performed cleavage plane can speed up wound healing, reduce bacterial infection, and minimize potential water-borne cues that could signal the presence of a wounded animal (Maginnis, 2006). Most studies on autotomized and injured animals investigate the immediate chemicals released, while individuals used in this study may have been autotomized for quite some time and may be less likely to be releasing cues. Further study into the chemical cues released by injured P. elongatus will be needed in order to fully understand the repercussions.

Overall, larger males from both autotomy states spent significantly more time under shelter than smaller individuals. While not statistically significant, larger size classes of non-autotomized individuals appeared to spend more time under shelter when in the presence of a predator, while smaller individuals of both autotomy states spent the least amount of time under shelter. While size can be an effective strategy for predator deterrence, size is also an important factor for prey preference among predators as larger prey provide a greater resource (Taylor \& Cox, 2019). The combination of injured conspecifics and predator cues could drive larger $P$. elongatus to seek shelter in comparison to my other experiments.

\section{Shoving interactions}

Overall, autotomized individuals engaged in more competitive interactions than nonautotomized individuals, shoving other individuals more as well as receiving more shoves. Many studies have recorded a loss in competitive ability when an animal is injured, through autotomy or otherwise (Smith, 1992) while in others, injured animals show either reduced aggression or receive more aggression (Dittus \& Ratnayeke, 1989). Specifically for crustaceans, the loss of a cheliped can be devastating as refuge defensive capabilities have been shown to decrease in alpheid shrimp, lobsters, and hermit crabs (Conover \& Miller, 1978; Vye \& Cobb, 1979; Neil, 1985). Autotomy is well documented in many species of invertebrates (Reviewed by Fleming et al., 2007) but I found no studies that indicated an increased competitive nature in autotomized animals. On the contrary, autotomy in the purple shore crab, Hemigrapsus nudus, resulted in decreased aggression and increased retreat behaviours (Maginnis et al., 2015) 
Interestingly, shoving interactions were not dominated by non-autotomized individuals and size appeared to be a more important predictor as individuals were more likely to shove smaller conspecifics than same size or larger individuals. Despite missing a claw, the shoving behaviours of autotomized individuals seemed to match those of non-autotomized conspecifics. The removal of only one cheliped still allows individuals the use of the other, and the ability to shove may not have been reduced significantly enough to see a difference. A study on leg autotomy in marbled cellar spiders, Holocnemus pluchei, found that leg loss did not have any effect on their ability to fight with a conspecific over a prey (Johnson \& Jakob, 1999). If body size is the main predictor in determining competitive interactions, then limb loss may only be important when the body size difference is small (Juanes \& Smith, 1995).

This experiment is able to tie shoving activity with the time spent under shelter, with larger individuals shoving more and spending more time under shelter, and indicates that refuge use is incredibly important for autotomized P. elongatus. Despite their apparent competitive disadvantage, they are willing to fight more for this resource than non-autotomized conspecifics. While autotomy is a well-documented phenomenon in porcelain crabs, little research has been done on competitive ability or survival rates after autotomy, other than expected decreases in growth rates (Barría \& González, 2008). In line with many other species, my work shows that autotomized P. elongatus seek shelter, even if there is no present threat. These individuals may also be outcompeted by non-autotomized individuals who will have a greater competitive advantage.

\section{Field survey data}

Cheliped size ratios did not differ in the smallest size class between males and females, but were significantly different for every other size class. Ratios in females did not differ between any size classes, but for males, ratios only did not differ between size classes that were one bigger or smaller. In males, the cheliped size ratio also increased as body size increased, with the largest size class (F: $>14 \mathrm{~mm})$ having the biggest ratio. Therefore, the difference in cheliped size ratios between males and females also increased as body size increased. Overall, males were larger in both body size and cheliped size than females, with no females collected greater than $14 \mathrm{~mm}$. Patterns of sexual dimorphism are common in many species of crustaceans (Shimoda et al., 2005; 
Da Silva Castiglioni et al., 2011) and these results are also complementary to studies on other porcelain crabs (Wasson \& Lyon, 2005; Wassick et al., 2017). Cheliped size ratios between size classes of males and females here can account for competitive behaviours seen in my experiments. With the significant difference between sexes found only in larger size classes of $P$. elongatus, male and female juveniles are less likely to differ in their aggressive outcomes, something also observed in juvenile Cherax cuspidatus crayfish (Pavey \& Fielder, 1996). The increasing size ratios as males grow bigger is not seen in females, and could explain the ability for smaller size class males to outcompete larger females.

In this field study, females were not more likely to be autotomized or have claw punctures compared to males. In other species of porcelain crabs, females have higher cases of autotomy (Wasson \& Lyon, 2005) and this trend may have been apparent in my results given a larger, more equal sample size. Claw puncture marks however, are consistent with other studies where sex did not affect the likelihood (Rypien \& Palmer, 2007). Both sexes had relatively high counts of injured individuals (males; $>30 \%$, females; \%50) which is consistent with findings from Rypien \& Palmer (2007) and suggests that $P$. elongatus experiences high levels of intraspecific competition. For females, size had a significant effect on autotomy and claw punctures, with increasing size resulting in a higher chance of injury. Size did not increase the likelihood of either injury in males. This finding contradict most studies; for example; Webb (2006) found adult geckos were less likely to autotomize their tails than juveniles, and Wasson \& Lyon (2005) recorded high counts of autotomy in juvenile porcelain crabs. I also noted that when collecting specimens, smaller individuals were more likely to autotomize than larger ones when grabbed. The costs of autotomy are large, therefore, must only be used if an individual's ability to fight back is small. Juveniles and female $P$. elongatus, with their smaller size, may rely on autotomy more than fighting as a way of predatory avoidance.

Ovigery was not associated with claw punctures or autotomy within females, however a trend may be apparent where non-ovigerous females may suffer higher rates of autotomy. Fecundity is known to decrease when ovigerous females are injured or autotomized (Juanes \& Smith, 1995) as females will then have to devote energy towards brood care as well as limb regeneration. This trend is also supportive of ovigerous females dominating non-ovigerous females for shelter as well as in shoving 
interactions, which will increase predation risk to non-ovigerous females. Of the autotomized limbs, for both sexes, chelipeds accounted for over half. Wasson \& Lyon (2005) described chelipeds as not only the largest body part of a porcelain crab, but the tool used to fend away predators, therefore increasing its likelihood of being autotomized. From my personal observations in a preliminary test, I saw individuals using their chelipeds to fend away a predatory crayfish. The predator grabbed onto the claw of a crab who was forced to autotomize in order to survive. The loss of the limb however, ultimately resulted in the individual's death, as the crab was not able to fend the crayfish away in a second attack.

\section{Conclusion and further research}

This study has shown that P. elongatus will preferentially seek shelter and compete for this resource under certain environmental conditions and that these competitive interactions can be predicted through characteristics that often govern many other species. Juveniles, ovigerous females and autotomized individuals all spent more time under shelter than their competitors, likely due to their increased vulnerability. Adults and males, with their larger size and bigger relative chelipeds, will outcompete smaller and female conspecifics through shoving interactions if they desire to seek shelter. Ovigerous females and autotomized individuals may display higher forms of aggression, and out-compete conspecifics in order to gain or retain shelter spaces. Size may play a more significant factor than the loss of a single cheliped, and further testing would need to be conducted in order to determine the point where autotomy becomes a significant competitive disadvantage. During low tide, $P$. elongatus will not compete for shelter spaces, but rather form aggregations possibly as a way to reduce water loss and protect themselves from predators. The effects of the presence of a predator were also fairly inconclusive only resulting in a significant increase in time spent under shelter for the male vs. female and ovigerous vs. nonovigerous experiment. This treatment also did not result in any significant differences in shoving activity for all experiments and could point to a more complex interaction of behaviours and environmental conditions. A comparison could be looked at using olive rockfish, another known predator of $P$. elongatus, or further studies into how predators are detected by $P$. elongatus may provide more conclusive results. 
There was a lot of variation in behaviours that were not recorded and are areas where future research could be aimed at. For example; courtship behaviour and mate competition was not assessed during the male vs. female experiment, or the "prior residence effect" on shelter competition and whether this would give the individual an advantage. Factors such as water flow and food availability may also have had unknown impacts on shelter-seeking behaviour and competitive interactions. Other combinations of characteristics could also be compared such as whether ovigerous females might outcompete males as other literature has recorded, or whether autotomy has an effect on the competitive abilities of ovigerous females against nonovigerous females, or males against females.

Larger sample sizes will improve the accuracy of testing in both the shelter-seeking behaviour experiment and the field survey on autotomy and cheliped characteristics. A great amount of variation was seen in the behaviour during the experimenting, and understanding the influences that drive an individual to aggregate, or seek shelter alone will need to be further explored. Limitations of class size may also have skewed data, given that cheliped size may have been more of an important predictor in mediating competitive interactions.

Behavioural responses, even in lower taxonomic groups, can be complex and are not often dictated by any one factor. While advantageous physical characteristics are often a good indicator of a dominant competitor, my study showed that this is not always the case when changing environmental conditions are taken into account. Competitive behaviours are often driven by the simple instinct of survival, and therefore, understanding how competitive interactions are influenced by a combination of conditions allows us to gain a deeper understanding of ecosystems. 


\section{Literature cited}

Achituv, Y. \& Pedrotti, M.L. (1999), “Costs and gains of porcelain crab suspension feeding in different flow conditions" - Marine Ecology Progress Series, Vol. 184: 161-169

Aguilera, M.A. (2011), “The functional roles of herbivores in the rocky intertidal systems in Chile: A review of food preferences and consumptive effects" - Revista chilena de historia natural, Vol. 84: 241-261

Aguilera, M.A. \& Navarrete, S.A. (2012), "Interspecific Competition for Shelters in Territorial and Gregarious Intertidal Grazers: Consequences for Individual Behaviour" - Public Library of Science, Vol. 7(9): 9

Allee, W.C. (1927), "Studies in Animal Aggregations: Causes and Effects of Bunching in Land Isopods" - Journal of Experimental Zoology, Vol. 45(1): 255-277

Alonso, J.C.; Martín, E. Morales M.B. \& Alonso, J.A. (2018), “Sibling competition and not maternal allocation drives differential offspring feeding in a sexually sizedimorphic bird" - Animal Behaviour, Vol. 137: 35-44

Andrée-Anne, L.; Jean-Denis, D.; Richard, L. \& Gaéten, D. (2010), “ Shelter use and behaviour of juvenile Spotted Wolffish (Anarhichas minor) in an experimental context" - Environmental Biology of Fishes, Vol. 88(3): 207-215

Antonelli, J.; Steele, C. \& Skinner, C. (1999), “Cover-seeking behaviour and shelter use by juvenile and adult crayfish, Procambarus clarkii: potential importance in species invasion" - Journal of Crustacean Biology, Vol. 19(2): 293-300

Aquilino, K.M.; Bracken, M.E.S.; Faubel, M.N. \& Stachowicz, J.J. (2009), “Local-scale nutrient regeneration facilitates seaweed growth on wave-exposed rocky shores in an upwelling system" - Limnology and Oceanography, Vol. 54(1): 309-317

Archer, J. (1988), “The behavioural biology of aggression” ( $1^{\text {st }}$ Edition) - Cambridge University Press, Cambridge. 
Arnott, G. \& Elwood, R.W. (2009), “Assessment of fighting ability in animal contests” - Animal Behaviour, Vol. 77(5): 991-1004

Baeza, J.A \& Asorey C.M. (2012), “Testing the role of male-male competition in the evolution of sexual dimorphism: a comparison between two species of porcelain crabs" - Biological Journal of the Linnean Society, Vol. 105: 548-558

Barki, A. \& Karplus, I. (2016), “The behavioural mechanism of competition for food between tilapia (Oreachromis hybrid) and crayfish (Cherax quadricarinatus)" Aquaculture, Vol. 450: 162-167

Barría, E.M. \& González, M.I. (2008), "Effect of autotomy and regeneration of the chelipeds on growth and development in Petrolisthes laevigatus (Guérin, 1835) (Decapoda, Anomura, Porcellanidae)" - Crustaceana, Vol. 81(6): 641-652

Beleem, I.; Poriya, P. \& Gohil, B. (2016), "Porcelain crabs (Crustacea: Decapoda: Anomura) of western coast of India" - Marine Biodiversity Records, Vol. 9: 43-50

Benton, A.H. \& Crump, A.J. (1979), “Observations on Aggregation and Overwintering in the Coccinellid Beetle Coleomegilla maculata (DeGeer)" - Journal of the New York Entomological Society, Vol. 87(2): 154-159

Berger, J. (1991), "Pregnancy incentives, predation constraints and habitat shifts: experimental and field evidence for wild bighorn sheep" - Animal Behaviour, Vol. 41: 61-77

Birch, L.C. (1957), “The meanings of competition" - The American Naturalist, Vol. 91: 5-18

Boaventura, D.; Ré, P.; Da Fonseca, L.C. \& Hawkins, S.J. (2002), “Intertidal rocky shore communities of the continental Portuguese coast: Analysis of distribution patterns" Marine Ecology, Vol. 23(1): 69-90 
Bonin, M.C.; Bostrom-Einarsson, L.; Munday, P.L. \& Jones, G.P. (2015), “The Prevalence and Importance of Competition Among Coral Reef Fishes" - Annual Review of Ecology, Evolution and Systematics, Vol. 46: 169-190

Branch, G.M. \& Branch, M.L. (1981), “Experimental Analysis of Intraspecific Competition in an Intertidal Gastropod, Littorina unifasciata" - Australian Journal of Marine and Freshwater Research, Vol. 32: 573-589

Briffa, M. \& Dallaway, D. (2007), "Intersexual contests in the hermit crab, Pagurus bernhardus: females fight harder but males win more encounters" - Behavioural Ecology and Sociobiology, Vol. 61(11): 1781-1787

Burrows, M.T. (2012), "Influences of wave fetch, tidal flow and ocean colour on subtidal rocky communities" - Marine Ecology Progress Series, Vol. 445: 193-207

Burrows, M.T. \& Hawkins, S.J. (1998), “Modelling Patch Dynamics on Rocky Shores using Deterministic Cellular Automata" - Marine Ecology Progress Series, Vol. 167: 113

Caine, E.A. (1975), "Feeding and masticatory structure of selected Anomura (Crustacea)" - Journal of Marine Biology and Ecology, Vol. 18: 277-301

Carlisle, D.B. (1957), “On the hormonal inhibition of molting in decapod crustacea: II the terminal anecdysis in crabs" - Journal of Marine Biological Association of the United Kingdom, Vol. 36: 291-307

Carlisle, A.B.; Perle, C.R.; Goldman, K.J. \& Block, B.A. (2011), "Seasonal changes in depth distribution of salmon sharks (Lamna ditropis) in Alaskan waters: implications for foraging ecology" - Canadian Journal of Fisheries \& Aquatic Sciences, Vol. 68: 19051921

Chapman, M.G. (1998), “Variability in trail-following and aggregation in Nodilittorina unifasciata Gray" - Journal of Experimental Marine Biology and Ecology, Vol. 224(1): 49-71 
Cieri, M.D. \& Stearns, D.E. (1999), "Reduction of grazing activity of two estuarine copepods in response to the exudate of a visual predator" - Marine Ecology Progress Series, Vol. 177: 157-163

Clutton-Brock, T.H.; Glenn, I.; Steve, A. \& Guinness, F. (2009), “Effects of lactation on feeding behaviour and habitat use in wild red deer hinds (Cervus elaphus, Rhum)" Journal of Zoology, Vol. 198: 227-236

Coffin, M.R.S.; Drolet, D.; Hamlton, D.J. \& Barbeau, M.A. (2008), “Effect of immersion at low tide on distribution and movement of the mud snail, Ilyanassa obsoleta (Say), in the upper Bay of Fundy, eastern Canada" - Journal of Experimental Marine Biology and Ecology, Vol. 364(2): 110-115

Coleman, R.M. \& Galvani, A.P. (1998), “Egg size determines offspring size in neotropical cichlid fishes (Teleostei: Cichlidae)" - Copeia, Vol. 1998(1): 209-213

Connell, J.H. (1961), “The influence of interspecific competition and other factors on the distribution of the barnacle Cthamalus stellatus" - Ecology, Vol. 42: 710-723

Connell, J.H (1983), “On the Prevalence and Relative Importance of Interspecific Competition: Evidence from Field Experiments" - The American Naturalist, Vol. 122: 661-696

Conover, M.R. \& Miller, D.E. (1978), "The importance of the large chela in the territorial and pairing behaviour of the snapping shrimp, Alpheus Heterochaelis" Marine behaviour and physiology, Vol. 5(3): 185-192

Conradt, L.; Clutton-Brock, T.H. \& Guinness, F.E. (2000), “Sex differences in weather sensitivity can cause habitat segregation: red deer as an example" - Animal Behaviour, Vol. 59: 1049-1060

Cooper, W.E.; Hawlena, D. \& Pérez-Mellado, V. (2009), “Islet tameness: escape behavior and refuge use in populations of the Balearic lizard (Podarcis lilfordi) exposed to differing predation pressure" - Canadian Journal of Zoology, Vol. 87: 912-919 
Creel, S. (2001), "Four Factors Modifying the Effect of Competition on Carnivore Population Dynamics as Illustrated by African Wild Dogs" - Conservation Biology, Vol. 15(1): 271-274

Cromie, G.L. \& Chapple, D.G. (2012), "Impact of Tail Loss on the Behaviour and Locomotor Performance of Two Sympatric Lampropholis Skink Species" - PLoS One, Vol. 7(4): e34732.

Cushing, J.M. \& Li, J. (1991), “Juvenile versus adult competition" - Journal of Mathematical Biology, Vol. 29: 457-473

Da Silva Castiglioni, D.; De Oliveira, P.J.A.; Da Silva, J.S. \& Coelho, P.A. (2011), "Population dynamics of Sesarma rectum (Crustacea: Brachyura: Grapsidae) in the Ariquinda River mangrove, north-east of Brazil" - Journal of the Marine Biological Association of the United Kingdom, Vol. 91(7): 1395-1401

Daleo, P.; Luppi, T.; Casariego, A.M.; Escapa, M. \& Ribeiro, P. (2009), "The effect of size and cheliped autotomy on sexual competition between males of the mud crab Cyrtograpsus angulatus Dana" - Marine Biology, Vol. 156(3): 269-275

Dayton, P.K. (1971), “Competition, Disturbance, and Community Organization: The Provision and Subsequent Utilization of Space in a Rocky Intertidal Community" Ecological Monographs, Vol. 41(4): 351-389

De Raedemaecker, F.; Miliou, A. \& Perkins, R. (2010), “Fish community structure on littoral rocky shores in the Eastern Aegean Sea: Effects of exposure and substratum" - Estuarine, Coastal and Shelf Science, Vol. 90(1): 35-44

Dellatorre, F.G. \& González-pisani, X. (2011), “Embryonic development and fecundity of the squat lobster Munida gregaria (Decapoda: Galatheidae) in northern Patagonia" - Journal of the Marine Biological Association of the United Kingdom, Vol. 91(3): 695-704

Dellinger, J.A., Shores, C.R.; Craig, A.; Heithaus, M.R., Ripple, W.J. \& Wirsing, A.J. (2019), "Habitat use of sympatric prey suggests divergent anti-predator responses to recolonizing gray wolves" - Oecologia, Vol. 189(2): 487-500 
Desrochers, A. (1989), “Sex, Dominance, and Microhabitat use in Wintering BlackCapped Chickadees: A Field Experiment" - Ecological Society of America, Vol. 70(3): 636-645

Díaz, M.; Torre, I.; Peris, A. \& Tena, L. (2005), “Foraging behaviour of wood mice as related to presence and activity of genets" - Journal of Mammalogy, Vol. 86(6): 11781185

Dittus, W.P.J. \& Ratnayeke, S.M. (1989), “Individual and Social Behavioral Responses to Injury in Wild Toque Macaques (Macaca sinica)" - International Journal of Primatology, Vol 10(3): 215-234

Donahue, M.J. (2004) "Size-dependent competition in a gregarious porcelain crab Petrolisthes cinctipes (Anomura: Porcellanidae)" - Marine Ecology Progress Series, Vol. 267: 219-231

Drzewina, A. \& Bohn, G. (1927), “Variations de la susceptibilite aux agents nocifs avec le nombre des animaux traites" - Proceedings of the Academy of Sciences, Vol. 72: 485487

Eifler, M.A.; Marchand, R.; Eifler D.A. \& Malela, K. (2017), “Habitat Use and Activity Patterns in the Nocturnal Gecko, Chondrodactylus turneri" - Herpetologica, Vol. 73(1): 43-47

Espmark, Y. (1964), "Studies in dominance - subordination relationship in a group of semi-domestic reindeer (Rangifer tarandus L.)" - Animal Behaviour, Vol. 12: 420-426

Faber, D.B. \& Baylis, J.R. (1993), “Effects of body size on agonistic encounters between male jumping spiders (Araneae: Salticidae)" - Animal Behaviour, Vol. 45(2): 289-299

Fernández, M. \& Brante, A. (2003), "Brood care in Brachyuran crabs: the effect of oxygen provision on reproductive costs" - Revista Chilena de Historia Natural, Vol. 76: 157-168 
Ferrari, M.C.O.; Wisenden, B.D. \& Chivers, D.P. (2010), “Chemical ecology of predator-prey interactions in aquatic ecosystems: a review and prospectus" Canadian Journal of Zoology, Vol. 88: 698-724

Figler, M.H.; Blank, G.S. \& Peeke, H.V.S. (1997), “Maternal aggression and post-hatch care in red swamp crayfish, Procambarus clarkii (Girard): The influences of presence of offspring, fostering, and maternal molting" - Marine and Freshwater Behaviour and Physiology, Vol. 30: 173-194

Figler, M.H.; Cheverton, H.M. \& Blank, G. (1999), "Shelter competition in juvenile red swamp crayfish (Procambarus clarkii): the influences of sex differences, relative size, and prior residence" - Aquaculture, Vol. 178(1-2): 63-75

Figler, M.H.; Twum, M.; Finkelstein, J.E. \& Peeke, H.V.S. (1995a), “Maternal Aggression in Red Swamp Crayfish (Procambarus clarkii, Girard): The Relation between Reproductive Status and Outcome of Aggressive Encounters with Male and Female Conspecifics" - Behaviour, Vol. 132: 107-125

Fitzgibbon, C. D. (1990), “Anti-predator strategies of immature Thomson's gazelles: hiding and the prone response" - Animal Behaviour, Vol. 40: 846-855.

Fitzpatrick, J.L.; Almbro, M.; Gonzalez-Voyer, A.; Kolm, N. \& Simmons L.W. (2012), "Male contest competition and the coevolution of weaponry and testes in pinnipeds" - Evolution, Vol. 66: 3595-3604

Fisher, D.O. \& Goldizen, A.W. (2001), "Maternal care and infant behavior of the bridled nailtail wallaby, Onychogalea fraenata" - The Zoological Society of London, Vol. 255: 321-330

Fleming, P.A.; Saccaggi, D.L. \& Bateman, P.W. (2007), “Leave it all behind: A taxonomic perspective of autotomy in invertebrates" - Biological Reviews, Vol. 82(3): 481-510 
Gagern, A.; Schürg, T.; Michiels, N.K.; Schulte, G.; Sprenger, D. \& Anthes, N. (2008), "Behavioral response in a sessile suspension feeder due to interference competition" - Marine Ecology Progress Series, Vol. 353: 131-135

Gibson, R.N. \& Atkinson, R.J.A (2003), “The effects of sedimentation on rocky coast assemblages" - Oceanography and Marine Biology: An Annual Review, Vol. 41: 161-236

Gregory, L.P.; Campbell, M.L.; Primo, C. \& Hewitt, C.L. (2012), “Biotic and abiotic factors affecting the Tasmanian distribution and density of the introduced New Zealand porcelain crab Petrolisthes elongatus" - Aquatic Invasions, Vol. 7: 491-501

Griffith, D. \& Poulson, T.L. (1993), "Mechanisms and consequences of intraspecific competition in a carabid cave beetle" - Ecology, Vol. 74: 1373-1383

Guerra-Bobo, M. \& Brough, T.E. (2011), “Neighbour density, body size and antipredator hiding time in the New Zealand mud-crab, Austrohelice crassa" - Journal of the Marine Biological Association of the United Kingdom, Vol. 91(3): 691-694

Haddy, E.; Burden, F. \& Proops, L. (2020), "Shelter seeking behaviour of healthy donkeys and mules in a hot climate" - Applied Animal Behaviour Science, Vol. 222: 104898

Hassall, M. \& Tuck, J.M. (2007), "Sheltering behaviour of terrestrial isopods in grasslands" - Invertebrate Biology, Vol. 126(1): 46-56

Hazlett, B. \& Mclay, C. (2005), "Responses of the Crab Heterozius rotundifrons to Heterospecific Chemical Alarm Cues: Phylogeny vs. Ecological Overlap" - Journal of Chemical Ecology, Vol. 31(3): 671-677

Heithaus, M. \& Dill, L. (2002), “Food availability and predation risk influence bottlenose dolphin habitat use" - Ecology, Vol. 83(2): 480-491

Heithaus, M.; Frid, A.; Wirsing, A.J. \& Worm, B. (2008), "Predicting ecological consequences of marine top predator declines" - Trends in Ecology and Evolution, Vol. 23(4): 202-210 
Heldt, K.A. (2013), “Individual behavioural variation of juvenile spiny lobster (Panulirus argus) denning behaviours and the role it plays in shelter competition during habitat loss" - All Theses. 1714

Hemmi, J.M. (2005), “ Predator avoidance in fiddler crabs: 2. The visual cues" - Animal Behaviour, Vol. 69(3): 615-625

Herrel, A.; Andrade, D.V.; de Carvelho, J.H.; Brito, A.; Abe, A. \& Navas, C. (2009), "Aggressive behaviour and performance in the tegu lizard Tupinambis merianae" Physiological and Biochemical Zoology, Vol. 82: 680-685

Heupel, M.R. \& Simpfendorfer, C.A. (2005), “Quantitative analysis of aggregation behaviour in juvenile blacktip sharks" - Marine Biology, Vol. 147: 1239-1249

Higgins, S.; Hecky, R. \& Taylor, W. (2001), “Epilithic nitrogen fixation in the rocky littoral zones of Lake Malawi, Africa" - Limnology and Oceanography, Vol. 46(4): 976982

Hill, F.H.; Wenner, A.M. \& Wells, P.H. (1976), "Reproductive Behavior in an Overwintering Aggregation of Monarch Butterflies" - The American Midland Naturalist, Vol. 95(1): 10-19

Holbrook, S.J. \& Schmitt, R.J. (2002), “Competition for shelter space causes densitydependent predation mortality in Damselfishes" - Ecology, Vol. 83: 2855-2868.

Hughes, M. (1996), “Size assessment via a visual signal in snapping shrimp" Behavioural Ecology and Sociobiology, Vol. 38: 51-57

Ibánẽz, A.; Marzal, A.; López, P. \& Martín, J. (2013), “Boldness and body size of male Spanish terrapins affect their responses to chemical cues of familiar and unfamiliar males" - Behavioural Ecology and Socio-biology, Vol. 67: 541-548

Imafuku, M. (1989), "Shell fights in the hermit crab, Pagurus geminus; Effect of Cheliped use and shell rapping" - Journal of Ethology, Vol. 7(1): 35-39 
Ioannou, C.C.; Payne, M. \& Krause, J. (2008), “Ecological Consequences of the BoldShy Continuum: The Effect of Predator Boldness on Prey Risk" - Oecologia, Vol. 157: $177-182$

Johnson, S.A. \& Jakob, E.M. (1999), “Leg autotomy in a spider has minimal costs in competitive ability and development" - Animal Behaviour, Vol. 57: 957-965

Jones, M.B. (1977), “Breeding and Seasonal population changes of Petrolisthes elongatus (Crustacea, Decopoda, Anomura) at Kaikoura, New Zealand" - Journal of The Royal Society of New Zealand, Vol. 7(3): 259-272

Juanes, F. \& Smith, L.D. (1995), “The ecological consequences of limb damage and loss in decapod crustaceans: a review and prospectus" - Journal of Experimental Marine Biology and Ecology, Vol. 193: 197-223

Judge, K.A. \& Bonanno, V.L. (2008), "Male Weaponry in a Fighting Cricket" - PloS ONE, Vol. 3(12): e3980

Karnofsky, E.B.; Atema, J. \& Elgin, R.H. (1989), “Field Observations of Social Behavior, Shelter Use, and Foraging in the Lobster, Homarus americanus" - Biological Bulletin, Vol. 176(3): 239-246

Karnofsky, E.B. \& Price H.J. (1989), "Dominance, territoriality and mating in the lobster, Homarus americanus: A mesocosm study" - Marine Behaviour and Physiology, Vol. 15(2): 101-121

Kindinger, T.L. (2018), "Invasive predator tips the balance of symmetrical competition between native coral-reef fishes" - Ecological Society of America, Vol.99(4): 792-800

Keevil, M.G.; Hewitt, B.S.; Brooks, R.J. \& Litzgus, J.D. (2017), “Patterns of intraspecific aggression inferred from injuries in an aquatic turtle with male-biased size dimorphism" - Canadian Journal of Zoology, Vol. 95: 393-403 
Klok, C.J. \& Chown, S.L. (2002), “Assessing the benefits of aggregation: thermal biology and water relations of anomalous Emperor Moth caterpillars" - Functional Ecology, Vol. 13(3): 417-427

Koga, T.; Yong, H.S. \& Murai, M. (1999), “Male-male competition and intersexual interactions in underground mating of the fiddle crab Uca paradussumieri" - Behaviour, Vol. 136(5): 651-667

Koivula, K.; Lahti, K.; Rytkönen, S. \& Orell, M. (1994), “Do subordinates expose themselves to predation? Field experiments on feeding site selection by Willow Tits" - Journal of Avian Biology, Vol. 25(3): 178-183

Konishi, M. \& Takata, K. (2004), "Size-dependent male-male competition for a spawning substrate between Pseudorasbora parva and Pseudorasbora pumila" Ichthyological Research, Vol. 51(2): 184-187

Kozminsky, E.V. (2012), "Effects of environmental and biotic factors on the fluctuations of abundance of Littorina obtusata (Gastropoda: Littorinidae)" Hydrobiologia, Vol. 706: 81-90

Kruckstuhl, K.E.; Clutton-Brock, T.H.; Conradt, L. \& du Toit, J.T. (2006), "Sexual Segregation in Vertebrates" (1st Edition) - Cambridge University Press

Kuker, K. \& Barrett-Lennard, L. (2010), "A re-evaluation of the role of killer whales Orcinus orca in a population decline of sea otters Enhydra lutris in the Aleutian Islands and a review of alternative hypotheses" - Mammal Review, Vol. 40(2): 1-22

Laidre, M.E. \& Greggor, A.L. (2015), "Swarms of swift scavengers: ecological role of marine intertidal hermit crabs in California" - Marine Biology, Vol. 162: 969-977

Lammers, J.H.; Warburton, K. \& Cribb, B.W. (2010), “Individual Competition and the Emergence of Density-Dependent Exposure to Predation: How Behaviours Influence Population Processes" - Adaptive Behavior, Vol. 18(2): 171-183 
Lee, S.Y. (1998), "Ecological role of grapsid crabs in mangrove ecosystems: a review" - Marine Freshwater Research, Vol. 49: 335-343

Lee, S.Y. \& Seed, R. (1992), "Ecological implications of cheliped size in crabs: some data from Carcinus maenas and Liocarcinus holsatus" - Marine Ecology Progress Series, Vol. 84(2): 151-160

Lensink, B.M. (1963), “Distributional ecology of some Acrididae (Orthoptera) in the dunes of Voorne, Netherlands" - Entomology, Vol. 106: 357-443

Leung, E.S.; Chilvers, B.S.; Nakagawa, S.; Moore, A.B \& Robertson, B.C (2012), “Sexual Segregation in Juvenile New Zealand Sea Lion Foraging Ranges: Implications for Intraspecific Competition, Population Dynamics and Conservation" - Public Library of Science, Vol. 7(9): e45389

Lohse, D.P. (2002), “Relative Strengths of Competition for Space and Food in a Sessile Filter Feeder" - Biological Bulletin, Vol. 293(2): 173-180

Losos, J.; Schoener, T. \& Spiller, D. (2004), "Predator-induced behaviour shifts and natural selection in field-experimental lizard populations" - Nature, Vol. 432: 505-508

Maggi, E.; Milazzo, M.; Chemello, R. \& Benedetti-Cecchi, L. (2015), “Latitudinal- and local-scale variations in a rocky intertidal interaction web" - Marine Ecology Progress Series, Vol. 534: 39-48

Maginnis, T.L. (2006), "The costs of autotomy and regeneration in animals: A review and framework for future research" - Behavioral Ecology, Vol. 17(5): 857-872

Maginnis, T.L.; Isikbay, M.; Degerstedt, S.G.; Leuthke, T.J. \& Ortman, M. (2015), “The effects of cheliped autotomy and regeneration on aggression in purple shore crabs (Hemigrapsus nudus)" - Marine and Freshwater Behaviour and Physiology, Vol. 48(4): 241251

Magurran, A.E. \& Garcia, C.M. (2000), "Sex differences in behaviour as an indirect consequence of mating system" - Fish Biology, Vol. 57(4): 839-857 
Marshall, D.J.; Baharuddin, N. \& McQuaid, C.D. (2013), “Behaviour moderates climate warming vulnerability in high-rocky shore snails: interactions of habitat use, energy consumption and environmental temperature" - Marine Biology, Vol. 160: 2525-2530

Martin, C.; Fodrie, F.; Heck, K. \& Mattila, J. (2010), “Differential habitat use and antipredator response of juvenile roach (Rutilus rutilus) to olfactory and visual cues from multiple predators" - Oecologia, Vol. 162: 893-902

Mason, J.C. (1970), “Maternal-offspring behaviour of the crayfish, Pacifastacus trowbridgi" - Nature, Vol. 255: 400-401

Matveev, V.F. (1987), "Effect of Competition on the Demography of Planktonic Cladocerans: Daphnia and Dispanosoma" - Ocealogia, Vol. 74(3): 468-477

Maxwell, B.E. (1955), "Hydrological observations for Wellington Harbour" Transactions and Proceedings of the Royal Society of New Zealand, Vol. 83(3): 493-803

McCarthy, T.M. \& Dickey, B.F. (2002), “Chemically Mediated Effects of Injured Prey on Behavior of Both Prey and Predators" - Behaviour, Vol. 139(5): 585-602

McCormick, M.I. \& Weaver, C.J. (2012), “It Pays to Be Pushy: Intracohort Interference Competition between Two Reef Fishes" - PloS ONE, Vol. 7(8): e42590

McEvoy, J.; While, G.M.; Sinn, D.L. \& Wapstra, E. (2012), “The role of size and aggression in intrasexual male competition in a social lizard species" - Behavioural Ecology and Sociobiology, Vol. 67: 79-90

McGlaun, K.A. \& Withers, K. (2012), "Metabolism, Consumption rates, and Scope for Growth of Porcelain Crab (Petrolisthes galathinus)" - Gulf of Mexico Science, Vol. 30(1): $1-6$

McLain, D.; Pratt, A.; Logue, J. \& Barke, R. (2019), “The importance of strength and stamina caries with ownership status in sand fiddler crab contests for breeding burrow" - Behavioral Ecology and Sociobiology, Vol. 73(3): 1-10 
McLay, C. (1988), "Brachyura and crab-like Anomura of New Zealand" - Leigh Laboratory Bulletin, Vol. 22: 463

Mendonça, V.; Vinagre, C.; Cabral, H. \& Silva, A.C.F. (2014), “Habitat use of intertidal chitons - role of colour morphism" - Marine Ecology, Vol. 36(4): 1098-1106

Menge, B.A. (1976), “Organisation of the New England rocky intertidal communities: role of predation, competition and environmental heterogeneity" - Ecological Monographs, Vol. 46: 355-393

Menge, B.A \& Sutherland, J.P. (1987), "Community regulation: variation in disturbance, competition, and predation in relation to environmental stress and recruitment." - The American Naturalist, Vol. 110: 351-369

Meyer-Rochow, V.B. \& Meha, W.P. (1994), "Tidal rhythm and the role of vision in shelter-seeking behaviour of the half-crab Petrolisthes elongatus (Crustacea: Anomura: Porcellanidae) - Journal of The Royal Society of New Zealand, Vol. 24(4): 423-427

Millidine, K.J.; Armstrong, A.D. \& Metcalfe, N.B. (2006), “Presence of shelter reduces maintenance metabolism of juvenile salmon" - Functional Ecology, Vol. 20(5): 839-845

Mirera, O.D. \& Moksnes P.O. (2013), “Cannibalistic interactions of juvenile mud crabs Scylla serrata: the effect of shelter and crab size" - African Journal of Marine Science, Vol. 35(4): 345-353

Mislan, K.; Blanchette, C. Broitman, B. \& Washburn, L. (2011), "Spatial variability of emergence, splash, surge, and submergence in wave-exposed rocky-shore ecosystems" - Limnology and Oceanography, Vol. 56(3): 857-866

Molenock, J. (1975), "Evolutionary Aspects of Communication in the Courtship Behaviour of Four Species of Anomuran Crabs (Petrolisthes)" - Behaviour, Vol. 53(1/2): $1-30$ 
Montgomery, E.W. \& Caldwell, R.L. (1984), “Aggressive brood defense by females in the stomatopod Gonodactylus bredini" - Behavioural Ecology and Sociobiology, Vol. 14: 247-251

Neil, S.J. (1985), "Size Assessment and Cues: Studies of Hermit Crab Contests" Behaviour, Vol. 92(1): 22-37

Nishikawa, K.C. (1985), "Competition and the Evolution of Aggressive Behaviour in Two Species of Terrestrial Salamanders" - Evolution, Vol. 39(6): 1282-1294

Nogueira, G.; Ajmone-Marsan, P.; Milanesi, M.; Zavarez, L.; Aguiar, T.S.; Sandre, D.; Maioli M.A.; Ferreira, G.; Bispo, G.; Stabile, S.; Caputo, R.; Toyama, C.; Garcia, J.F. \& Lima, J.C.P. (2016), “1283 Understanding behavior patterns of cattle adaptation to heat stress" - Journal of Animal Science, Vol. 94(5): 619

Nybakken, J.W. (1993), “Marine Biology: An Ecological Approach” (6 ${ }^{\text {th }}$ Edition) Harpercollins College Div (1822)

Ortega, S. (1985), "Competitive interactions among tropical intertidal limpets" Journal of Experimental Marine Biology and Ecology, Vol. 90(1): 11-25

Osenberg, C.W.; Mittelbach, G.G. \& Wainwright, P.C. (1992), “2-Stage Life Histories in Fish - The Interaction between Juvenile Competition and Adult Performance" Ecology, Vol. 73(1): 255-267

O'Shaughnessy, K.A.; Harding, J.M. \& Burge, E.J. (2014), “Ecological effects of the invasive parasite Loxothylacus panopaei on the flatback mud crab Eurypanopeus depressus with implications for estuarine communities" - Bulletin of Marine Science, Vol. 90(2): 611-621

Page, B.; McKenzie J. \& Goldsworthy, S.D. (2005), “Dietary resource partitioning among sympatric New Zealand and Australian fur seals" - Marine Ecology Progress Series, Vol. 293: 283-302 
Palmer, T.M. (2003), "Spatial habitat heterogeneity influences competition and coexistence in an African acacia ant guild" - Ecological Society of America, Vol. 84(11): 2843-2855

Paszkowski, C.A.; Tonn, W.M.; Piironen, J. \& Holopainen, I.J. (1990), “Behavioural and population-level aspects of intraspecific competition in crucian carp" - Annales Zoologici Fennici, Vol. 27: 77-85

Pavey, C.R. \& Fielder D.R. (1996), “The influence of size differential on agonistic behaviour in the freshwater crayfish, Cherax cuspidatus (Decapoda: Parastacidae)" Journal of Zoology, Vol. 238(3): 445-457

Peeke, H.V.S.; Sippel, J. \& Figler, M.H. (1995), “Prior residence effects in shelter defence in adult signal crayfish (Pacifastacus leniusculus (Dana)): results in same- and mixed-sex dyads" - Crustaceana, Vol. 68: 873-881

Peeke, H.V.S.; Figler, M.H. \& Changa, S. (1998), "Sex differences and prior residence effects in shelter competition in juvenile lobsters, Homarus americanus Milne-Edwards" - Journal of Experimental Marine Biology and Ecology, Vol. 229(1): 149-156

Persons, M.H.; Walker, S.E. \& Rypstra, A.L. (2002), "Fitness costs and benefits of antipredator behaviour mediated by chemo-tactile cues in the wolf spider, Pardosa milvina (Araneae: Lycosidae)" - Behavioural Ecology, Vol. 13: 386-392

Peters, W.D. \& Grubb Jr., T.C. (1983), “An Experimental Analysis of Sex-Specific Foraging in the Downy Woodpecker, Picoides Pubescens" - Ecological Society of America, Vol. 64(6): 1437-1443

Plard, F.; Bonenfant, C. \& Gaillard, J.M. (2011), "Revisiting the allometry of antlers among deer species: male-male sexual competition as a driver" - Synthesising Ecology, Vol. 120: 601-606

Pollard, J.C. \& Littlejohn, R.P. (1999), “Shelter for lambing in southern New Zealand. II. Sheltering behaviour and effects on productivity" - New Zealand Journal of Agricultural Research, Vol. 42(2): 171-177 
Prenter, J.; Taylor, P.W. \& Elwood, R.W. (2008), “Large body size for winning and large swords for winning quickly in swordtail males, Xiphophorus helleri" - Animal Behaviour, Vol. 75(6): 1981-1987

Proops, L.; Osthaus, B.; Bell, N.; Long, S.; Hayday, K. \& Burden F. (2019), “Shelterseeking behaviour of donkeys and horses in a temperate climate" - Journal of Veterinary Behaviour, Vol. 32: 16-23

Putnam, A.B. \& Peckol, P. (2018), "Asymmetric interference competition between herbivorous gastropods, introduced Littorina littorea and indigenous L. obtusata" Marine Ecology Progress Series, Vol. 594: 135-147

Ramsay, K.; Kaiser,M.J. \& Hughes, R.N. (1997), “A Field Study of Intraspecific Competition for Food in Hermit Crabs (Pagurus bernhardus)" - Estuarine, Coastal and Shelf Science, Vol. 44:213-220

Ratcliffe, N.; Adlard, S.; Stowasser, G. \& McGill, R. (2018), “Dietary divergence is associated with increased intra-specific competition in a marine predator" - Scientific Reports, Vol. 8(6827)

Riesch, R.; Duwe, V.; Herrmann, N.; Padur, L.; Ramm, A.; Scharnweber, K.; Schulte, M.; Schulz-Mirbach, T.; Ziege, M. \& Plath, M. (2009), "Variation along the Shy-Bold Continuum in Extremophile Fishes (Poecilia mexicana, Poecilia sulphuraria)" Behavioural Ecology and Socio-biology, Vol. 63: 1515-1526

Robinson, M.R. \& Kruuk, L.E.B. (2007), “Function of weaponry in females: the use of horns in intrasexual competition for resources in female Soay sheep" - Biology Letters, Vol. 3: 651-654

Rodrigues, L.J.; Dunham, D.W. \& Johnson, C. (2002), “Effect of Size on Intraspecific Shell Competition in the Endemic Bermudiam Hermit Crab, Calcinus verrili (Rathbun, 1901) (Decapoda, Anomura)" - Crustaceana, Vol. 75(8): 1012-1023

Rosen, E.; Schwartz, B. \& Palmer, A.R. (2009), "Smelling the difference: Hermit crab responses to predatory and non-predatory crabs" - Animal Behaviour, Vol. 78: 691-695 
Rossong, M.A.; Quijón, P.A.; Snelgrove, P.V.R.; Barrett, T.J.; McKenzie C.H. \& Locke, A. (2011), "Regional differences in foraging behaviour of invasive green crab (Carcinus maenas) populations in Atlantic Canada" - Biological Invasions, Vol. 14: 659-669

Rypien, K.L. \& Palmer, A.R. (2007), “The Effect of Sex, Size and Habitat on the Incidence of Puncture Wounds in the Claws of the Porcelain Crab Petrolisthes cinctipes (Anomura: Porcellanidae)" - Journal of Crustacean Biology, Vol. 27(1): 59-64

Sams, M.A.; Warren-Myers, F. \& Keough, M.J. (2015), “Increased larval planktonic duration and post-recruitment competition influence survival and growth of the bryozoan Watersipora subtorquata" - Marine Ecology Progress Series, Vol. 531: 179-191

Schulte-Hostedde, A.I. \& Millar, J.S. (2002), “'Little Chipmunk' Syndrome? Male Body Size and Dominance in Captive Yellow-Pine Chipmunks (Tamias amoenus)" - Ethology, Vol. 108: 127-137

Seebacher, F. \& Alford, R.A. (2002), "Shelter Microhabitats Determine Body Temperature and Dehydration Rates of a Terrestrial Amphibian (Bufo marinus)" Journal of Herpetology, Vol. 36(1): 69-75

Shaeffer, C.M. (2016), "The effects of autotomy and regeneration on the locomotion and behavior or brittle stars (Echinodermata: Ophiuroidea) of Moorea, French Polynesia" - Environmental Science, Policy, and Management, University of California, Berkeley, Berkeley, CA, United States

Shimoda, K.; Wardiatno, Y.; Kubo, K. \& Tamaki, A. (2005), “Intraspecific behaviours and major cheliped sexual dimorphism in three congeneric callianassid shrimp" Marine Biology, Vol. 146(3): 543-557

Shoji, J.; Sakiyama, K.; Hori, M.; Yoshida, G. \& Hamaguchi, M. (2007), “Seagrass habitat reduces vulnerability of red sea bream, Pagrus major, juveniles to piscivorous fish predator" - Fisheries of Science, Vol. 73: 1281 - 1285

Shulman, M.J. (1985), "Coral reef fish assemblages: intra- and interspecific competition for shelter sites" - Environmental Biology of Fishes, Vol. 13: 81-92 
Sibomana, C.; Jia, X.; Qiu, Y.P. \& Wang, G.X. (2013), “Self-thinning in a space-limited rocky intertidal barnacle system" - Annales Zoological Fennici, Vol. 50(1/2): 64-70

Smith, A.D.; Houde, A.L.S.; Neff, B. \& Peres-Neto, P.R. (2017), “Effects of competition on fitness-related traits" - Oecologia, Vol. 183: 701-713

Smith, D. (2013), "Ecology of the New Zealand Rocky Shore Community" - New Zealand Marine Studies Centre

Smith, L.D. (1992), "The impact of limb autotomy on mate competition in blue crabs Callinectes sapidus Rathbun" - Oecologia, Vol. 89: 494-501

Sol, D.; Santos, D.M. \& Cuarado, M. (2000), “Age-related feeding site selection in urban pigeons (Columba livia): experimental evidence of the competition hypothesis" - Canadian Journal of Zoology, Vol. 78(1): 144-149

Spooner, E.H.; Coleman, R.A. \& Attrill, M.J. (2010), Sex differences in body morphology and multitrophic interactions involving the foraging behaviour of the crab Carcinus maenas" - Marine ecology, Vol. 28 (3): 394-403

Spotila, J.R.; Standora, E.A.; Easton, D.P. \& Rutledge P.S. (1989), “Bioenergetics, Behavior, and Resource Partitioning in Stressed Habitats: Biophysical and Molecular Approaches" - Physiological Zoology, Vol. 62(2): 253-285

Stahr, K.J. \& Shoup D.E. (2015), “American Water Willow Mediates Survival and Antipredator Behaviour of Juvenile Largemouth Bass" - Transaction of the American Fisheries Society, Vol. 144(5): 903-910

Stamp, N. \& Bowers, M. (1993), "Presence of predatory wasps and stinkbugs alters foraging behavior of cryptic and non-cryptic caterpillars on plaintain (Plantago laneolata) - Oecologia, Vol. 95(3): 376-384

Steele, M.A. (1998), "The relative importance of predation and competition in two reef fishes" - Oecologia, Vol. 115: 222-232 
Steinberg, M.K. \& Epifanio, C.E. (2011), “Three's a crowd: Space competition among three species of intertidal shore crabs in the genus Hemigrapsus" - Journal of Experimental Marine Biology and Ecology, Vol. 404: 57-62

Stevens, B.G. (2014), "King Crabs of the World" (1st Edition) - Biology and Fisheries Management

Stewart, N.L.; Konar, B. \& Tinker, M.T. (2015), "Testing the nutritional-limitation, predator-avoidance, and storm avoidance hypotheses for restricted sea otter habitat use in the Aleutian Islands, Alaska" - Oecologia, Vol. 177: 645-655

Stillman, J.H. \& Somera, G.N. (1996), “Adaptation to temperature stress and aerial exposure in congeneric species of intertidal porcelain crabs (Genus: Petrolisthes): correlation of physiology, biochemistry and morphology with vertical distribution." - Journal of Experimental Biology, Vol. 199(8): 1845-1855

Stone, R.P. \& O'Clair, C.E. (2002), “Behavior of Female Dungeness Crabs, Cancer magister, in a Glacial Southeast Alaska Estuary: Homing, Brooding-Site Fidelity, Seasonal Movements, and Habitat Use" - Journal of Crustacean Biology, Vol. 22(2): 481492

Stump, K.; Crooks, C.J.; Fitchett, M.; Gruber, S. \& Guttridge, T.L. (2017), “Hunted hunters: An experimental test of the effects of predation risk on juvenile lemon shark habitat use" - Marine Ecology Progress Series, Vol. 574: 85-95

Sutherland, J.P. \& Ortega, S. (1985), "Competition conditional on recruitment and temporary escape from predators on a tropical rocky shore" - Journal of Experimental Marine Biology and Ecology, Vol. 95: 155-166

Swanson, B.O.; Gibb, A.C.; Marks, J.C. \& Hendrickson, D.A. (2003), “Trophic Polymorphism and Behavioural Differences decrease Intraspecific Competition in a Cichlid, Herichthys minckleyi" - Ecology, Vol. 84: 1441-1446 
Tang, L.; Wolf, A.A.; Gao, Y.; Wang, C.H. (2018), "Photosynthetic tolerance to nonresource stress influences competition importance and intensity in an invaded estuary" - Ecological Society of America, Vol. 99(6): 1327-1337

Taylor, Q. \& Cox, C.L. (2019), “Evidence of predation risk increases with body size in a diminutive snake" - Journal of Zoology, Vol. 307(2): 141-148

Thompson, A.R. (2005), “Dynamics of demographically open mutualists: immigration, intraspecific competition, and predation impact goby populations" - Oecologia, Vol. 143(1): 61-69

Thrush, S.F.; Chiantore, M.; Asnaghi, V.; Hewitt, J.; Fiorentino, D. \& Cattaneo-Vietti, R. (2011), “Habitat-diversity relationships in rocky shore algal turf infaunal communities" - Marine Ecology Progress Series, Vol. 424: 119-132

Tobias, J.A.; Montgomerie, R. \& Lyon, B.E. (2012), “The evolution of female ornaments and weaponry: social selection, sexual selection and ecological competition" Philosophical Transactions: Biological Sciences, Vol. 367(1600): 2247-2293

Tran, M.V. (2013), "The use of Olfactory foraging cues by intertidal hermit crabs" Michigan State University, ProQuest Dissertations Publishing

Tran, M.V.; O'Grady, M.; Colborn, J.; Van Ness, K. \& Hill R.W. (2014), “Aggression and Food Resource Competition between Sympatric Hermit Crab Species" - PLoS ONE, Vol. 9(3): e91823

Truemper, N. (2012), "Spatial dynamics and life history characteristics of an aggregating species, Petrolisthes elongatus" - Victoria University of Wellington

Turra, A. \& Leite, F.P.P. (2000), “Clustering behavior of hermit crabs (Decapoda, Anomura) in an intertidal rocky shore at São Sebastião, southeastern Brazil" - Revista Brasileira de Biologia, Vol. 60(1): 39-44

Underwood, A.J. (1978), “An experimental evaluation of competition between three species of intertidal prosobranch gastropods" - Oecologia, Vol. 33: 185-202 
Underwood, A.J.; Denley, E.J. \& Moran, M.J. (1983) “Experimental Analyses of the Structure and Dynamics of Mid-Shore Rocky Intertidal Communities in New South Wales" - Oecologia, Vol. 56(2/3): 202-219

Vági, B. \& Hettyey, A. (2016), "Intraspecific and interspecific competition for mates: Rana temporaria males are effective satyrs of Rana dalmatina females" - Behavioural Ecology and Socio-biology, Vol. 70:1477-1484

von der Meden, C.E.O.; Cole, V.J. \& McQuaid, C.D. (2015), "Do the threats of predation and competition alter larval behaviour and selectivity at settlement under field conditions?" - Journal of Experimental Marine Biology and Ecology, Vol. 471: 240246

Vye, C.; Cobb, J.S.; Bradley, T.; Gabbay, J.; Genizi, A. \& Karplus, I. (1979), “Predicting the winning or losing of symmetrical contests in the American lobster Homarus americanus (Milne-Edwards)" - Journal of Experimental Marine Biology and Ecology, Vol. 217(1): 19-29

Walsby, J. (1990), “The Secret World of Crabs” - New Zealand Geographic, Iss. 8

Wan, Y.; Quan, R.C.; Ren, G.P., Wang, L.; Long, Y.C.; Liu, X.H. \& Zhu, J.G. (2013), "Niche Divergence Among Sex and Age Classes in Black and White Snub-nosed Monkeys" - International Journal of Primatology, Vol. 34: 946-956

Ward, A.J.W.; Thomas, P.; Hart, P.J.B. \& Krause, J. (2004), “Correlates of Boldness in Three-Spined Sticklebacks (Gasterosteus aculeatus)" - Behavioural Ecology and Sociobiology, Vol. 55: 561-568

Wassick, A.; Hughes, M.; Baeza, J.A.; Fowler, A. \& Wilber D. (2017), “Spacing and movement in the green porcelain crab Petrolisthes armatus: evidence for male competition and mate guarding" - Marine and Freshwater Behaviour and Physiology, Vol. 50(2): 165-177

Wasson, K. \& Lyon, B.E. (2005), “Flight or fight: flexible anti-predatory strategies in porcelain crabs" - Behavioural Ecology, Vol. 16: 1037-1041 
Wasson, K.; Lyon, B.E. \& Knope, M. (2002), “Hair-trigger autotomy in porcelain crabs is a highly effective escape strategy" - Behavioural Ecology, Vol. 13(4): 481-486

Watson, N.L. \& Simmons, L.W. (2010), "Reproductive competition promotes the evolution of female weaponry" - Proceedings: Biological Sciences, Vol. 27(1690): 20352040

Wearmouth, V.J. \& Sims, D.W. (2008), "Sexual segregation in marine fish, reptiles, birds and mammals behaviour patterns, mechanisms and conservation implications" - Advances in Marine Biology, Vol. 54: 107-170

Webb, J.K. (2006), "Effects of tail autotomy on survival, growth and territory occupation in free-ranging juvenile geckos (Oedura lesueurii)" - Austral Ecology, Vol. 31(4): $432-440$

Webb, P. (2006), "Use of fine-scale current refuges by fishes in a temperate warmwater stream" - Canadian Journal of Zoology, Vol. 84(8): 1071-1078

Webster, M.M.; Ward, A.J.W. \& Hart, P.J.B. (2007), “Boldness is influenced by social context in three-spine sticklebacks (Gasterosteus aculeatus)" - Behaviour, Vol. 144: 351371

Wilkens, S. \& Ahyong, S. (2015), "Coastal crabs: a guide to the crabs of New Zealand"

Witman, J.D. \& Grange, K.R. (1998), “Links between Rain, Salinity, and Predation in a Rocky Subtidal Community" - Ecology, Vol. 79(7): 2429-2447

Williams, J. B.; Tieleman, B. I. \& Shobrak, M. (1999), “Lizard burrows provide thermal refugia for larks in the Arabian desert" - Condor, Vol. 101(3): 714-717

Wilson, D. (2009), “Causes and Benefits of Chick Aggregations in Penguins” - The Auk; Waco, Vol. 126(3): 688-693 
Woerner, L.L.B. \& Nelson, N. (2009), “Aggression and Competition for Space and Food in Captive Juvenile Tuatara (Sphenodon punctatus)" - Victoria University of Wellington

Wooster, D. \& Sih, A. (1995), "A Review of the Drift and Activity Responses of Stream Prey to Predator Presence" - Oikos, Vol. 73(1): 3-8

Worm, B.; Lotze H.K. \& Sommer, U. (2001), "Algal Propagule Banks Modify Competition, Consumer and Resource Control on Baltic Rocky Shores" - Oecologia, Vol. 128(2): 281-293

Xavier, J.C. \& Croxall, J. (2006), "Sexual differences in foraging behaviour and diets: A case study of wandering albatrosses" - Sexual Segregation in Vertebrates ( $1^{\text {st }}$ Edition): 74-91

Yaldwyn, J.C. \& Webber R.W. (2011), “Annotated checklist of New Zealand Decapoda (Arthropoda: Crustacea)" - Tuhinga, Vol. 22: 171-272

Yoshino, K.; Koga, T. \& Oki, S. (2011), “Chelipeds are the real weapon: cheliped size is a more effective determinant than body size in male-male competition for mates in a hermit crab" - Behavioural Ecology and Sociobiology, Vol. 65(9): 1825-1832

Zimba, P.V.; Hill, E.M. \& Withers, K. (2016), “Benthic microalgae serve as the major food resource for porcelain crabs (Petrolisthes spp.) in oyster reefs: gut content and pigment evidence" - Journal of Experimental Marine Biology, Vol. 483: 53-58

Zittin, D. (1979), "Factors influencing the vertical distributions of two intertidal porcelain crab populations" - The University of British Columbia (Thesis) 


\section{Appendices}

Table A1: 3 way ANOVA table showing all interactions, for time spent under shelter in the male vs. female experiment.

\begin{tabular}{|l|l|l|l|l|}
\hline Source & DF & Mean Sq & F Value & P Value \\
\hline Sex & 1 & 405557 & 3.1212 & 0.09000 \\
\hline Size.class & 2 & 602626 & 4.6378 & 0.01982 \\
\hline Treatment & 1 & 606322 & 4.6662 & 0.04097 \\
\hline Sex:Size.class & 2 & 306057 & 2.3554 & 0.11641 \\
\hline Sex:treatment & 1 & 11556 & 0.0889 & 0.76810 \\
\hline Size.class:treatment & 2 & 21050 & 0.1620 & 0.85136 \\
\hline Sex:Size.class:treatment & 2 & 93812 & 0.7220 & 0.49604 \\
\hline Residuals & 24 & 129938 & & \\
\hline
\end{tabular}

Table A2: 3 way ANOVA table showing all interactions, for shoves given in the male vs. female experiment.

\begin{tabular}{|l|l|l|l|l|}
\hline Source & DF & Mean Sq & F Value & P Value \\
\hline Sex & 1 & 1750.03 & 36.6072 & $<0.0001$ \\
\hline SizeClass & 2 & 752.69 & 15.7449 & $<0.0001$ \\
\hline Treatment & 1 & 20.25 & 0.4326 & 0.5213 \\
\hline Sex:SizeClass & 2 & 103.03 & 2.1551 & 0.1378 \\
\hline Sex:Treatment & 1 & 51.36 & 1.0744 & 0.3103 \\
\hline SizeClass:Treatment & 2 & 33.25 & 0.6955 & 0.5086 \\
\hline Sex:SizeClass:Treatment & 2 & 22.69 & 0.4747 & 0.6278 \\
\hline Residuals & 24 & 47.81 & & \\
\hline
\end{tabular}


Table A3: 3 way ANOVA table showing all interactions, for shoves received in the male vs. female experiment.

\begin{tabular}{|l|l|l|l|l|}
\hline Source & DF & Mean Sq & F Value & P Value \\
\hline Sex & 1 & 66.694 & 1.5611 & 0.22355 \\
\hline SizeClass & 2 & 130.528 & 3.0553 & 0.06575 \\
\hline Treatment & 1 & 20.250 & 0.4740 & 0.49776 \\
\hline Sex:SizeClass & 2 & 25.861 & 0.6053 & 0.55402 \\
\hline Sex:Treatment & 1 & 4.694 & 0.1099 & 0.74315 \\
\hline SizeClass:Treatment & 2 & 17.583 & 0.4116 & 0.6672 \\
\hline Sex:SizeClass:Treatment & 2 & 69.694 & 1.6313 & 0.21663 \\
\hline Residuals & 24 & 42.722 & & \\
\hline
\end{tabular}

Table A4: 3 way ANOVA table showing all interactions, for the relative size of conspecifics that were shoved in the male vs. female experiment.

\begin{tabular}{|l|l|l|l|l|}
\hline Source & DF & Mean Sq & F Value & P Value \\
\hline Treatment & 1 & 9.39 & 0.603 & 0.44123 \\
\hline Shove & 2 & 429.43 & 27.5816 & $<0.0001$ \\
\hline Interaction & 3 & 307.81 & 19.7704 & $<0.0001$ \\
\hline Treatment:Shove & 2 & 35.10 & 2.2542 & 0.11595 \\
\hline Treatment:Interaction & 3 & 9.5 & 0.6102 & 0.61168 \\
\hline Shove:Interaction & 6 & 35.47 & 2.2780 & 0.05149 \\
\hline Treatment:Shove:Interaction & 6 & 8.87 & 0.57 & 0.75209 \\
\hline Residuals & 48 & 15.57 & & \\
\hline
\end{tabular}


Table A5: 3 way ANOVA table showing all interactions, for time spent under shelter in the autotomous vs. non-autotomous experiment.

\begin{tabular}{|l|l|l|l|l|}
\hline Source & DF & Mean Sq & F Value & P Value \\
\hline Autotomy & 1 & 2792798 & 13.5219 & 0.0012 \\
\hline Size.Class & 2 & 737104 & 3.5688 & 0.0439 \\
\hline Treatment & 1 & 21025 & 0.1018 & 0.7524 \\
\hline Autotomy:Size.Class & 2 & 144392 & 0.6991 & 0.5069 \\
\hline Autotomy:Treatment & 1 & 82656 & 0.4002 & 0.533 \\
\hline Size.Class:Treatment & 2 & 106240 & 0.5144 & 0.6043 \\
\hline Autotomy:Size.Class:Treatment & 2 & 179524 & 0.8692 & 0.4321 \\
\hline Residuals & 24 & 206539 & & \\
\hline
\end{tabular}

Table A6: 3 way ANOVA table showing all interactions, for shoves given in the autotomous vs. non-autotomous experiment.

\begin{tabular}{|l|l|l|l|l|}
\hline Source & DF & Mean Sq & F Value & P Value \\
\hline Autotomy & 1 & 406.69 & 1.5869 & 0.2199 \\
\hline SizeClass & 2 & 956.33 & 3.7316 & 0.0388 \\
\hline Treatment & 1 & 250.69 & 0.9782 & 0.3325 \\
\hline Autotomy:SizeClass & 2 & 171.44 & 0.6690 & 0.5215 \\
\hline Autotomy:Treatment & 1 & 23.36 & 0.0912 & 0.7653 \\
\hline SizeClass:Treatment & 2 & 49.78 & 0.1942 & 0.8248 \\
\hline Autotomy:SizeClass:Treatment & 2 & 19.11 & 0.0746 & 0.9284 \\
\hline Residuals & 24 & 256.28 & & \\
\hline
\end{tabular}


Table A7: 3 way ANOVA table showing all interactions, for shoves received in the autotomous vs. non-autotomous experiment.

\begin{tabular}{|l|l|l|l|l|}
\hline Source & DF & Mean Sq & F Value & P Value \\
\hline Autotomy & 1 & 1089.00 & 6.4746 & 0.0178 \\
\hline SizeClass & 2 & 629.78 & 3.7384 & 0.0386 \\
\hline Treatment & 1 & 245.44 & 1.4593 & 0.2388 \\
\hline Autotomy:SizeClass & 2 & 36.33 & 0.216 & 0.80727 \\
\hline Autotomy:Treatment & 1 & 49.00 & 0.2913 & 0.5943 \\
\hline SizeClass:Treatment & 2 & 161.78 & 0.9618 & 0.3964 \\
\hline Autotomy:SizeClass:Treatment & 2 & 1.33 & 0.0079 & 0.9921 \\
\hline Residuals & 24 & 168.19 & & \\
\hline
\end{tabular}

Table A8: 3 way ANOVA table showing all interactions, for the relative size of conspecifics that were shoved in the autotomous vs. non-autotomous experiment.

\begin{tabular}{|l|l|l|l|l|}
\hline Source & DF & Mean Sq & F Value & P Value \\
\hline Treatment & 1 & 122.72 & 2.2512 & 0.14 \\
\hline Shove & 2 & 786.85 & 12.4339 & $<0.0001$ \\
\hline Interaction & 3 & 253.54 & 4.6509 & 0.0062 \\
\hline Treatment:Shove & 2 & 72.18 & 1.3241 & 0.2756 \\
\hline Treatment:Interaction & 3 & 40.50 & 0.7429 & 0.5318 \\
\hline Shove:Interaction & 6 & 69.72 & 1.2789 & 0.2848 \\
\hline Treatment:Shove:Interaction & 6 & 39.57 & 0.7259 & 0.6309 \\
\hline Residuals & 48 & 54.51 & & \\
\hline
\end{tabular}

